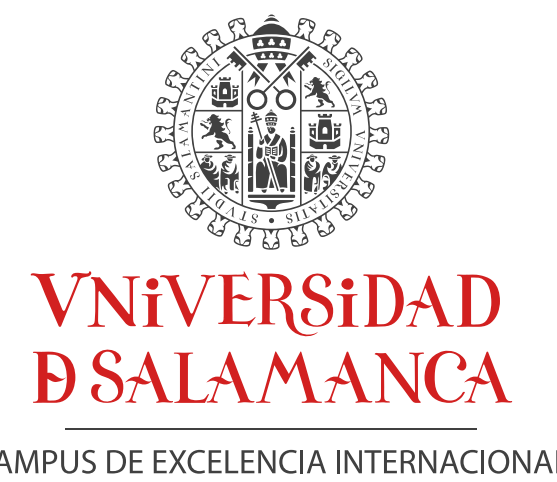

\title{
VENTILACIÓN MECÁNICA NO INVASIVA EN UNA UNIDAD DE CUIDADOS INTENSIVOS
}

TESIS DOCTORAL PARA LA OBTENCIÓN DEL GRADO DE DOCTOR EN MEDICINA POR LA UNIVERSIDAD DE SALAMANCA.

Félix Martín González

Salamanca, 2012 



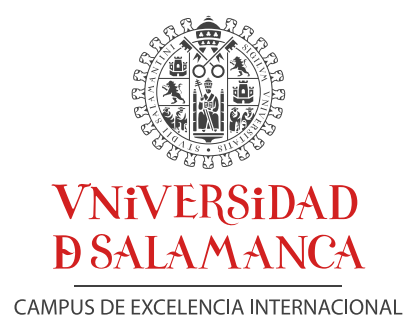

Fernando Sánchez Hernández y María N. Moreno García, ambos Doctores por la Universidad de Salamanca, y Profesores Titulares de Universidad en la Universidad de Salamanca,

\section{HA C E M O S C O N S T A R:}

Que el estudio llevado a cabo como trabajo de Tesis Doctoral titulado "Ventilación mecánica no invasiva en una Unidad de Cuidados Intensivos" ha sido realizado por Félix Martín González bajo nuestra dirección.

Que a nuestro juicio, el mismo, reúne suficientes requisitos científicos para optar al Grado de Doctor por la Universidad de Salamanca.

En Salamanca, a veintiséis de noviembre de dos mil doce. 

Todas las fotografías de esta tesis han sido realizadas por el autor salvo las de las figuras 2 y 4, utilizadas bajo licencia Creative Commons by-nc-nd, y la de la figura 3, que se encuentra bajo dominio público. Los créditos de estas fotografías son los siguientes:

$\checkmark$ Figura 2: Science Museum, London. Wellcome Images, images@wellcome.ac.uk, http://images.wellcome.ac.uk

$\checkmark$ Figura 3: James Gathany, Public Health Image Library, Centers for Disease Control and Prevention

$\checkmark$ Figura 4: Science Museum, London. Wellcome Images, images@wellcome.ac.uk, http://images.wellcome.ac.uk 



\section{ÍNDICE GENERAL DE LA TESIS}

I. Índice de abreviaturas................................................... 5

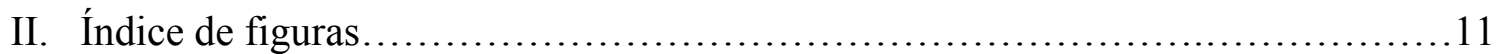

III. Agradecimientos..................................................... 15

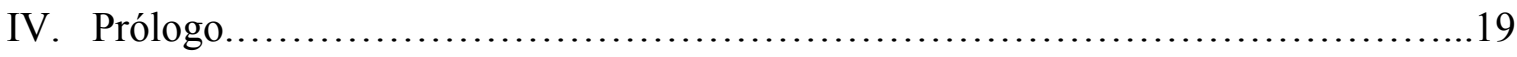

V. Objetivos............................................................. 27

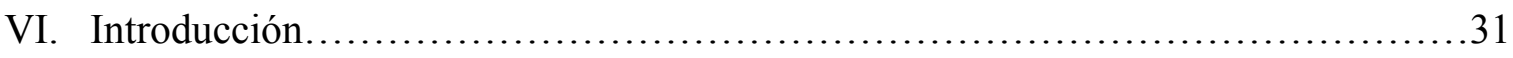

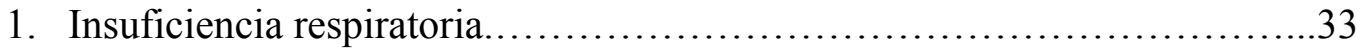

- Definición de insuficiencia respiratoria............................35

- Tipos de insuficiencia respiratoria.................................36

- Efectos de la hipoxemia y de la hipercapnia........................39

- Tratamiento de la insuficiencia respiratoria..........................39

2. Historia de la ventilación mecánica....................................43

3. Ventilación mecánica invasiva.......................................53

- Definición de ventilación mecánica invasiva......................55

- Objetivos de la ventilación mecánica.............................55

- Indicaciones de intubación orotraqueal y conexión a ventilación mecánica......................................................56

- Complicaciones de la ventilación mecánica invasiva................56

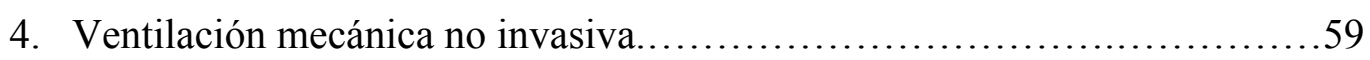

- Definición de ventilación mecánica no invasiva....................61

- Tipos de ventilación mecánica no invasiva........................61

- Consecuencias fisiológicas de la ventilación mecánica no invasiva..62

- Beneficios clínicos de la ventilación mecánica no invasiva...........62

- Tipos de respiradores para ventilación mecánica no invasiva.........63

- Modalidades de ventilación mecánica no invasiva..................64

- Interfases para ventilación mecánica no invasiva...................66

- Indicaciones de la ventilación mecánica no invasiva en el paciente agudo......................................................... 67

- Contraindicaciones de la ventilación mecánica no invasiva...........68

- Complicaciones de la ventilación mecánica no invasiva..............69 
VII. Material y métodos...................................................... 71

VIII. Resultados............................................................. 91

1. Estudio descriptivo.............................................95

2. Estudio comparativo................................................. 103

- Diferencias analíticas y fisiológicas por tipo de insuficiencia respiratoria............................................... 105

- Horas de ventilación mecánica no invasiva según el resultado de la ventilación mecánica no invasiva..............................107

- Días de estancia hospitalaria y estancia en UCI según el resultado de la ventilación mecánica no invasiva. 107

- Diferencias fisiológicas y analíticas al inicio y a las 2 horas según el resultado de la ventilación mecánica no invasiva. .107

- Variables categóricas según el resultado de la ventilación mecánica no invasiva....

- Días de estancia en UCI y hospitalaria según el tipo de insuficiencia respiratoria y el resultado de la ventilación mecánica no invasiva...109

- Mortalidad según el resultado de la ventilación mecánica no invasiva

- Mortalidad según el resultado de la ventilación mecánica no invasiva, ajustada por gravedad.

- Mortalidad según el resultado de la ventilación mecánica no invasiva y las horas de ventilación mecánica no invasiva

- Mortalidad según el tipo de insuficiencia respiratoria y el resultado de la ventilación mecánica no invasiva ...........................111

- Fracaso por parada cardiorrespiratoria.........................112

- Incidencia de neumonía asociada a ventilación mecánica...........112

- Diferencias analíticas y fisiológicas al inicio y a las 2 horas en insuficiencia respiratoria aguda hipoxémica según el resultado de la ventilación mecánica no invasiva

- Diferencias en las variables categóricas en la insuficiencia respiratoria aguda hipoxémica según el resultado de la ventilación mecánica no invasiva. 
3. Modelización....................................................... 115

4. Minería de datos..................................................... 121

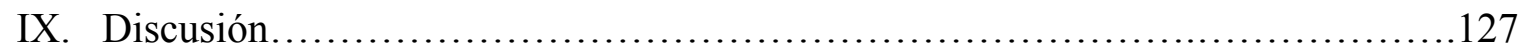

1. Distribución de pacientes........................................129

2. Éxito de la ventilación mecánica no invasiva..........................130

3. Complicaciones relacionadas con la ventilación mecánica no invasiva......137

4. Diferencias intergrupales de las variables analíticas y fisiológicas..........139

5. Variables pronósticas según la modelización.............................139

6. Minería de datos...................................................... 142

7. Limitaciones del estudio.........................................143

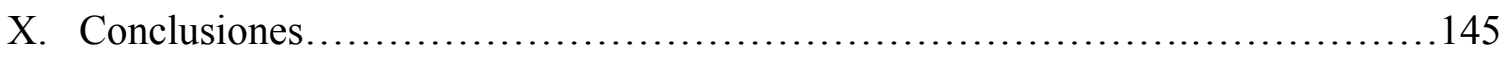

XI. Bibliografía............................................................ 149 



\section{I. ÍNDICE DE ABREVIATURAS}



a.C. $=$ antes de Cristo.

$\mathrm{AID}=$ Automatic Interaction Detection (Detección Automática de Interacciones).

$\mathrm{AF}=$ AutoFlow

APACHE II= Acute Physiology and Chronic Health Evaluation II (Evaluación de la

Fisiología aguda y la Salud Crónica II).

$\mathrm{BPAP}=$ bi-level positive airway pressure (presión positiva bi-nivelada en la vía aérea).

$\mathrm{CFS}=$ Correlation-based Feature Subset Selection (Correlación basada en Función de

Selección de Subconjunto).

$\mathrm{CO}_{2}=$ Dióxido de Carbono.

$\mathrm{CPAP}=$ presión positiva continua en vía aérea.

d.C. $=$ después de Cristo.

$\mathrm{EAP}=$ edema agudo de pulmón.

$\mathrm{EPAP}=$ presión positiva espiratoria en vía aérea.

$\mathrm{EPOC}=$ enfermedad pulmonar obstructiva crónica.

$\mathrm{FC}=$ frecuencia cardiaca.

$\mathrm{FiO}_{2}=$ fracción inspirada de Oxígeno.

$\mathrm{FN}=$ falsos negativos.

$\mathrm{FP}=$ falsos positivos.

$\mathrm{FR}=$ frecuencia respiratoria.

$\mathrm{g} / \mathrm{dl}=$ gramos por decilitro.

GCS $=$ Glasgow Coma Scale (Escala de Coma de Glasgow).

$\mathrm{GI}=$ índice de ganancia.

$\mathrm{Hb}=$ Hemoglobina.

IOT $=$ intubación orotraqueal.

$\mathrm{IPAP}=$ presión positiva inspiratoria en vía aérea.

$\mathrm{IR}=$ insuficiencia respiratoria.

IRA $=$ insuficiencia respiratoria aguda.

LMSV= limitación de medidas de soporte vital.

lpm= latidos por minuto.

$\mathrm{mEq} / \mathrm{l}=$ miliequivalentes por litro.

$\mathrm{mg} / \mathrm{dl}=$ miligramos por decilitro .

$\mathrm{ml} / \mathrm{kg}=$ mililitros por kilogramo. 
$\mathrm{mm}^{3}=$ milímetro cúbico.

$\mathrm{mmHg}=$ milímetros de Mercurio.

$\mathrm{mmol} / \mathrm{l}=$ milimoles por litro.

$\mathrm{NAVM}=$ neumonía asociada a ventilación mecánica.

$\mathrm{NAVMNI}=$ neumonía asociada a ventilación mecánica no invasiva.

NPPV= noninvasive positive pressure ventilation (ventilación no invasiva con presión positiva).

$\mathrm{NS}=$ no significativo.

$\mathrm{O}_{2}=$ Oxígeno.

${ }^{\circ} \mathrm{C}=$ grados centígrados.

$\mathrm{PaCO}_{2}=$ presión arterial de Dióxido de Carbono.

$\mathrm{PAFI}=$ cociente $\mathrm{PaO}_{2} / \mathrm{FiO}_{2}$.

$\mathrm{PAO}_{2}=$ presión alveolar de Oxígeno.

$\mathrm{PaO}_{2}=$ presión arterial de Oxígeno.

$\mathrm{PC}=$ presión control.

$\mathrm{PCR}=$ parada cardiorrespiratoria .

$\mathrm{PEEP}=$ presión positiva al final de la espiración.

PELOD $=$ Pediatric Organ Dysfunction Score (Score de Disfunción Orgánica Pediátrica).

$\mathrm{PO}_{2}=$ presión de Oxígeno.

$\mathrm{PS}=$ presión de soporte.

resp/min= respiraciones por minuto.

ROC $=$ Receiver Operating Characteristic (Característica Operativa del Receptor).

$\mathrm{SAOS}=$ síndrome de apnea del sueño.

SAPS II= Simplified Acute Physiology Score II (Score Simplificado Agudo Fisiológico II).

$\mathrm{SatO}_{2}=$ saturación de Oxígeno.

$\mathrm{SDRA}=$ síndrome de distrés respiratorio agudo.

SIMV= ventilación sincronizada mandatoria intermitente.

$\mathrm{SNC}=$ sistema nervioso central.

SOFA = Sequential Organ Failure Assesment index Score (Score de Evaluación Secuencial de Fallo Orgánico).

$\mathrm{TAD}=$ tensión arterial diastólica.

TAS $=$ tensión arterial sistólica. 
$\mathrm{TEP}=$ tromboembolismo pulmonar.

$\mathrm{TP}=$ true positives (verdaderos positivos).

$\mathrm{UCI}=$ Unidad de Cuidados Intensivos.

$\mathrm{V} / \mathrm{Q}=$ ventilación/perfusión.

$\mathrm{VAP}=$ ventilación asistida proporcional.

$\mathrm{VC}=$ volumen control.

$\mathrm{V}_{\mathrm{c}}=$ volumen corriente.

VILI= lesión pulmonar inducida por ventilación mecánica.

$\mathrm{VM}=$ ventilación mecánica.

VMI= ventilación mecánica invasiva.

$\mathrm{VMNI}=$ ventilación mecánica no invasiva.

$\mathrm{VPN}=$ valor predictivo negativo.

$\mathrm{VPP}=$ valor predictivo positivo. 



\section{II. ÍNDICE DE FIGURAS}



Figura 1: Dispositivos para oxigenoterapia...................................... 40

Figura 2: Instrumental para la resucitación de ahogados..............................47

Figura 3: Pulmón de acero................................................48

Figura 4: Set de intubación Dwyer........................................49

Figura 5: Complicaciones de la ventilación mecánica no invasiva.......................69

Figura 6: Respirador BiPAP Vision............................................. 77

Figura 7: Respirador Carina........................................................ 78

Figura 8: Diferentes tipos de mascarillas oronasales para ventilación mecánica no

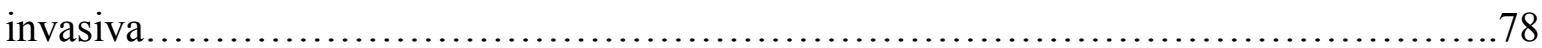

Figura 9: Algoritmo básico de aprendizaje de árboles de decisión.......................87

Figura 10: Distribución por sexo..........................................97

Figura 11: Porcentaje de fracaso de ventilación mecánica no invasiva..................97

Figura 12: Causa de fracaso de la ventilación mecánica no invasiva.....................98

Figura 13: Número de pacientes por tipo de insuficiencia respiratoria....................99

Figura 14: Porcentaje de pacientes en los que fracasa la ventilación mecánica no invasiva, porcentaje de exitus y porcentaje de exitus entre los que fracasan...................... 100

Figura 15: Número de pacientes por tipo de insuficiencia respiratoria y año.............100

Figura 16: Cociente $\mathrm{PaO}_{2} / \mathrm{FiO}_{2}$ y frecuencia respiratoria al inicio, a las 2 y a las 12

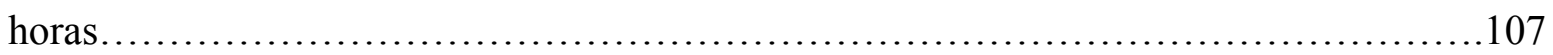

Figura 17: Características fisiológicas y de laboratorio basales.......................108

Figura 18: Características fisiológicas y de laboratorio tras 2 horas de ventilación mecánica no invasiva.

Figura 19: Número de pacientes que tuvieron éxito o fracasaron con la ventilación mecánica no invasiva según la presencia de variables categóricas

Figura 20: Exitus por horas de ventilación mecánica no invasiva en los pacientes en los que tuvo éxito

Figura 21: Exitus por horas de ventilación mecánica no invasiva en los pacientes en los que fracasó.

Figura 22: Modelo de regresión logística.

Figura 23: Árbol de decisión..................................................... 119

Figura 24: Resumen de resultados sobre el fichero completo..........................125 
Figura 25: Resumen de resultados sobre los atributos seleccionados mediante ganancia de información.....

Figura 26: Resumen de resultados sobre los atributos seleccionados mediante

CFS.

Figura 27: Resultados con Bagging con J48 sobre atributos seleccionados mediante CFS. 125

Figura 28: Precisión según tipo de algoritmo y los atributos seleccionados.... 126 


\section{AGRADECIMIENTOS}



o puedo empezar de otra forma que dando mil gracias al Prof. Dr. D. Fernando Sánchez Hernández, director de esta tesis doctoral, por todos los esfuerzos dedicados durante su realización, pero principalmente por aceptar dirigirla el día que se lo pedí, sin dudarlo un instante, asumiendo el trabajo extra que eso implicaba a su ya sobrecargada agenda. También quiero agradecerle sus frases de ánimo y apoyo en todo este tiempo; espero que sepa lo importantes que han sido.

A la Profa. Dra. Dña. María N. Moreno García, codirectora de esta tesis doctoral, por su trabajo en la realización de la sección de la minería de datos y por su implicación en que yo lo entendiese.

Al Prof. Dr. D. Javier Martín Vallejo y a la Profa. Dra. Dña. Inmaculada Barreda Mellado, por su inestimable ayuda con el análisis estadístico de los datos, siempre dispuestos a resolver mis dudas en cuanto surgían, con su gran conocimiento y toda la paciencia del mundo en un campo tan difícil, a veces, para mí.

A mis compañeros de la Unidad de Cuidados Intensivos, especialmente al Dr. D. Ángel Rodríguez Encinas, por todo lo que me han enseñado durante estos años.

A todos mis compañeros de Residencia, sobre todo a Javi y a Marta, porque más que compañeros son amigos. 
A todo el personal de la Unidad de Cuidados Intensivos, por el cariño que siempre me han mostrado, haciendo que trabajar con ellos sea tan fácil, y por su afán para que cada día los pacientes puedan curarse. Sin ellos el uso de la ventilación mecánica no invasiva sería imposible.

Quiero mencionar especialmente a Carmen, secretaria de la Unidad, por su ayuda a la hora de solicitar las historias clínicas a revisar, siempre pendiente de que llegasen en el momento oportuno y de que nunca me faltasen.

A mis padres, por su amor, y porque siempre me han apoyado a la hora de seguir mi camino.

Al resto de mi familia, en especial a mis hermanas, por hacerme sentir que están ahí incluso cuando están lejos.

A Gema, por todo su apoyo durante el tiempo que ha requerido esta tesis, por las horas que esto nos ha quitado, por su sacrificio para que no tuviese otras preocupaciones, pero sobre todo por hacerme feliz cada segundo del día. 

"Analizar los efectos de las ayudas técnicas y aparatajes sobre los pacientes, en las unidades de cuidados intensivos, tiene la gran ventaja de incentivar la curiosidad innata que todos tenemos y que desde niños nos hace desmontar los juguetes, para intentar comprender como funcionan"

Anónimo

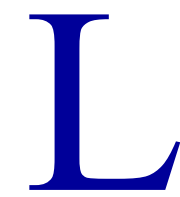

a ventilación mecánica no invasiva (VMNI) existe desde principios del siglo XIX, con la creación de los primeros respiradores de presión negativa. Sin embargo, tras el desarrollo de las técnicas de aislamiento de la vía aérea (mediante traqueotomía o intubación translaríngea) y la ventilación con presión positiva, su utilización disminuyó rápidamente hasta convertirse en anecdótica.

Pese al gran avance que supuso el desarrollo de esta modalidad ventilatoria, las complicaciones asociadas, como las lesiones en vía aérea o infecciones como la sinusitis y la neumonía asociada a ventilación mecánica (NAVM), y la necesidad frecuente de sedación profunda para poder ser utilizada hicieron que durante todo el siglo XX fueran mejorándose progresivamente sistemas de aplicación de ventilación con presión positiva no invasiva.

Con el desarrollo de esta tecnología nace la VMNI moderna. Inicialmente será utilizada para ventilar a pacientes con enfermedades neuromusculares como los síndromes post- 
poliomielitis, o a pacientes con alteraciones restrictivas como la caja torácica posttoracoplastia. El beneficio en cuanto a calidad de vida, supervivencia y mejoría de la insuficiencia respiratoria (IR) demostró la gran utilidad de esta técnica. Pero es sobre todo el éxito en el tratamiento del síndrome de apnea del sueño (SAOS) mediante presión positiva continua en la vía aérea (CPAP) lo que da el impulso definitivo a la VMNI.

En los años posteriores se fue extendiendo de forma progresiva su utilización a pacientes con insuficiencia respiratoria aguda (IRA). En las últimas tres décadas numerosos estudios han demostrado su utilidad para reducir la intubación orotraqueal (IOT), la morbimortalidad y la estancia hospitalaria, siendo cada vez mayor el número de patologías susceptibles de ser tratadas de este modo.

Además de evitar las potenciales complicaciones ya mencionadas de la ventilación mecánica invasiva (VMI), la VMNIes más confortable para el paciente, permitiéndole comer, beber y expectorar, no precisa sedación profunda y mantiene los mecanismos de defensa de la vía aérea.

La VMNI moderna se basa en la utilización de una presión positiva (supraatmosférica) en la vía aérea. Así se va a crear un gradiente de presión que producirá el flujo inspiratorio, siendo la espiración un fenómeno pasivo. Al generarse una presión intratorácica positiva van a producirse cambios a diferentes niveles. Desde el punto de vista respiratorio consigue mejorar el intercambio gaseoso, disminuir el trabajo de los músculos respiratorios y reclutar zonas pulmonares colapsadas.

El aumento de presión intratorácica disminuye el retorno venoso y el gasto cardiaco, además de aumentar las resistencias vasculares pulmonares, pudiendo afectar la función del ventrículo derecho. También puede producir retención hidrosalina (por estimulación de barorreceptores o producción del péptido atrial natriurético).

La VMNI puede ser aplicada por un respirador que va a encargarse de generar la presión positiva en la vía aérea. Esa presión es trasmitida a la vía aérea mediante la interfase, que es el dispositivo que trata de poner en contacto al paciente con el respirador, creando un sistema lo más hermético posible para evitar fugas y caídas de presión. Existen multitud de respiradores e interfases, y de la elección correcta de ambos depende en gran parte el éxito a 
la hora de aplicar la técnica. Sin embargo, el punto fundamental en el uso de la VMNI es la selección del paciente candidato a ser tratado con ella.

La mayor evidencia disponible se centra en el manejo de las exacerbaciones graves de pacientes con enfermedad pulmonar obstructiva crónica (EPOC). Existen multitud de ensayos clínicos que demuestran la superioridad del tratamiento con VMNI frente al tratamiento convencional (tratamiento médico y oxigenoterapia); desde hace tiempo la VMNI es parte fundamental del estándar de tratamiento en estos pacientes.

También en el edema agudo de pulmón (EAP) cardiogénico se dispone de evidencia de gran calidad a favor de su uso, con disminución de la necesidad de IOT y la mejoría de los parámetros respiratorios. Esta disminución se consigue tanto con CPAP como con VMNI "real" (noninvasive positive pressure ventilation, NPPV). Sin embargo, los resultados son contradictorios a la hora de dar superioridad a una de las dos modalidades. Aunque existen datos que sugieren que la NPPV permite una mejoría clínica más rápida, no hay evidencia clara de que esto suponga un beneficio en cuanto a mortalidad o necesidad de IOT. Además, un ensayo clínico controlado mostró un aumento del riesgo de infarto agudo de miocardio en los pacientes tratados con NPPV frente a los que recibieron CPAP, aunque este efecto no se ha confirmado en estudios posteriores.

El manejo de la IRA en pacientes inmunocomprometidos es otra área donde la VMNI ha demostrado ser eficaz, permitiendo reducir la mortalidad, la necesidad de IOT y la estancia en Unidad de Cuidados Intensivos (UCI). Además, la posibilidad de aplicación en planta permite disminuir la exposición de estos pacientes, con un alto riesgo de infecciones nosocomiales, al ambiente de las UCIs.

En el destete precoz de pacientes EPOC sometidos a ventilación mecánica (VM) existe evidencia a favor de su uso ya que puede permitir disminuir la duración de la IOT y de la VM.

En otro tipo de patologías como asma, IR postoperatoria, fracaso en la extubación, neumonía grave, síndrome de distrés respiratorio agudo (SDRA), traumatismo torácico, enfermedades neuromusculares, etc., la evidencia es menor, pero cada día aparecen más estudios que apoyan su posible utilidad. 
Además, existen multitud de pacientes en situación crónica que se pueden beneficiar de la VMNI: alteraciones del centro respiratorio, enfermedades restrictivas (enfermedades neuromusculares, alteraciones de la caja torácica) u obstructivas (EPOC) en situación estable.

Desde el punto de vista general, las indicaciones de la VMNI el la patología aguda son:

- Cociente Presión arterial de Oxígeno $\left(\mathrm{PaO}_{2}\right) /$ Fracción inspirada de Oxígeno $\left(\mathrm{FiO}_{2}\right)$, PAFI $<200$.

- Presión arterial de Dióxido de Carbono $\left(\mathrm{PaCO}_{2}\right)>45 \mathrm{mmhg}$ y $\mathrm{pH}<7,35$.

- Disnea moderada o grave, con uso de musculatura accesoria.

- Taquipnea: Frecuencia respiratoria (FR) > 24 respiraciones/minuto (resp/min).

Sin embargo, la VMNI tiene una serie de contraindicaciones "clásicas":

- Parada respiratoria.

- Parada cardiorrespiratoria (PCR).

- Inestabilidad hemodinámica (shock, hipotensión, isquemia miocárdica no controlada $\mathrm{o}$ arritmias).

- Incapacidad para proteger la vía aérea.

- Incapacidad para fijar una interfase correctamente.

- Cirugía esofágica o de vía aérea superior reciente.

- Secreciones excesivas.

- Agitación psicomotriz o no colaboración.

Algunas de estas contraindicaciones son absolutas, pero la mayoría son relativas, y una juiciosa selección del paciente, del respirador y de la interfase adecuada, además de unos cuidados de enfermería correctos, pueden conseguir completar el tratamiento con éxito, incluso ante la presencia de alguna de estas situaciones.

Pese a que la VMNI se desarrolló entre otras cosas para evitar los problemas asociados a la VMI, no es una técnica exenta de complicaciones, siendo las más habituales las lesiones cutáneas, la congestión nasal y la irritación nasal, bucal u ocular, y las más graves la neumonía por aspiración, la hipotensión arterial y el neumotórax. 
El objetivo de este trabajo es analizar de forma retrospectiva el uso de la VMNI en la UCI del Hospital Clínico de Salamanca: grado de utilización, tipo de patología en la que se utiliza y eficacia.

Así, se pretende entender de una manera más profunda qué pacientes son los más susceptibles de ser tratados y en cuáles no va a ser eficaz y sería más conveniente la VMI; además, se intenta identificar marcadores precoces de fracaso de la VMNI para no retrasar la VMNI en no respondedores.

Consideramos, pues, de sumo interés y originalidad hacer un estudio de la importancia del uso de la VMNI, y de la identificación de factores predictores de éxito o fracaso que permita la optimización del enfoque terapéutico de manera precoz (mediante IOT y conexión a VM si es necesario), haciendo que la morbimortalidad de los pacientes pueda disminuir de manera significativa. 



\section{OBJETIVOS}



1 desarrollo de la VMNI para el tratamiento de pacientes con insuficiencia
respiratoria aguda ha supuesto uno de los grandes avances en el seno de los
pacientes críticos, cambiando de una forma sustancial el abordaje inicial de multitud de patologías.

La búsqueda de una menor agresividad es una de las principales características de la investigación médica. Basándose en el clásico primum non nocere, el desarrollo de técnicas mínimamente invasivas, de cirugías menos cruentas o de fármacos con menores efectos secundarios ha crecido en las últimas décadas de forma exponencial.

Es evidente que el tratamiento de los pacientes críticos suele ser muy agresivo, siendo necesarias multitud de medidas para mantener al paciente con vida y para monitorizar su tratamiento de una forma correcta. Estas medidas en ocasiones son responsables de complicaciones que pueden llegar a ser fatales. La aparición de la VMNI moderna ha permitido un tratamiento alternativo en pacientes que anteriormente solo podían ser manejados con IOT y conexión a VM.

Sin embargo, uno de los riesgos de las técnicas poco invasivas es el de retrasar medidas que pueden ser necesarias: existe un porcentaje de enfermos en los que un tratamiento rápido y agresivo puede ser necesario, y la tardanza en su instauración puede empeorar el pronóstico. 
En el caso de la IR, la dilación en la IOT y la aplicación de VMNI en pacientes que no van a mejorar aumenta su morbimortalidad.

La identificación y correcta selección de pacientes respondedores supone por tanto un reto importante en la aplicación de la VMNI.

Una de las mayores dificultades a las que se enfrenta la investigación en Medicina Intensiva es la gran heterogeneidad poblacional. Las UCIs tratan pacientes de todo tipo, tanto quirúrgicos como médicos, con multitud de patologías, y muchos van a necesitar VM. Pero esta gran diversidad hace que resulte complicado obtener resultados significativos.

El objetivo de este estudio es analizar los pacientes sometidos a VMNI; así, conocer el porcentaje de pacientes que son tratados mediante esta técnica, las patologías que presentaban y el grado de eficacia. También se trata de identificar marcadores precoces de éxito o fracaso de la VMNI, complicaciones relacionadas con ella y posibles errores en su aplicación. 



\section{INSUFICIENCIA RESPIRATORIA}



"Yo mismo soy, pese a mis treinta y nueve años, aún no cumplidos, un veterano de la disnea. Dificultad de respirar, dice el diccionario. Pero el diccionario no puede explicar los matices. La primera vez que uno experimenta esa dificultad, cree por supuesto que llegó la hora final. Después uno se acostumbra, sabe que tras esa falsa agonía sobrevendrá la bocanada salvadora, y entonces deja de ponerse nervioso, de arañar empavorecidamente las sábanas, de abrir los ojos con desesperación”

(Mario Benedetti, "El fin de la disnea")

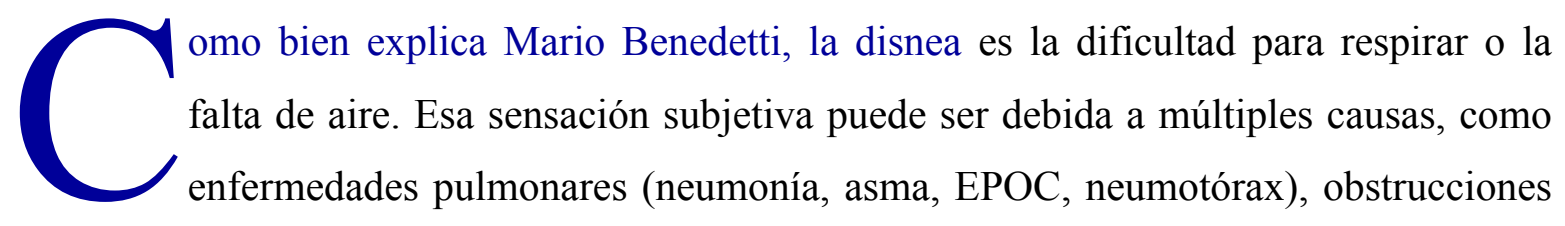
de vía aérea, o patologías cardiovasculares (EAP, cardiopatía isquémica).

La expresión objetiva de esta sensación subjetiva es la IR, un concepto gasométrico que intenta delimitar analíticamente esta sensación de dificultad respiratoria.

\section{Definición de IR:}

La $\mathrm{IR}^{1}$ se define como el fracaso del sistema respiratorio para mantener el intercambio gaseoso, es decir, la oxigenación arterial y la eliminación de Dióxido de Carbono $\left(\mathrm{CO}_{2}\right)$ necesario según la situación metabólica del organismo. Aunque no existe un nivel absoluto de $\mathrm{PaO}_{2}$ y de $\mathrm{PaCO}_{2}$ que defina la IR, habitualmente se utilizan 60 milímetros de Mercurio (mmHg) y 45-50 $\mathrm{mmHg}$ respectivamente (en reposo y respirando aire ambiente). 


\section{Tipos de IR:}

\section{Según el tiempo de instauración:}

Aguda: Suele presentarse en sujetos previamente sanos (desde el punto de vista respiratorio).

$>$ Crónica: Existe una enfermedad previa lo suficientemente prolongada como para que el organismo inicie mecanismos de compensación.

* Según las alteraciones gasométricas:

$>$ IR tipo 1 (o hipoxémica): La que cursa con una $\mathrm{PaO}_{2}<60 \mathrm{mmHg}$.

$>$ IR tipo 2 (o hipercápnica): Presentan $\mathrm{PaCO}_{2}>50 \mathrm{mmHg}$.

\section{* Según el mecanismo fisiopatogénico:}

$>$ Hipoventilación alveolar.

$>$ Alteración de la ventilación/perfusión (V/Q).

$>$ Efecto shunt.

$>$ Alteración de la difusión.

$>$ Reducción de lo Presión de $\mathrm{O}_{2}\left(\mathrm{PO}_{2}\right)$ inspirada.

Todos estos mecanismos (hipoventilación, alteración V/Q, shunt, alteración en la difusión y reducción de $\mathrm{PO}_{2}$ inspirada) pueden causar IRA hipoxémica; en cambio, la IR hipercápnica solo la causan la hipoventilación alveolar y el desequilibrio $\mathrm{V} / \mathrm{Q}^{2}$. Por supuesto, es relativamente frecuente que varios mecanismos se mezclen en un solo paciente, haciendo que la interpretación se complique.

Hipoventilación alveolar: Se produce una disminución del gas fresco que llega a los alvéolos. Esto produce hipoxemia e hipercapnia. La hipoxemia es fácilmente corregible aumentando el suministro de Oxígeno $\left(\mathrm{O}_{2}\right)$ mediante una máscara facial. Es importante remarcar que la hipoxemia no es la alteración principal en este mecanismo, ya que una hipoventilación que duplique la $\mathrm{PaCO}_{2}$ tan solo reducirá discretamente la $\mathrm{PaO}_{2}$, lo que puede llevar a menospreciar la gravedad del paciente si únicamente nos fijamos en la Saturación de $\mathrm{O}_{2}\left(\mathrm{SatO}_{2}\right)$.

Existen múltiples causas de hipoventilación alveolar ${ }^{3}$ : depresión del centro respiratorio por fármacos, lesiones del bulbo raquídeo o de la médula espinal (encefalitis, hemorragias, traumatismos, poliomielitis), afectación de los nervios motores (Guillain-Barré), 
enfermedades de la placa neuromuscular (miastenia gravis, botulismo), enfermedades musculares (distrofia muscular de Duchenne), alteración de la caja torácica (cifoescoliosis, traumatismos torácicos), obstrucciones de la vía aérea alta (compresión traqueal, apnea obstructiva del sueño).

Trastorno de la difusión: En condiciones normales se produce un equilibrio entre la sangre capilar pulmonar y el gas alveolar. Este equilibrio se alcanza rápidamente, aproximadamente en un tercio de los 0,75 segundos que permanecen en contacto. En ocasiones (asbestosis, sarcoidosis, fibrosis pulmonar, conectivopatías) la membrana alveoloarterial se encuentra engrosada, pudiendo retardar la difusión e impedir ese equilibrio. Además, la hipoxemia aumentará con el aumento del gasto cardiaco, al disminuir el tiempo de contacto de la sangre con el gas alveolar. La difusión del $\mathrm{CO}_{2}$ es mucho más rápida que la del $\mathrm{O}_{2}$, por lo que habitualmente no suele estar elevado (es frecuente que haya incluso ligera hipocapnia, por la hiperventilación secundaria a la hipoxemia). En los trastornos puros de la difusión el aporte de $\mathrm{O}_{2}$ suplementario corrige fácilmente la hipoxemia, al aumentar la presión alveolar de $\mathrm{O}_{2}\left(\mathrm{PAO}_{2}\right)$, lo que permite vencer la resistencia de la membrana.

Efecto shunt: Se produce un cortocircuito (shunt) por el que parte de la sangre venosa llega al sistema arterial sin pasar por una zona ventilada del pulmón. Esto se produce cuando existen áreas del pulmón con relación $\mathrm{V} / \mathrm{Q}=0$, es decir, donde los alvéolos están perfundidos pero no ventilados. Puede aparecer en neumonías con consolidaciones totales, en el SDRA, o en hemorragias pulmonares. También puede ocurrir con alteraciones arteriovenosas pulmonares o extrapulmonares, o en comunicaciones cardiacas con shunt derecha-izquierda. Es característico en este mecanismo de IR que respirando $\mathrm{O}_{2}$ al $100 \% 1 \mathrm{la} \mathrm{PaO}_{2}$ no asciende hasta niveles casi normales, cuando en el resto de las causas de hipoxemia sí ocurre. Esto se debe a que al diluirse una pequeña cantidad de sangre no oxigenada, aunque el descenso en la concentración de $\mathrm{O}_{2}$ sea pequeño, como la curva de disociación de la Hemoglobina $(\mathrm{Hb})$ es muy aplanada en el rango alto la $\mathrm{PaO} 2$ se reduce mucho. Habitualmente la $\mathrm{PaCO}_{2}$ se mantiene normal o algo disminuida.

Desequilibrio V/Q: Es el mecanismo más habitual de hipoxemia. En condiciones normales existe un pequeño grado de desigualdad entre la ventilación y la perfusión dentro de los 
pulmones. En bipedestación la relación disminuye del vértice hasta la base (por lo que la sangre procedente de los vértices tiene una $\mathrm{PaO}_{2}$ más alta y una $\mathrm{PaCO}_{2}$ más baja que la de las bases). En un pulmón patológico, el desequilibrio aparece desorganizado, con áreas bien ventiladas y mal perfundidas, y otras con perfusión correcta y mala ventilación.

Es fundamental remarcar que los desequilibrios de V/Q están marcados por la forma de la curva de disociación de la $\mathrm{Hb}$. En la parte alta de esta curva la $\mathrm{Hb}$ está casi saturada a $\mathrm{PaO}_{2}$ de $60 \mathrm{mmHg}$. A partir de ahí aunque elevemos mucho la $\mathrm{PaO}_{2}$ el transporte de $\mathrm{O}_{2}$ se eleva mínimamente. Por el contrario, en la zona descendente, pequeñas caídas de la $\mathrm{PaO}_{2}$ implican grandes descensos de $\mathrm{O}_{2}$. De esta manera, las zonas con un desequilibrio de la V/Q no pueden ser compensadas por las zonas con una relación próxima a uno, porque el aporte extra de $\mathrm{O}_{2}$ de estas últimas es mucho menor que el descenso que supone el de las zonas alteradas $^{4}$. Patologías como la EPOC, las enfermedades intersticiales, el EAP o el tromboembolismo pulmonar (TEP) presentan hipoxemia por este mecanismo.

La hipercapnia no es constante, ya que en muchas ocasiones la hipoxemia y la hipercapnia inicial estimulan el aumento de la ventilación/minuto, lo que puede conseguir corregir la $\mathrm{PaCO}_{2}$, pero no la $\mathrm{PaO}_{2}$. Esto es debido en parte a la distinta capacidad de la sangre para transportar los diferentes gases ${ }^{5}$. Mientras que el transporte de $\mathrm{O}_{2}$ se lleva a cabo fundamentalmente mediante la $\mathrm{Hb}$, el $\mathrm{CO}_{2}$ difunde fácilmente a la sangre, lo que hace que su cantidad aumente de manera lineal al aumentar la $\mathrm{PaCO}_{2}$.

Así, al doblar la ventilación alveolar se elimina el doble de $\mathrm{CO}_{2}$, mientras que desde el punto de vista del $\mathrm{O}_{2}$ el aumento de ventilación de los alvéolos con relación V/Q elevados no es capaz de compensar los que tienen esa relación baja, en los que la $\mathrm{Hb}$ no se satura.

Cuando las alteraciones de la V/Q son graves, este aumento de la ventilación no es capaz de compensarlas, apareciendo la hipercapnia. El gradiente alveolo-arterial de $\mathrm{O}_{2}$ permite diferenciar la hipercapnia por desequilibrio V/Q (se encuentra elevado) de la causada por hipoventilación alveolar ${ }^{4}$.

Reducción de la $\mathrm{PO}_{2}$ inspirada: Es una causa mucho menos frecuente; ocurre en las grandes alturas (al disminuir la presión barométrica), o al respirar una mezcla de gases con escasa concentración de $\mathrm{O}_{2}$ (como en espacios cerrados o en incendios al consumirse el $\mathrm{O}_{2}$ ). 


\section{Efectos de la hipoxemia y de la hipercapnia:}

La importancia de la hipoxemia es que produce hipoxia tisular. Es fundamental remarcar no obstante que la hipoxia no siempre está causada por hipoxemia; el aporte de $\mathrm{O}_{2}$ a los tejidos es el producto del gasto cardiaco por el contenido arterial de $\mathrm{O}_{2}{ }^{1}$. Cualquier circunstancia que disminuya una de las dos variables (anemia, disminución de la contractilidad cardiaca, bradicardias importantes) puede producir hipoxia. Además, alteraciones en la curva de disociación de la $\mathrm{Hb}$, alteraciones locales en el flujo sanguíneo o incapacidad celular para metabolizar el $\mathrm{O}_{2}$ pueden producir hipoxia.

Es conocida la distinta sensibilidad de los tejidos a la hipoxia. Mientras unos pueden aguantar horas sin presentar daños graves, otros como el miocardio o sobre todo el sistema nervioso central (SNC) son extremadamente sensibles ${ }^{2}$. Pocos minutos sin aporte de $\mathrm{O}_{2}$ al cerebro pueden causar daños irreversibles. La hipoxia grave puede producir obnubilación, somnolencia, cefalea, hipertensión arterial, taquicardia (y posteriormente bradicardia e hipotensión) o deterioro de la función renal.

La hipercapnia ${ }^{6}$ produce aumento del flujo sanguíneo cerebral, pudiendo llegar a aumentar la presión de líquido cefalorraquídeo. Causa cefalea, inquietud, asterixis y deterioro del nivel de consciencia. Cuando la elevación de la $\mathrm{PaCO}_{2}$ se produce de manera progresiva, el organismo es capaz de excretar hidrogeniones y retener bicarbonato, permitiendo mantener el $\mathrm{pH}$ en cifras normales.

\section{Tratamiento de la IR:}

Es complicado explicar en unas líneas las posibilidades terapéuticas que existen en la IR, sobre todo teniendo en cuenta la multitud de patologías y los diversos mecanismos que pueden ocasionarla. Pero existen varios puntos que pueden ser útiles ${ }^{2}$ :

Obstrucción de las vías aéreas: Es una causa habitual de IR. Puede ocurrir por broncoespasmo o por acúmulo de secreciones bronquiales. La hidratación adecuada, la humidificación de los gases administrados o el uso de broncodilatadores pueden mejorar esta obstrucción. 
Infección respiratoria: El tratamiento antibiótico es básico en este caso. Incluso pequeñas infecciones respiratorias pueden producir IR en pacientes EPOC ${ }^{7}$.

Insuficiencia cardiaca: El tratamiento con diuréticos y con cloruro mórfico, que actúa disminuyendo la precarga y el trabajo respiratorio, es útil en los pacientes en los que el deterioro respiratorio se atribuye a fallo cardiaco ${ }^{8}$.

Oxigenoterapia: Como se ha mencionado previamente, el tratamiento con $\mathrm{O}_{2}$ suplementario es capaz de corregir la hipoxemia en los trastornos de la difusión y en la hipoventilación alveolar. Con respecto al desequilibrio $\mathrm{V} / \mathrm{Q}$, su eficacia depende de la magnitud de la desigualdad. Si este desequilibrio es elevado, la $\mathrm{PaO}_{2}$ no va a corregirse hasta cifras normales con el aporte de $\mathrm{O}_{2}$ suplementario. El efecto shunt es el único mecanismo en el que de ninguna manera se produce aumento de la $\mathrm{PaO}_{2}$ hasta niveles de un pulmón normal al ventilar con $\mathrm{O}_{2}$ al $100 \%$.

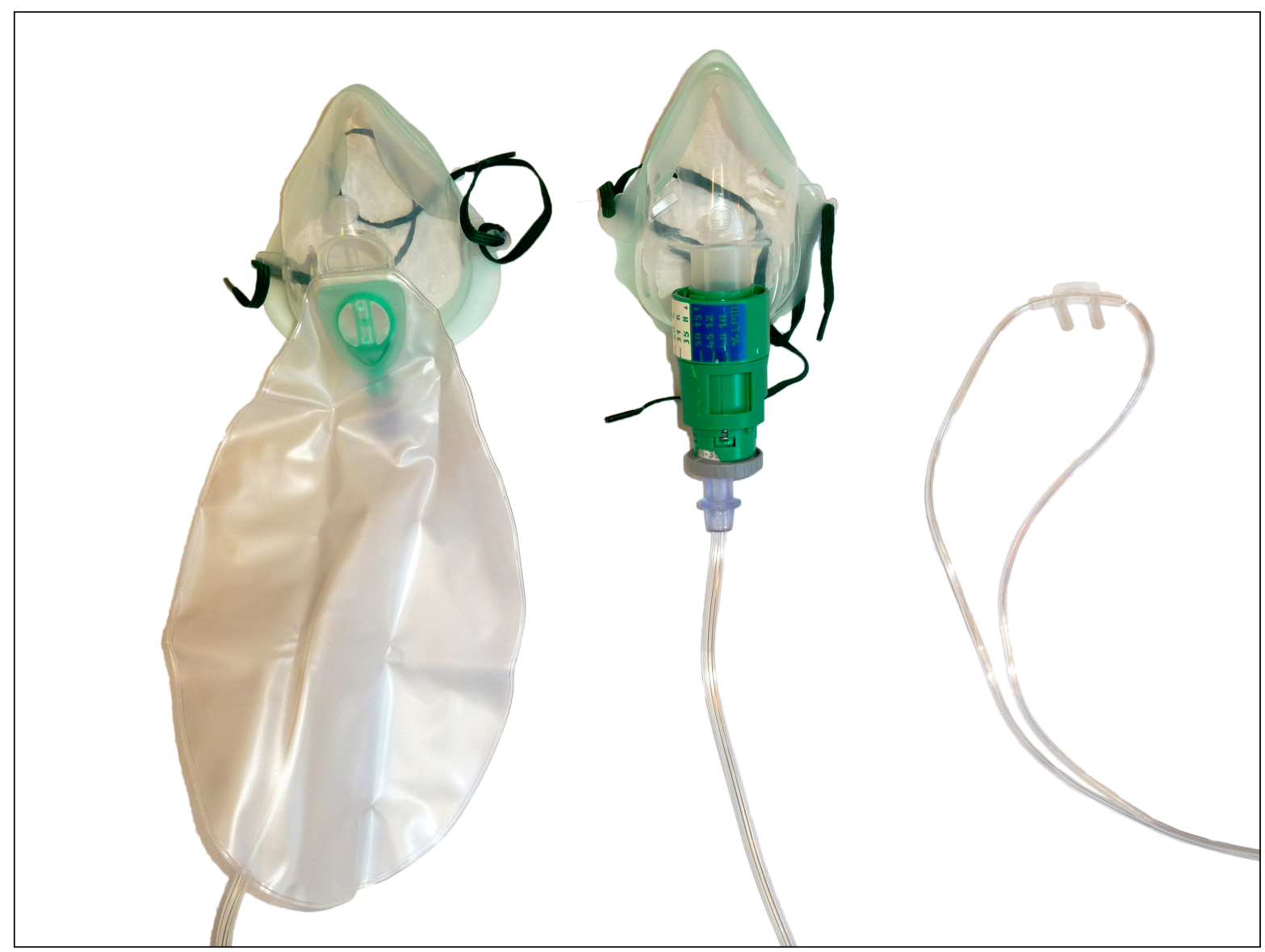

Figura 1: Mascarilla-reservorio (izquierda), mascarilla facial tipo Venturi (centro) y gafas nasales (derecha). 
La oxigenoterapia puede ser administrada mediante múltiples métodos. Los más habituales son las gafas nasales, que permiten administrar entre un 25 y un $30 \%$ de $\mathrm{FiO}_{2}$ y las mascarillas faciales (habitualmente utilizando el efecto Venturi, que permite regular fácilmente la $\mathrm{FiO}_{2}$ administrada y evitar la reinhalación de $\mathrm{CO}_{2}$ ).

Cuando estos métodos no son suficientes, persistiendo la IR, puede ser necesaria la aplicación de VM. 



\section{HISTORIA DE LA VENTILACIÓN MECÁNICA}




1 papel fundamental de la respiración en el mantenimiento de la vida es conocido desde la antigüedad ${ }^{9}$. Más allá de referencias bíblicas como la de Dios insuflando aire a Adán y convirtiéndolo en un ser vivo, fueron los griegos los primeros en tratar de entender de una manera científica para qué respiramos y cómo lo hacemos. Desde Anaxímedes, en el 550 antes de Cristo (a.C.) hasta Galeno, en el 160 después de Cristo (d.C.), observaron que los pulmones estaban íntimamente relacionados con el corazón, las venas y las arterias. Fue Galeno el primero en sugerir que los pulmones servían tanto para administrar aire al organismo como para eliminar productos de desecho.

Durante el Renacimiento, Vesalio y los sucesores de sus estudios comenzaron a entender que la sangre viajaba del ventrículo derecho a los pulmones y volvía de ellos hacia el ventrículo izquierdo mezclada con aire.

William Harvey describió el flujo continuo de la sangre, entendiendo que todo el volumen de sangre se mantenía circulando permanentemente, e intuyó que la sangre funcionaría únicamente como transporte de nutrientes para el organismo. 
El descubrimiento de Malpighi (1650 d.C.) de cavidades microscópicas en los pulmones y de los capilares (vasos tortuosos unidos por un lado a venas y por otro a arterias), y por otro lado la explicación por parte de Borelli del concepto de difusión (el aire disuelto en líquido puede pasar a través de membranas sin poros) permitió entender finalmente cómo el aire se mezclaba con la sangre en los pulmones.

Mientras tanto, químicos y físicos como Von Helmont, Boyle, Torricelli, Pascal y Lavoisier investigaron y comprendieron que el aire se componía de varias partículas, y que una de ellas era utilizada para producir una combustión interna que generaba energía. Aunque todos estos avances fueron necesarios para entender el funcionamiento de la respiración, desde hace miles de años se ha tratado de suplirla.

Fue Galeno el primero en describir la ventilación de un animal: "Si coges un animal muerto e insuflas aire a través de su laringe (mediante una caña), se llenarán sus bronquios y verás sus pulmones distenderse". Sin embargo, estas apreciaciones no le permitieron entender el valor de la ventilación para la vivisección. Galeno realizó multitud de ellas, pero su trabajo se vio limitado por la aparición constante de neumotórax al abrir la cavidad torácica; no fue hasta cientos de años después cuando Vesalio comprendió que la ventilación podía proteger a los animales de la aparición de neumotórax.

En 1664 Hooke describió la vivisección de un perro al que ventiló mediante un fuelle y un tubo, manteniéndolo vivo durante una hora. Lower mostró además que la respiración artificial mantenía el color rojo de la sangre durante la disección.

El punto de inflexión para el paso del uso de la respiración artificial en animales a su aplicación en humanos son los intentos de reanimar a los ahogados en el siglo XVIII. La respiración boca a boca fue recomendada para ello, siendo Tossach el primero en usar exitosamente esta técnica para salvar una vida.

A finales del XVIII comienzan a aparecer recomendaciones para utilizar la intubación traqueal y fuelles para administrar la respiración. Hay que destacar que Chaussier fabricó una bolsa con mascarilla facial como alternativa a la intubación. Además, durante este periodo se diseñaron varios instrumentos para ayudar a la canulación de la tráquea. 


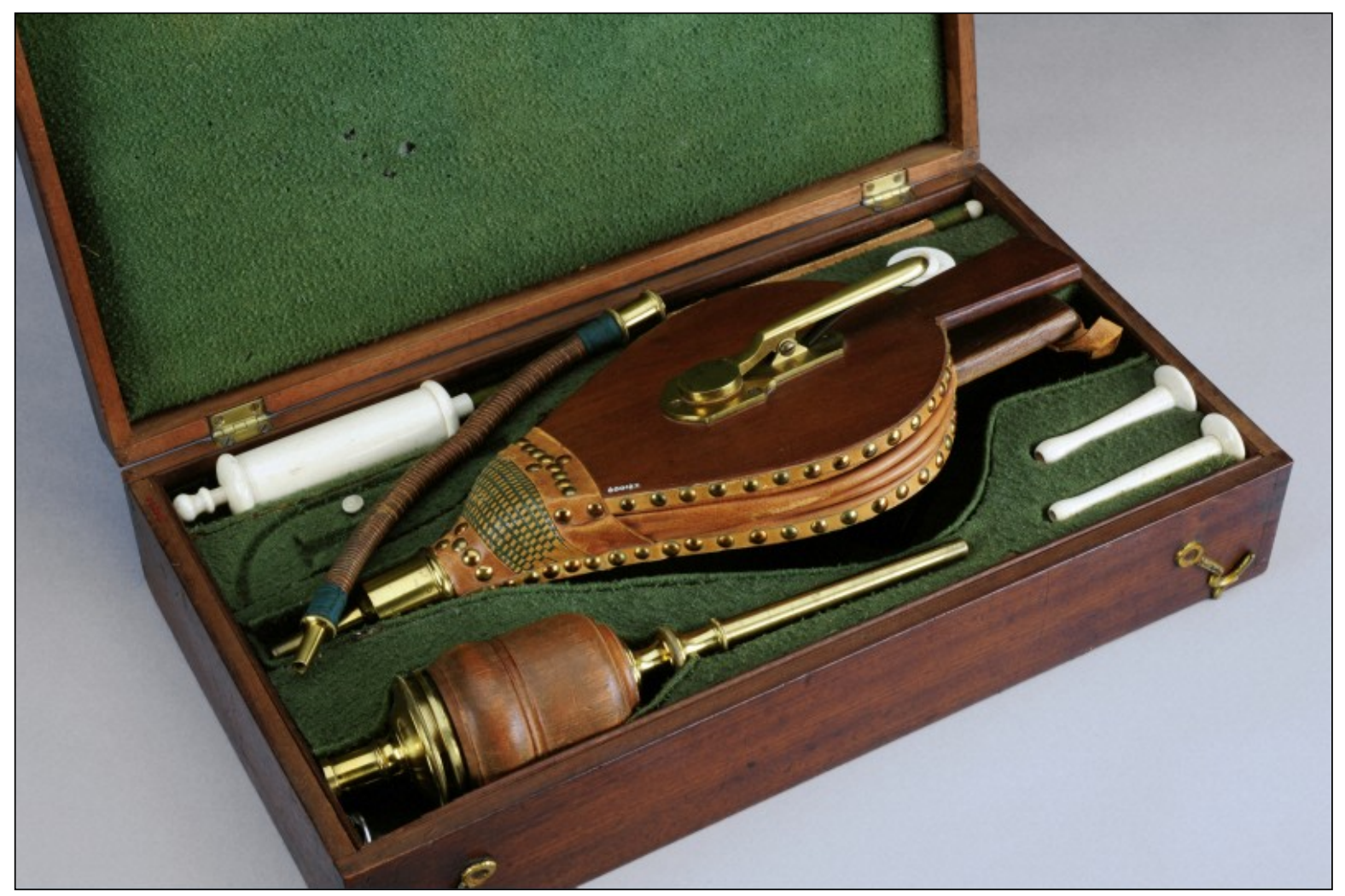

Figura 2: Instrumental para la resucitación de ahogados.

Sin embargo, en los primeros años del siglo XIX comienzan a aparecer dudas sobre la efectividad de la ventilación con fuelles. Estudios realizados en animales demostraron que la aplicación de insuflaciones excesivas producía neumotórax fatales. Después de este descubrimiento, la Academia Francesa y la Royal Humane Society (anteriormente la Sociedad para la Recuperación de Personas Aparentemente Ahogadas) recomendaron abandonar esta técnica. Así, la ventilación con presión positiva fue proscrita de la práctica médica hasta el siglo XX.

Al abandonarse el uso de la ventilación con presión positiva se empezaron a desarrollar aparatos para ventilación con presión negativa. El primero fue construido por Dalziel en 1832. Tras éste fueron apareciendo nuevos tanques, como el de Woillez en 1876, que añadió un testigo apoyado sobre el pecho del paciente que permitía medir si la ventilación era adecuada. Otros sistemas, como el biomotor Eisemberger, en 1927, solo cubrían parte del cuerpo, lo que significaba una ventaja a la hora de la aplicación de cuidados de enfermería. 
El primer sistema de presión negativa utilizado de forma masiva fue el pulmón de acero Drinker-Shaw (1928), que mantenía el cuerpo dentro del cilindro mientras la cabeza quedaba fuera. Este sistema se utilizó en varias epidemias de polio, salvando miles de vidas.

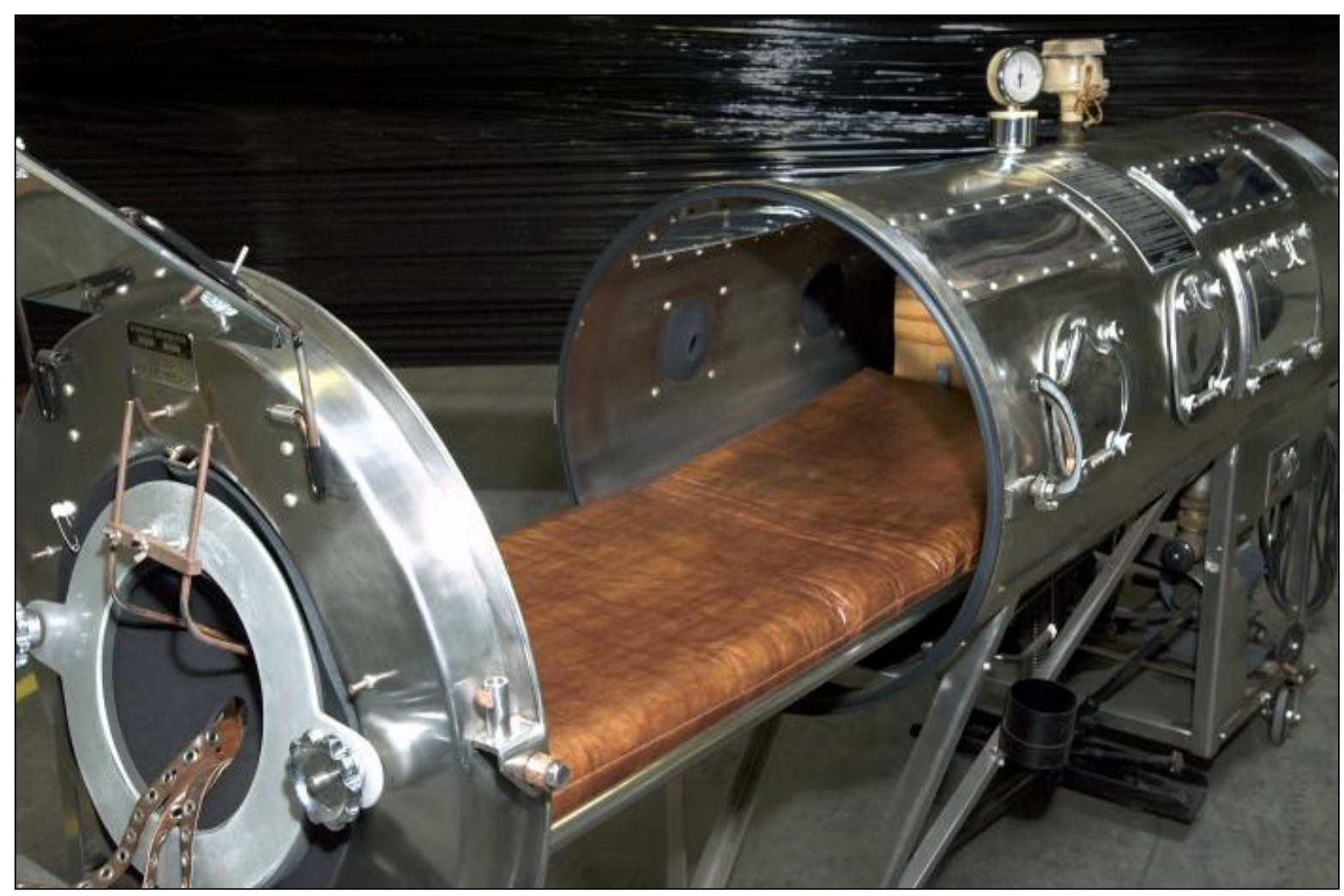

Figura 3: Pulmón de acero.

Sin embargo, aunque la presión positiva había sido desterrada de la práctica clínica, continuó siendo utilizada regularmente en la investigación fisiológica con animales. El avance en el conocimiento de sus efectos y limitaciones permitió que a principios del siglo $\mathrm{XX}$ se reintrodujera en el tratamiento médico.

Durante el siglo XIX se había observado la elevada mortalidad de la cirugía torácica por la aparición de neumotórax. Al entender que era necesario mantener una diferencia de presión para evitar esto, y dada la complejidad que suponía conseguir la diferencia de presión mediante presión negativa, empezó a utilizarse de nuevo la ventilación con presión positiva en el quirófano.

Para poder aplicar esta presión positiva era necesario aislar de alguna manera la tráquea. La traqueotomía era bien conocida desde la antigüedad (en el Rig Veda o el Papiro de Eber) 
como tratamiento en la obstrucción de la vía aérea superior. Durante el siglo XVIII se desarrollaron sistemas para realizar la intubación translaríngea como alternativa a la traqueotomía. Mediante estos sistemas comenzó a utilizarse la ventilación positiva, añadiendo además la posibilidad de usar éter o cloroformo intratraqueal, por lo que empezaron a diseñarse sistemas de fuelles que permitían ventilar y anestesiar a la vez. Además, comenzaron a fabricarse cánulas de traqueostomía o de tubos orotraqueales con balón, que evitaban las fugas, mejorando el mantenimiento de la presión positiva.

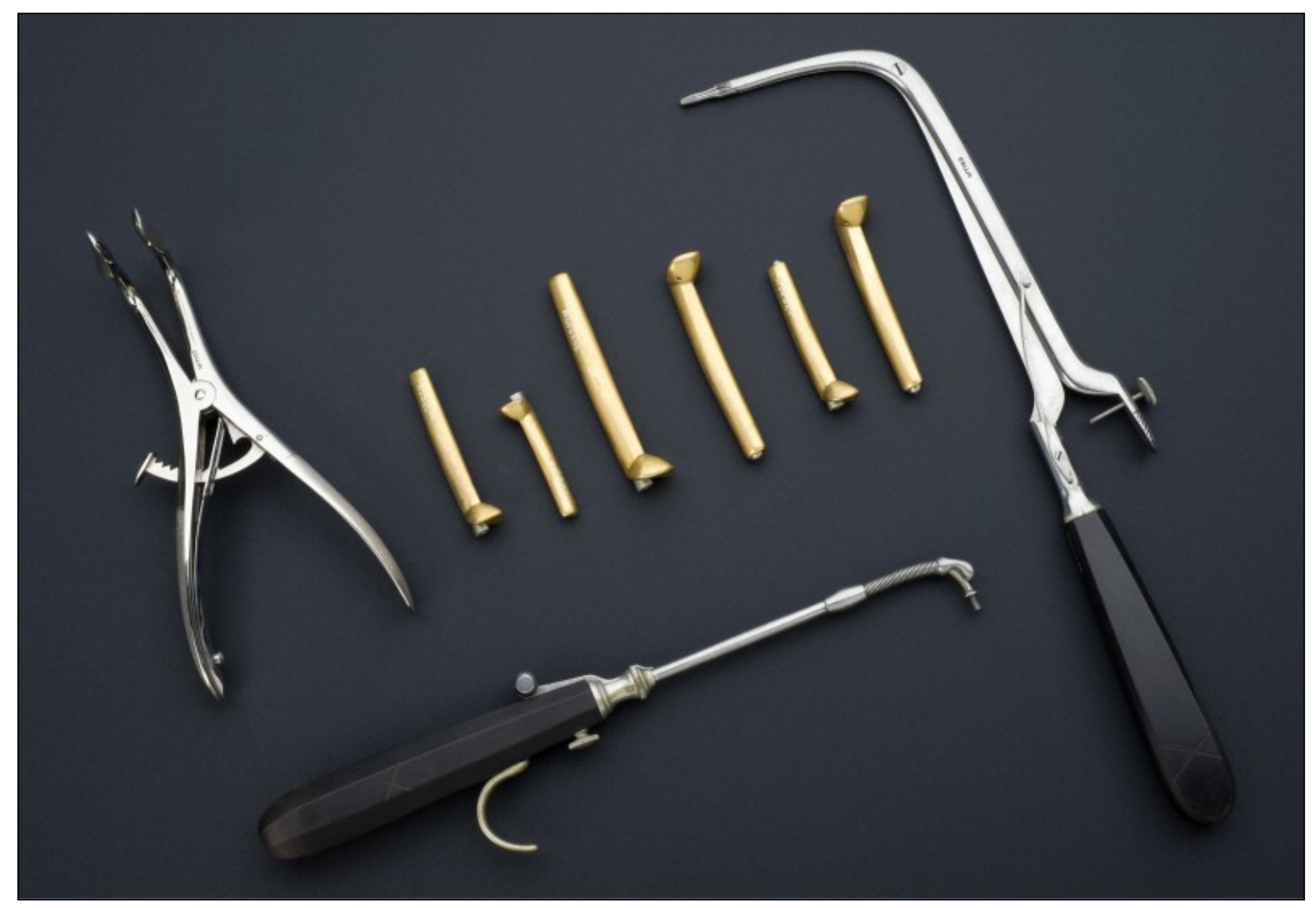

Figura 4: Set de intubación Dwyer.

Una vez se comprobó su utilidad y las ventajas sobre la presión negativa, empezó a valorarse de nuevo el uso de la ventilación positiva en pacientes médicos.

Durante la primera mitad del siglo XX las parálisis respiratorias secundarias a poliomielitis en las diversas epidemias de esta enfermedad fueron tratadas mediante ventilación negativa con pulmones de acero. Aunque este tratamiento supuso un gran avance, la mortalidad persistía elevadísima (en torno al 85\%). En 1952, una de estas epidemias tuvo lugar en Copenhague. Al evaluar los primeros fallecidos que fueron ventilados con presión negativa se observó que no presentaban grandes atelectasias que justificasen que su ventilación fuera 
imposible. Además, se detectaron elevados niveles sanguíneos de $\mathrm{CO}_{2}$. Ante esta situación se plantearon que la causa de la muerte era una ventilación inadecuada, por lo que el Dr. Björn Ibsen ${ }^{10}$ decidió ventilar con presión positiva (tras realizar una traqueotomía) a una niña de 12 años. Tras el éxito obtenido con ella, la medida se generalizó. Ocho días después, todos los pacientes con IR secundaria a poliomielitis habían recibido una traqueotomía y estaban siendo ventilados con presión positiva. Durante el resto de la epidemia unos 1500 estudiantes de Medicina y de Odontología se turnaron día y noche para ventilar de forma manual a los pacientes.

La epidemia de polio de Copenhague marca un hito en la Historia de la Medicina: se evidencia el gran valor de la ventilación con presión positiva y la necesidad de respiradores mecánicos; además, confirma la idoneidad de agrupar a los pacientes más graves en un espacio del hospital donde puedan ser tratados con la mejor tecnología disponible y de una forma adecuada, lo que supuso el nacimiento de las UCIs.

Posteriormente, multitud de patologías comenzaron a ser tratadas con ventilación con presión positiva: reagudizaciones de pacientes EPOC, intoxicación por barbitúricos, tras la cirugía cardiaca o torácica, neumonías, EAP, etc.

La segunda mitad del siglo XX, tras la confirmación de la eficacia de la ventilación con presión positiva, es testigo de la evolución tecnológica de los respiradores para VM, que presentan cada vez más funciones, permitiendo múltiples modos de ventilación y una aplicación más segura y eficaz.

Pese a los grandes avances conseguidos en la VM, las complicaciones que puede conllevar su uso (principalmente NAVM, lesiones traqueales por la intubación o barotrauma) hicieron que se continuase buscando alternativas menos agresivas.

El germen de la VMNI ${ }^{11}$ es la creación del Pulmotor por Heinrich Dräger, en 1907, un respirador con presión positiva ciclado por tiempo.

A partir de los años 60 (tras la época de la ventilación con presión negativa, que conceptualmente también es VMNI, y del inicio de la VMI con presión positiva) se empieza a utilizar la VMNI con presión positiva en pacientes con enfermedades crónicas, sobre todo 
neuromusculares, destacando el trabajo realizado por Augusta Alba en el Gold Water Memorial Hospital de Nueva York. Durante las siguientes décadas se fueron desarrollando interfases para ventilación oral o nasal, que aumentaron la eficacia de la técnica.

La utilización por parte de Colin Sullivan de CPAP para tratar a los pacientes con SAOS ${ }^{12}$, permitiendo mantener la vía aérea superior abierta (y así disminuyendo la apnea nocturna, la somnolencia diurna y los reingresos) supone el espaldarazo definitivo a la VMNI, comenzando a usarse en procesos agudos.

Durante las últimas dos décadas los estudios sobre VMNI han crecido de manera exponencial, así como las patologías tratadas con ella. 




\section{Definición de VMI:}

Se entiende como VM cualquier procedimiento mecánico utilizado para suplir total o parcialmente las necesidades de flujo aéreo a los pulmones ${ }^{13}$. La VMI es la que para ser administrada precisa un dispositivo intratraqueal (tubo orotraqueal o traqueotomía habitualmente).

\section{Objetivos de la VM:}

Los objetivos principales de la VM son:

Mejorar el intercambio de gases.

Corregir la hipoxemia.

$>$ Corregir la acidosis respiratoria.

Aliviar el trabajo respiratorio.

$>$ Disminuir el consumo de $\mathrm{O}_{2}$.

> Corregir la fatiga de los músculos respiratorios.

* Alterar las relaciones de presión-volumen.

$>$ Prevenir y corregir atelectasias.

> Mejorar la compliance pulmonar.

$>$ Prevenir lesiones futuras.

Permitir la curación de la patología pulmonar y de la vía aérea.

Evitar complicaciones. 


\section{Indicaciones de IOT y VM:}

Aislamiento de la vía aérea y protección pulmonar (pacientes en coma).

* Evitar la obstrucción de la vía aérea.

Incapacidad para eliminar secreciones bronquiales.

IR grave ${ }^{14}$

$>$ Ventilación alveolar inadecuada: $\mathrm{PaCO}_{2}$ aumentada sobre la basal del paciente.

$>$ Expansión pulmonar inadecuada: Volumen corriente $\left(\mathrm{V}_{\mathrm{c}}\right)<4-5$ mililitros por kilogramo $(\mathrm{ml} / \mathrm{Kg}), \mathrm{FR}>35 \mathrm{resp} / \mathrm{min}$.

Excesivo trabajo respiratorio.

\section{Complicaciones de la VMI:}

La utilización de VM es esencial en un gran número de pacientes, y es responsable de mantenerlos con vida hasta la mejoría de la patología que ha hecho necesario su uso. Pero desde hace mucho tiempo es conocido que la VM no es inocua. Pese a los grandes avances conseguidos durante los últimos 100 años, que han conseguido disminuir las complicaciones, éstas siguen existiendo. Entre las más habituales se encuentran ${ }^{14}$ :

Infección nosocomial: La IOT y conexión a VM facilita la colonización por los microorganismos prevalentes durante los primeros días de ingreso. Estos microorganismos son responsables de producir NAVM. Esta patología conlleva una morbilidad y mortalidad elevada. Su diagnóstico y tratamiento correcto supone un reto fundamental en las UCIs ${ }^{15}$.

Hemorragia digestiva: Los pacientes bajo VM presentan mayor incidencia de hemorragia digestiva alta. La profilaxis con antiH $\mathrm{H}_{2}$, sucralfato o inhibidores de la bomba de protones permite disminuir su aparición.

Traumatismo laríngeo: La incidencia de lesiones laríngeas durante la laringoscopia inicial es elevada (destacando úlceras mucosas en la zona posterior de las cuerdas vocales). Además, a mayor tiempo de intubación aumenta el riesgo de presentar lesiones, pudiendo aparecer ronquera que incluso puede persistir durante meses.

Estenosis traqueal: La utilización de presiones altas en el balón de neumotaponamiento es la responsable de las ulceraciones y estenosis traqueales, por lo que los modernos de alto 
volumen y baja presión han disminuido su aparición. Es fundamental la medición frecuente de las presiones para evitar superar los 20-25 mmHg. Sigue sin estar claro el momento ideal de realización de una traqueostomía a los pacientes que precisan VM prolongada.

Sinusitis paranasal: Más frecuente con la intubación nasotraqueal que con la orotraqueal, puede ser difícil de diagnosticar (exigiendo un alto índice de sospecha).

Complicaciones de la traqueostomía: Hemorragia, infecciones del estoma, aspiración o enfisema subcutáneo son complicaciones habituales. También pueden aparecer neumotórax, mediastinitis, traumatismos tiroideos u obstrucciones de vía aérea.

Fístula traqueoesofágica: Complicación muy poco frecuente, ocurre por necrosis traqueal por hiperpresión del neumotaponamiento. Sus síntomas pueden ser inespecíficos, dificultando el diagnóstico. Precisa reparación quirúrgica.

Disminución del gasto cardiaco: El descenso del gasto cardiaco es habitual en los pacientes conectados a ventilación con presión positiva. Los mecanismos que lo producen son variados: disminución del retorno venoso con el aumento de la presión intratorácica; desplazamiento del tabique interventricular por el aumento de la presión en aurícula y ventrículo derechos; disminución del llenado diastólico por ese desplazamiento del septo y por la presión positiva ejercida por el pulmón que rodea los ventrículos.

Lesión pulmonar inducida por VM (VILI): Múltiples estudios han demostrado que la VM puede agravar la lesión pulmonar aguda. Esta lesión pulmonar secundaria se produce por varios mecanismos ${ }^{16}$ :

Barotrauma: Las presiones inspiratorias elevadas (tanto presiones pico como presiones medias) suponen un traumatismo para el parénquima pulmonar. Su incidencia se estima entre un $7-25 \%$. Habitualmente el barotrauma aparece como neumotórax, neumomediastino o enfisema subcutáneo.

Volutrauma y atelectrauma (lesión por cizallamiento): El volutrauma es la lesión pulmonar producida por la sobreinsuflación del pulmón (aunque no haya presiones altas). La lesión por cizallamiento se produce por el colapso repetido de alvéolos al final de la espiración y su apertura durante la siguiente inspiración. Este traumatismo repetido sobre el endotelio y 
el epitelio de las unidades pulmonares puede producir lesión pulmonar. Como se verá más tarde, uno de los beneficios de la presión positiva al final de la espiración (PEEP) es evitar este colapso alveolar.

Daño pulmonar por $\mathrm{FiO}_{2}$ elevadas: Existen múltiples estudios de laboratorio con animales de experimentación que muestran la aparición de alteraciones histopatológicas con la aplicación de altas $\mathrm{FiO}_{2}$ de forma prolongada, relacionadas principalmente con la producción de diferentes agentes oxidantes; sin embargo, desde el punto de vista clínico estos hallazgos no han podido ser comprobados. Sí está demostrada la atelectasia por reabsorción (que se produce al disminuir la concentración de nitrógeno y disminuir la tensión superficial del alveolo) que contribuye a la lesión por cizallamiento ${ }^{17}$.

Biotrauma: El concepto de biotrauma aparece en $1998^{18}$ para referirse a la respuesta inflamatoria pulmonar y sistémica mediada por sustancias proinflamatorias liberadas como respuesta a la distensión, ruptura y/o necrosis celular pulmonar. Así, la lesión pulmonar inducida por VM pasa de ser un fenómeno local a poder afectar a todo el organismo.

Otras complicaciones: La VM induce retención hidrosalina por inhibición de la secreción de hormonas diuréticas. Además, habitualmente es necesario el uso de sedación profunda e incluso relajantes musculares, lo que puede dificultar el destete y contribuir a la polineuropatía del paciente crítico.

Todas estas complicaciones dejan claro que la VMI no es una técnica exenta de riesgos, lo que ha hecho que se busquen alternativas que permitan evitarlas. En el seno de esa búsqueda surge el interés en la VMNI. 


\section{VENTILACIÓN MECÁNICA NO INVASIVA}





\section{Definición de VMNI:}

En contraposición a la VMI, la VMNI es el dispositivo utilizado para aplicar soporte ventilatorio que no precisa tubo traqueal. Esta definición engloba la ventilación aplicada con presión positiva y la que utiliza presión negativa, además de poder incluirse aquí unos sistemas de ayuda a la respiración actualmente anecdóticos ${ }^{9}$.

\section{Tipos de VMNI:}

VMNI con presión negativa: Como ya se mencionó en el recuerdo histórico, la utilización de presión negativa se inicia hace casi 200 años. Funciona aplicando presión subatmosférica a la superficie del tórax durante la inspiración. Esto crea el gradiente de presión necesario para facilitar el paso de aire a los alvéolos. La espiración se realiza pasivamente al dejar de aplicar esta presión.

$>$ Tanque de ventilación: Todo el cuerpo queda introducido en un tanque rígido, mientras que la cabeza permanece fuera. La presión negativa se mantiene mediante una bomba que la genera; un sello alrededor del cuello evita que esta presión se pierda. Su gran desventaja es la aparatosidad del sistema, y la dificultad de acceder al paciente (aunque suelen disponer de ventanas para poder hacerlo).

$>$ Pulmo-wrap o poncho-wrap: Consiste en una chaqueta con estructura rígida, que cubre tórax y abdomen, sellando el cuello, los brazos y las caderas para permitir la creación de la presión negativa. Su uso está destinado a la VMNI domiciliaria, dada su menor eficacia en la IRA.

$>$ Armadura (cuirass): Utiliza un escudo rígido fijado al tórax anterior, aplicando la presión negativa tan solo sobre esa superficie, lo que limita su eficacia.

Sistemas no invasivos de ayuda a la respiración: Utilizan el efecto de la gravedad para ayudar al movimiento del diafragma. Su indicación principal es en pacientes con debilidad o parálisis diafragmática. Vivieron su mayor expansión durante las grandes epidemias de poliomielitis, siendo actualmente muy poco utilizadas.

Cama basculante (rocking bed): Funciona colocando al paciente en decúbito supino sobre ella y alternando el trendelemburg y el antitrendelemburg, utilizando el peso de los órganos intraabdominales para la inspiración y la espiración. 
$>$ Neumobelt: Consiste en un corsé con un balón inflable aplicado sobre el abdomen. Al hincharse desplaza el contenido abdominal hacia arriba, forzando la espiración. Cuando se desinfla, las vísceras vuelven a su posición, facilitando la inspiración. Fue diseñado para ayudar a la ventilación mientras los pacientes se encontraban sentados, permitiendo su movilidad en silla de ruedas.

VMNI con presión positiva: Utiliza una mascarilla o similar para transmitir la presión positiva a la vía aérea. Actualmente la VMNI con presión positiva es el sistema más utilizado, siendo el uso del resto prácticamente marginal. A partir de ahora en esta tesis al hablar de VMNI nos estaremos refiriendo a VMNI con presión positiva. Es necesario además reflejar que aunque la CPAP no es un sistema de ventilación estrictamente hablando, se engloba dentro de la VMNI para diferenciarlo de la oxigenoterapia convencional, ya que sí utiliza una presión positiva.

\section{Consecuencias fisiológicas de la VMNI:}

Es evidente que cuando se decide utilizar VMNI se persigue solucionar una situación de IR, que puede ser aguda o crónica. La VMNI puede conseguir esto de varias maneras ${ }^{19}$ :

Sobre el intercambio gaseoso: Mejora la hipoxemia, lo que permite disminuir la $\mathrm{FiO}_{2}$, y reducir así la posible toxicidad del $\mathrm{O}_{2}$. Se consigue mediante el reclutamiento de alvéolos colapsados, lo que mejora los desequilibrios V/Q y disminuye el shunt.

* Sobre la mecánica respiratoria: La aplicación de una presión positiva inspiratoria en vía aérea (IPAP) y una presión positiva espiratoria en vía aérea (EPAP) disminuye el trabajo de los músculos respiratorios, permitiendo su reposo y favoreciendo la recuperación funcional.

Sobre el ciclo respiratorio: Al aumentar el $\mathrm{V}_{\mathrm{c}}$ y disminuir la FR, varía los flujos y tiempos inspiratorios y espiratorios.

Sobre la función pulmonar: Aumenta el $\mathrm{V}_{\mathrm{c}}$, reclutando alvéolos colapsados, por lo que aumenta la capacidad residual funcional y la distensibilidad.

\section{Beneficios clínicos de la VMNI ${ }^{20}$ :}

Reducción de la IOT (con lo que se evitan o disminuyen sus complicaciones, como la NAVM, las lesiones traqueales, las lesiones relacionadas con la laringoscopia). 
Mejoría del confort del paciente. Se evita la necesidad de sedación profunda, y permite hablar y comer, disminuyendo su ansiedad.

* Disminución de la estancia en UCI y hospitalaria.

* Disminución de la mortalidad hospitalaria.

\section{Tipos de respiradores para VMNI:}

Existen multitud de respiradores utilizados para VMNI. Con todos ellos es posible realizarla, pero dependiendo de una serie de características su eficacia será mayor o menor. Los podemos dividir en varios tipos ${ }^{11}$ :

Respiradores de UCI: Los respiradores clásicos de VM utilizados en las UCIs pueden ser usados para realizar VMNI. Presentan importantes ventajas, entre las que están la posibilidad habitual de monitorizar curvas, presiones o volúmenes, el poder elegir la $\mathrm{FiO}_{2}$, o la monitorización de alarmas. El mayor problema es que los más antiguos no compensan las fugas, aunque esa debilidad se ha corregido en los más modernos.

* Respiradores volumétricos domiciliarios: Son útiles en pacientes crónicos, pero no deberían ser usados para pacientes en situaciones agudas, ya que presentan claras limitaciones, como el no poder ventilar por presión, ni utilizar PEEP. Además, ni compensan fugas, ni administran $\mathrm{FiO}_{2}$ elevadas.

* Respiradores domiciliarios volumétrico-presurométricos: Son similares a los respiradores de UCI en cuanto a modos, alarmas y capacidades, aunque de menor tamaño y peso, por lo que resultan mejores que los anteriores para la VMNI en pacientes agudos.

- Respiradores de doble nivel de presión: Diseñados durante los últimos años para la aplicación de VMNI, son los respiradores ideales para este fin. Dependiendo de su complejidad, unos serán más adecuados para su utilización en pacientes menos graves, y otros para pacientes en UCIs. De entre todos ellos, el BiPAP Vision de Respironics es el único diseñado específicamente para pacientes críticos. La desventaja principal de este tipo de respiradores es que al no tener una tubuladura espiratoria real, la espiración ha de hacerse a través de un orificio cerca de la interfase. Esto puede producir que parte del $\mathrm{CO}_{2}$ espirado pase al circuito respiratorio, pudiendo ser reinhalado (lo que se conoce como rebreathing). 
Sistemas de CPAP: Existen multitud de sistemas para administrar CPAP, desde respiradores de UCI convencionales a simples sistemas de flujo continuo. Básicamente un sistema de CPAP necesita un generador de alto flujo y válvulas de PEEP (además de mascarilla, tubuladura y válvulas unidireccionales). Los respiradores convencionales producen un flujo a demanda (una válvula se abre cuando detecta un impulso inspiratorio). Su mayor inconveniente es que se pueden producir flujos inspiratorios inadecuados, o sensibilidades erróneas que aumenten el trabajo respiratorio. En cambio, los sistemas de flujo continuo son sistemas no mecánicos con un mezclador de alto flujo (donde se puede seleccionar $\mathrm{FiO}_{2}$ ) conectado a un sistema que genera PEEP. Ésta puede ser creada mediante umbrales de resistencia (dispositivos que producen una fuerza constante en la rama de salida, precisando que se ejerza una presión superior a la que crean para permitir el flujo a su través), orificios de resistencia (utilizados únicamente en pediatría) o válvulas de Boussignac (que generan una PEEP virtual mediante un flujo de aire inyectado a través de orificios colaterales de un cilindro, creando turbulencias). Los sistemas comerciales más utilizados son Whisperflow-caradyne, CPAP Vital-Sign, CPAP CF-800 Dräger y CPAP Boussignac-Vigon.

\section{Modalidades de VMNI:}

Existen varios modos de VMNI, de forma paralela a la VM convencional ${ }^{11}$ :

- CPAP: La CPAP no es técnicamente un modo ventilatorio, ya que únicamente mantiene una presión constante en la vía aérea, siendo el paciente el que realiza el trabajo respiratorio.

* Modos limitados por presión: El respirador administra una presión positiva programada con cada respiración, con una morfología de flujo decelerado (es decir, inicialmente a un flujo elevado y posteriormente va disminuyendo para mantener la presión en vía aérea constante).

$>$ Limitados por presión ciclados por flujo:

- Presión de soporte (PS): Cada esfuerzo respiratorio del paciente es suplementado con una presión positiva inspiratoria (la que se haya programado). Cuando el respirador detecta un impulso respiratorio (mediante un trigger de flujo o de presión), se administra el flujo inspiratorio; cuando el flujo inspiratorio 
disminuye por debajo del trigger espiratorio, se detiene dicho flujo, comenzando la espiración.

Limitados por presión ciclados por tiempo: En estas modalidades el paso de inspiración a espiración está programado por tiempo.

- Presión control (PC): En el respirador se programa la presión aplicada en la vía aérea, manteniéndose ésta durante todo el tiempo inspiratorio mediante un flujo decelerado. Además se selecciona la FR (si el paciente no tiene estímulo respiratorio el respirador administrará las ventilaciones que se hayan pautado, pero si presenta impulsos respiratorios éstos serán asistidos con esa presión) y la relación inspiración-espiración.

- Presión bi-nivelada o BPAP (bi-level positive airway pressure): Esta modalidad está diseñada para suministrar presión positiva mediante generadores de flujo continuo, más o menos portátiles, que permiten entregar presión positiva de forma decelerada para mantener la presión que sea pautada. En este caso, esta presión se conoce como IPAP. El ciclado se produce por tiempo en la modalidad controlada y por flujo en la espontánea, pasando a la espiración, disminuyendo la presión positiva hasta la EPAP. Dentro de la BPAP tenemos los modos S (spontaneous, todas las inspiraciones son disparadas por el paciente), S/T (spontaneous/timed, como el modo $\mathrm{S}$ pero si el paciente no realiza impulso inspiratorio se puede pautar un número de respiraciones controladas) y modo $\mathrm{T}$ (timed, se programa la frecuencia). Dependiendo de los distintos tipos de respiradores se pueden programar diferentes parámetros, como la pendiente de la IPAP (rampa o rise time), los trigger inspiratorios y espiratorios, $1 \mathrm{a} \mathrm{FiO}_{2}$, etc. Por tanto, algunos de estos respiradores serán útiles para su utilización en pacientes agudos, mientras que otros solo servirán para pacientes crónicos. Es frecuente ${ }^{21}$ que los términos BiPAP y BIPAP sean utilizados incorrectamente para referirse a esta modalidad, ya que ambos son dos formas de BPAP registradas por los respectivos fabricantes de los respiradores que las suministran.

- Ventilación asistida proporcional (VAP): Es una modalidad de asistencia parcial en la que el respirador detecta la intensidad del impulso respiratorio y varía la presión positiva suministrada adaptándose al flujo y al volumen generado por el paciente. 
Limitados por volumen: En estas modalidades la variable programada es el volumen, dependiendo la presión en vía aérea de dicho volumen, del tiempo inspiratorio y de la mecánica pulmonar. Son mucho menos utilizados que los modos limitados por tiempo.

\section{Interfases para VMNI:}

Ya que la VMNI no utiliza la canalización traqueal para la aplicación de presión positiva, es necesario algún tipo de dispositivo que permita transmitir esta presión del respirador a la vía aérea del paciente ${ }^{11}$. Durante los últimos años se ha comprobado que la elección de la interfase adecuada para cada paciente es un factor fundamental para el éxito de la técnica. Según la interfase que se elija podrán aparecer además distintas complicaciones. Actualmente existen multitud de interfases, pudiendo dividirlas en tres tipos:

Interfase oral (piezas bucales): Se colocan entre los labios, manteniéndose mediante un dispositivo específico.

* Interfase nasal (mascarillas nasales o pillow nasales): La mascarilla nasal cubre únicamente la nariz; los pillow nasales son sistemas cilíndricos que se adaptan a las fosas nasales.

* Interfases oronasales (mascarillas faciales, mascarillas totales, helmets): Incluyen la nariz y la boca. Las mascarillas faciales tapan solo nariz y boca, las totales cubren toda la cara, y los helmets incluyen cabeza y cuello.

Para la ventilación de pacientes agudos lo más habitual es la utilización de algún tipo de interfase oronasal $^{22}$, ya que en muchas ocasiones el paciente ante la disnea realiza respiración bucal, por lo que estas interfases serán mucho más eficaces. Hay que destacar que dado que una de las complicaciones más frecuentes (como se verá más tarde) es la aparición de lesiones cutáneas, la alternancia de diferentes interfases para cambiar las zonas de apoyo en los pacientes que precisen VMNI durante muchas horas puede disminuir su incidencia $^{23}$.

Idealmente la interfase debería ser lo más pequeña y hermética posible (para reducir el espacio muerto y disminuir las fugas), transparente, ligera, confortable, fácil de colocar y retirar, biocompatible, hipoalergénica, fácil de lavar, y con válvula antiasfixia ${ }^{24}$. 
Uno de los problemas fundamentales a la hora de aplicar VMNI es la aparición de fugas. Por eso, es esencial a la hora de elegir la interfase que minimice éstas. Sin embargo, hay que asumir un pequeño volumen de fugas, ya que esto no afecta a la eficacia de la terapia ${ }^{25}, \mathrm{y}$ sin embargo el exceso de presión para aumentar el sellado y disminuirlas sí puede favorecer la aparición de lesiones cutáneas ${ }^{26}$.

La interfase se fija al rostro mediante un arnés, existiendo también numerosos tipos, con mayor o menor número de puntos de fijación. Este arnés debería repartir la presión de forma uniforme evitando los ya comentados riesgos de fugas y lesiones cutáneas.

\section{Indicaciones de la VMNI en el paciente agudo:}

La elección del paciente que precisa VMNI y que se puede beneficiar de ella es fundamental: es una técnica que no está exenta de complicaciones, por lo que no se debe utilizar en pacientes que no la precisen; además, la aplicación de VMNI en pacientes que no van a mejorar y que precisen VM, retrasando la IOT, puede empeorar el pronóstico ${ }^{27}$, por lo que se debería evitar.

Indicaciones por parámetros clínicos/fisiológicos ${ }^{28}$ :

* Hipoxemia: PAFI < 200.

* Fallo ventilatorio agudo o crónico: $\mathrm{PaCO}_{2}>45 \mathrm{mmHg}$ y $\mathrm{pH}<7,35$.

* Disnea moderada o grave.

* Signos de aumento del trabajo respiratorio, como uso de musculatura accesoria o respiración abdominal.

* Taquipnea: FR > 24 resp/min o > 30 en pacientes con patología restrictiva.

Indicaciones por patologías ${ }^{28}$.

Reagudización de pacientes EPOC. IR hipercápnica.

* EAP cardiogénico.

* Ayuda en el destete.

* IR postextubación.

* IR en pacientes inmunodeprimidos.

* IR hipoxémica. 
- Periodo postquirúrgico (prevención y tratamiento de IR).

Enfermedad neuromuscular.

* Obstrucción parcial de vía aérea.

* Trauma torácico.

* Prevención o tratamiento de IR en pacientes con asma.

* SDRA.

* Fibrosis quística.

* Síndrome hipoventilación-obesidad.

Fibrosis pulmonar idiopática.

* Pacientes con orden de no intubar.

El nivel de evidencia es muy dispar dependiendo de las patologías. Mientras que en las reagudizaciones de EPOC la evidencia es abrumadora ${ }^{29}$, en otros tipos son únicamente series de casos o estudios de escasa calidad.

\section{Contraindicaciones de la VMNI:}

Aunque la VMNI tiene contraindicaciones, la gran mayoría de ellas son relativas, pudiendo encontrarse en muchas ocasiones soluciones a estas contraindicaciones que pueden permitir su uso ${ }^{28}$.

Contraindicaciones absolutas:

Parada respiratoria.

* PCR.

* Incapacidad para fijar una interfase correctamente.

Contraindicaciones relativas:

Inestabilidad hemodinámica (shock, hipotensión, isquemia miocárdica no controlada o arritmias).

* Incapacidad para proteger la vía aérea.

* Trastornos de deglución.

* Cirugía esofágica o de vía aérea superior reciente.

* Secreciones excesivas. 
Agitación psicomotriz o no colaboración.

Hemorragia digestiva alta incontrolada.

* Fallo multiorgánico (dos o más órganos).

\section{Complicaciones de la VMNI:}

En general la VMNI es una técnica bien tolerada y con pocos efectos adversos importantes. Las complicaciones más habituales suelen estar relacionadas con la interfase o con el flujo de aire. La mayoría de ellas no hacen que sea necesaria la retirada de la ventilación, pudiendo corregirse o aliviarse con medidas relativamente simples. Una adecuada aplicación de la técnica puede disminuir la incidencia de aparición ${ }^{30}$.

\begin{tabular}{|c|c|c|}
\hline Tipo de complicación & $\begin{array}{l}\text { Frecuencia } \\
(\%)\end{array}$ & Posibles soluciones \\
\hline $\begin{aligned} & \text { Relacionada con la mascarilla: } \\
& \text { - } \text { Incomodidad } \\
& \text { - } \text { Eritema cutáneo } \\
& \text { - } \text { Claustrofobia } \\
& \text { - } \text { Ulceración del puente } \\
& \text { nasal } \\
& \text { - } \text { Rash acneiforme } \\
&\end{aligned}$ & $\begin{array}{c}30-50 \\
20-34 \\
5-10 \\
5-10 \\
5-10\end{array}$ & $\begin{array}{l}\text { Recolocar, ajustar, cambiar a otro tipo } \\
\text { Aflojar arnés, colocar protecciones } \\
\text { Mascarilla más pequeña, sedación } \\
\text { Aflojar arnés, protecciones, mascarilla } \\
\text { diferente } \\
\text { Esteroides o antibióticos tópicos }\end{array}$ \\
\hline $\begin{array}{cl}\text { Relacionada con el flujo de aire: } \\
\text { - } & \text { Congestión nasal } \\
\text { - } & \text { Dolor de senos } \\
& \text { paranasales } \\
\text { - } & \text { Sequedad nasal/bucal } \\
\text { - } & \text { Irritación ocular } \\
\text { - } & \text { Distensión gástrica }\end{array}$ & $\begin{array}{c}20-50 \\
10-30 \\
10-20 \\
10-20 \\
5-10\end{array}$ & $\begin{array}{l}\text { Esteroides nasales, antihistamínicos } \\
\text { Reducir presión si no se tolera } \\
\text { Suero salino, humidificador, reducir fugas } \\
\text { Comprobar mascarilla, reajustar. } \\
\text { Reducir presión, simeticona. Valorar } \\
\text { sonda nasogástrica }\end{array}$ \\
\hline Fuga aérea & $80-100$ & $\begin{array}{l}\text { Usar mascarilla facial, recolocar, reducir } \\
\text { presión }\end{array}$ \\
\hline $\begin{aligned} & \text { Complicaciones mayores: } \\
& \text { - } \text { Neumonía por aspiración } \\
& \text { - } \text { Hipotensión } \\
& \text { - } \text { Neumotórax }\end{aligned}$ & $\begin{array}{l}<5 \\
<5 \\
<5\end{array}$ & $\begin{array}{l}\text { Selección adecuada del paciente } \\
\text { Reducir presión } \\
\text { Retirar VMNI si es posible, disminuir } \\
\text { presión si no. Tubo de drenaje si está } \\
\text { indicado }\end{array}$ \\
\hline
\end{tabular}

Figura 5 Complicaciones de la VMNI. 



\section{MATERIAL Y MÉTODOS}




ara la realización del presente trabajo de Tesis Doctoral se han revisado de forma retrospectiva todos los pacientes que recibieron tratamiento mediante VMNI (tanto CPAP como BPAP) durante su ingreso en la Unidad de Cuidados Intensivos del Hospital Clínico de Salamanca entre los años 2006 y 2011.

Esta Unidad consta de 16 camas, 12 de UCI polivalente y 4 para el postoperatorio de Cirugía Cardiaca. La UCI polivalente recibe tanto pacientes médicos como quirúrgicos (principalmente cirugías pancreáticas, hepáticas y esofágicas). Durante los seis años revisados se produjeron 4661 ingresos, contabilizándose un total de 4249 pacientes, ya que 412 ingresos fueron de pacientes que lo hicieron más de una vez.

2401 ingresos procedían de quirófano; 1036 del S. de Urgencias; 365 de plantas quirúrgicas; 571 de plantas médicas; 65 del Hospital Virgen de la Vega; 138 de otros hospitales; 41 de otras Unidades especiales (34 de la Unidad Coronaria y 7 de la Unidad de Reanimación); 4 pacientes de la planta de Psiquiatría.

En cuanto a los pacientes quirúrgicos destacan 2014 pacientes de C. Cardiaca, 37 pacientes de C. Torácica, 434 de C. General y 36 pacientes de C. Vascular.

De los 4661 ingresos, 534 fueron exitus. 


\section{Aplicación de VMNI.}

El inicio de la VMNI era decidido por el médico responsable del paciente si éste cumplía alguno de los criterios de inicio:

Hipoxemia: $\mathrm{PaO}_{2} / \mathrm{FiO}_{2}<200$.

* Fallo ventilatorio agudo o crónico: $\mathrm{PaCO}_{2}>45 \mathrm{mmHg}$ y $\mathrm{pH}<7,35$.

* Disnea moderada o grave.

- Signos de aumento del trabajo respiratorio, como uso de musculatura accesoria o respiración abdominal.

* Taquipnea (FR $>24$ respiraciones/minuto o $>30$ en pacientes con patología restrictiva).

Además se descartaba la presencia de contraindicaciones:

Contraindicaciones absolutas:

$>$ Parada respiratoria.

$>$ PCR.

$>$ Incapacidad para fijar una interfase correctamente.

Contraindicaciones relativas:

$>$ Inestabilidad hemodinámica (shock, hipotensión, isquemia miocárdica no controlada o arritmias).

$>$ Incapacidad para proteger la vía aérea.

$>$ Trastornos de deglución.

$>$ Cirugía esofágica o de vía aérea superior reciente.

$>$ Secreciones excesivas.

Agitación psicomotriz o no colaboración.

> Hemorragia digestiva alta incontrolada.

Fallo multiorgánico (dos o más órganos).

La existencia de contraindicaciones relativas era evaluada por el médico, que decidía si el paciente podía ser sometido a una prueba de VMNI o se realizaba IOT y conexión a VMI. 
Una vez decidido el inicio de la VMNI se seleccionaba el material necesario, se conectaba el respirador de VMNI a la toma de $\mathrm{O}_{2}$ de alta presión y se elegía la modalidad ventilatoria. En el caso de BPAP, se programaba inicialmente un nivel bajo de IPAP y EPAP, en torno a 8 y 4 centímetros de agua $\left(\mathrm{cmH}_{2} \mathrm{O}\right)$ respectivamente, y se iba subiendo la IPAP progresivamente, buscando una $\mathrm{FR}<30 \mathrm{resp} / \mathrm{min}$ y un $\mathrm{V}_{\mathrm{c}}>6 \mathrm{ml} / \mathrm{Kg}$ en EPOC y $8 \mathrm{ml} / \mathrm{Kg}$ en hipoxemias. $\mathrm{La} \mathrm{FiO}_{2}$ inicialmente se titulaba para buscar una $\mathrm{SatO}_{2}$ en torno al $90 \%$ (tolerando $\mathrm{SatO}_{2}$ algo más bajas en reagudizaciones de enfermedades crónicas respiratorias).

Para la EPAP o si se decidía la utilización de CPAP, se aumentaba su nivel para permitir la disminución de $\mathrm{FiO}_{2}$, aunque niveles mayores de $10 \mathrm{cmH}_{2} \mathrm{O}$ usualmente implican mala tolerancia y fracaso de la técnica.

Inicialmente la mascarilla se sujetaba manualmente (sin arnés), para permitir que el paciente se adaptase a ella; posteriormente se colocaba el arnés y se ajustaba intentando encontrar un balance adecuado entre fugas y tolerabilidad del paciente.

La VMNI se mantenía mientras la situación clínica lo precisase, permitiendo desconexiones puntuales para descansar, beber agua o administrar aerosoles (si no se realizaba con sistemas específicos de VMNI).

Se realizaban gasometrías antes del inicio de la VMNI (si la situación clínica lo permitía) y a los 60-120 minutos de iniciada. Durante las primeras horas los controles gasométricos eran frecuentes, siendo posteriormente cada 8-12 horas o si la situación clínica cambiaba. Si era posible las gasometrías eran arteriales; si el acceso arterial no era posible o se decidía no canalizar arteria, se monitorizaba mediante gasometría venosa y $\mathrm{SatO}_{2}$ por pulsioximetría.

\section{Monitorización:}

Todos los pacientes recibían monitorización continua de constantes vitales:

- Pulsioximetría.

- Presión arterial (no invasiva o invasiva).

- Electrocardiografía.

- Frecuencia cardiaca (FC). 
- FR.

- Nivel de consciencia.

- Evaluación clínica de trabajo respiratorio (uso de musculatura accesoria, disociación tóraco-abdominal).

La monitorización de presión arterial invasiva y presión venosa central (PVC) era decidida por el médico según la situación del paciente y la accesibilidad.

También se controlaban parámetros de VMNI:

- IPAP.

- EPAP.

- $\mathrm{FiO}_{2}$.

$-\mathrm{V}_{\mathrm{c}}$.

- Asincronía paciente-respirador.

De forma opcional, además de la presión arterial invasiva y la presión venosa central en ocasiones se realizaba monitorización hemodinámica avanzada mediante Edwards Lifesciences Vigileo ${ }^{\circledR}$, Pulsion $\mathrm{PICCO}_{2}{ }^{\circledR}$ o mediante catéter de arteria pulmonar.

Además se monitorizaba la aparición de efectos secundarios locales, como la sequedad de mucosas, la conjuntivitis o las lesiones cutáneas.

Si el paciente presentaba mejoría se disminuía el soporte respiratorio de forma progresiva hasta permitir la retirada definitiva de la VMNI.

Si la situación clínica o gasométrica no mejoraba el médico responsable decidía la continuación de la VMNI o su cese para IOT y conexión a VM.

La aplicación de VMNI fue efectuada mediante respiradores específicos: BiPAP Vision (Respironics Inc. ${ }^{\circledR}$, Pensilvania, USA) o Carina (Dräger ${ }^{\circledR}$, Alemania), y mascarillas faciales transparentes. 


\section{BiPAP Vision:}

De entre todos los respiradores con doble nivel de presión, fabricados para la aplicación de VMNI, el sistema BiPAP Vision de Respironics Inc. ${ }^{\circledR}$ es el único diseñado para su utilización en pacientes críticos. Varias características lo convierten en el más adecuado para esto:

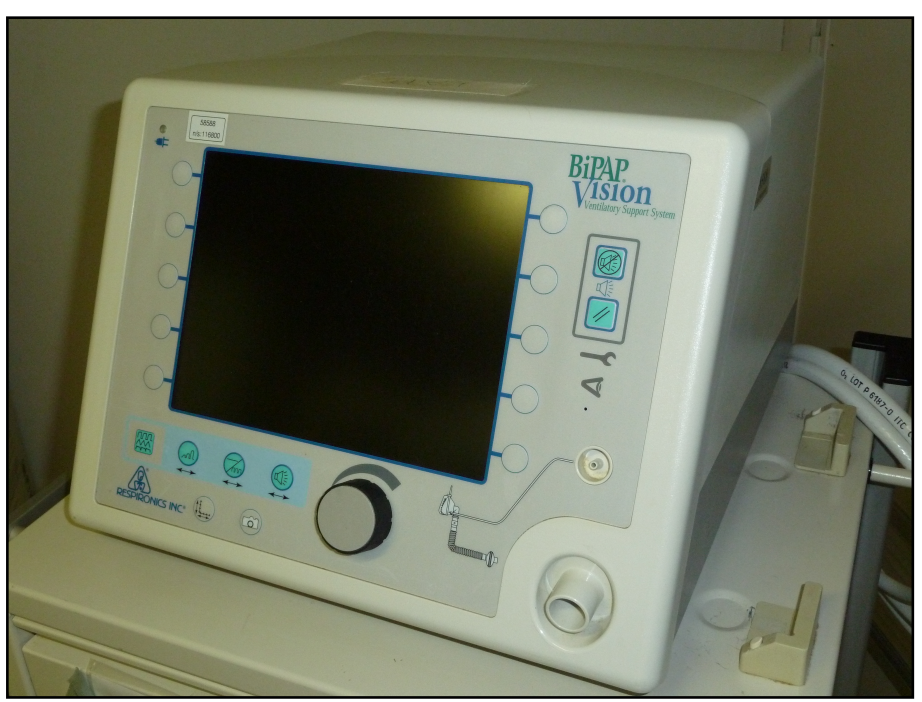

Pantalla integrada para la monitorización de la ventilación del paciente, incluyendo curvas de flujo o volumen.

Posibilidad de regular de forma adecuada la $\mathrm{FiO}_{2}$ desde el $21 \%$ al $100 \%$.

Alarmas de control adecuadas a pacientes críticos.

Figura 6: Respirador BiPAP Vision.

Los nuevos modelos de BiPAP Vision disponen de la modalidad VAP. Sin embargo, el que se utiliza en nuestra Unidad únicamente permite BiPAP S/T (con IPAP entre 4 y $40 \mathrm{cmH}_{2} \mathrm{O}$ y EPAP entre 4 y $20 \mathrm{cmH}_{2} \mathrm{O}$ ) y CPAP (entre 4 y $20 \mathrm{cmH}_{2} \mathrm{O}$ ).

Funciona conectado a la corriente y a una fuente de $\mathrm{O}_{2}$ de alta presión (opcional) para aumentar la $\mathrm{FiO}_{2}$.

\section{Carina:}

Es un respirador diseñado para realizar VMI o VMNI en pacientes semicríticos. Permite ventilar en Volumen control-Ventilación Sincronizada Mandatoria Intermitente con AutoFlow (VC-SIMV AF), PC, BIPAP, PS y CPAP. Puede utilizar tubuladura con válvula de fuga o con válvula espiratoria (para VMI). 


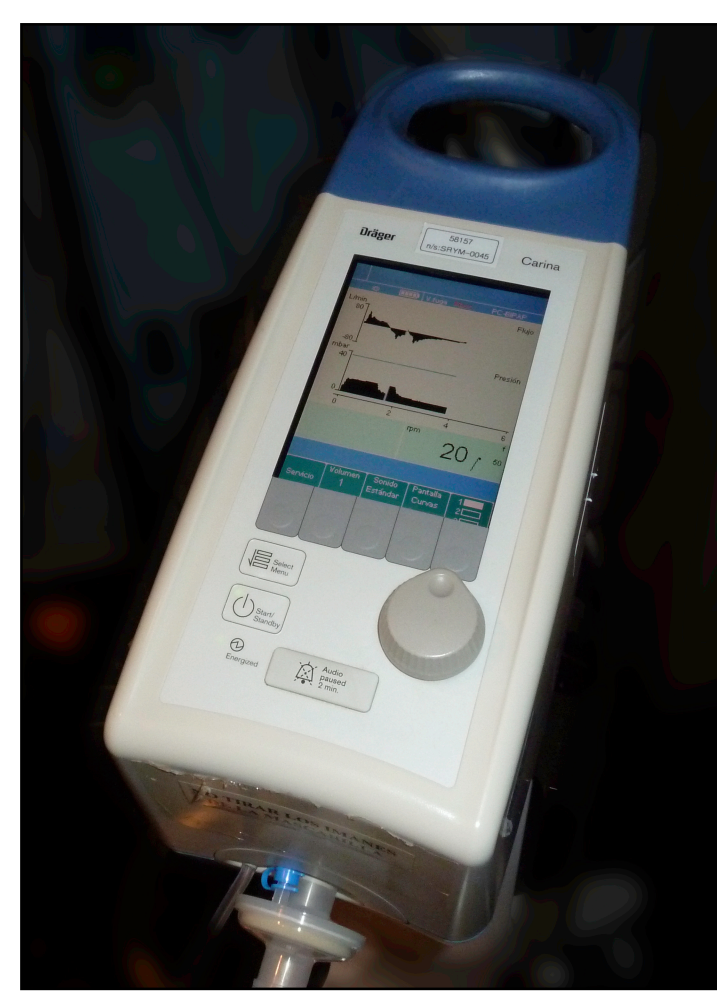

Figura 7: Respirador Carina.
Dispone de una batería interna que posibilita su funcionamiento sin estar conectado a la corriente.

Es posible regular la $\mathrm{FiO}_{2}$ del 21 al $100 \%$ (conectándolo a una fuente de $\mathrm{O}_{2}$ de alta presión, aunque también puede funcionar sin fuente de $\mathrm{O}_{2}$ o con una de baja presión).

Se puede regular la presión inspiratoria entre 5 y $40 \mathrm{cmH}_{2} \mathrm{O}$ (hasta 50 si se utiliza válvula de inspiración) y la PEEP o CPAP entre 3 y 20 $\mathrm{cmH}_{2} \mathrm{O}$.

Posee una pantalla para su programación y para la monitorización y un sistema de alarmas.

\section{Interfases:}

La VMNI fue aplicada mediante mascarillas faciales (oronasales):

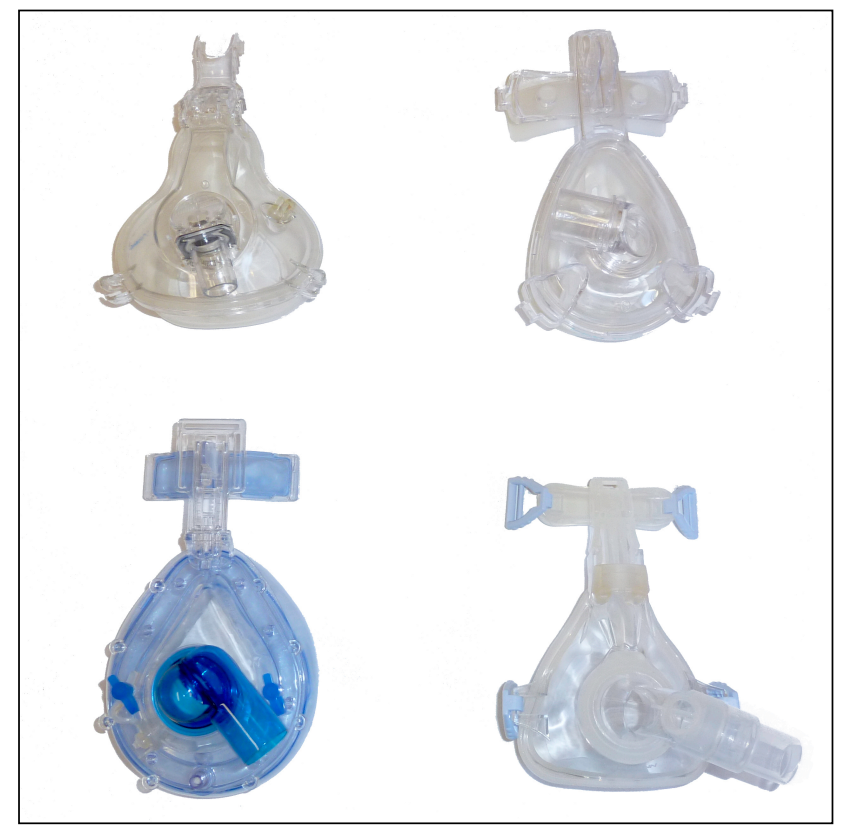

- Dräger NovaStar ${ }^{\circledR}$.

- Dräger ClassicStar ${ }^{\circledR}$.

- Respironics PerformaTrak®.

- Pulmodyne BiTrac ${ }^{\circledR}$ Full Face Mask.

- Weinmann Joyce ${ }^{\circledR}$ Full Face Mask.

Figura 8: Diferentes tipos de mascarillas oronasales para VMNI. 
Se utilizaron mascarillas faciales ya que su eficacia es mayor en pacientes con IR. No se utilizaron otros tipos de interfases (total face o helmet) ya que no se encuentran disponibles en nuestro hospital.

\section{Recogida de datos:}

Mediante la base de datos de la Unidad se identifican todos los pacientes que recibieron VMNI (BPAP y/o CPAP) durante los años 2006-2011. Se revisan las historias clínicas de estos pacientes, descartando los que recibieron VMNI como continuación de su tratamiento domiciliario. De las historias clínicas se extraen las variables seleccionadas, introduciéndolas en una base de datos creada en Access 2007 (Microsoft Office) para el registro de datos. De esta base son exportadas al programa IBM SPSS Statistics 19.

Durante el periodo estudiado (2006-2011) se identificaron 456 ingresos de pacientes que recibieron VMNI. Tras la revisión de las historias clínicas se seleccionaron 406 ingresos que recibieron VMNI, descartándose 50 pacientes debido a:

- 14 pacientes por desaparición de su historia clínica.

- 3 pacientes porque recibieron VMNI con su respirador domiciliario como continuación de su tratamiento habitual, no por episodio de IR.

- 33 pacientes porque fueron erróneamente etiquetados como tratados con VMNI, ya que no la recibieron realmente.

Tras estos descartes se contabilizaron 389 pacientes que recibieron VMNI. Un paciente tuvo tres ingresos en los que la recibió, quince pacientes ingresaron y necesitaron VMNI en dos ocasiones y cuatro pacientes presentaron dos episodios de IR que fueron tratados con VMNI durante el mismo ingreso en UCI, por lo que en total se incluyeron 410 casos de VMNI.

\section{Variables recogidas:}

Variables demográficas: Fecha de nacimiento, edad, sexo.

$>$ Antecedentes personales.

> Etiología de la IR.

$>$ Diagnósticos. 
> Fecha de ingreso (hospitalario y en UCI), fecha de alta (de UCI y hospitalaria), fecha de inicio de VMNI, fecha de finalización de VMNI, horas de VMNI, éxito o fracaso de VMNI, causa de fracaso, tipo de VMNI (CPAP y/o BPAP), IOT, traqueotomía, existencia de tratamiento inotrópico o vasoactivo al inicio de la VMNI, necesidad de sedación para tolerar la VMNI, establecimiento de limitación de medidas de soporte vital (LMSV), Acute Physiology and Chronic Health Evaluation II score (APACHE II), aparición de complicaciones mayores, exitus (tanto intraUCI como hospitalario), causa del exitus y hallazgos radiológicos en Rx de tórax.

$>$ Variables fisiológicas: tensión arterial sistólica (TAS), tensión arterial diastólica (TAD), FC, FR, Glasgow Coma Scale (GCS) y temperatura $\left(\mathrm{T}^{\mathrm{a}}\right)$ previas al inicio de la VMNI, a las 2 horas, a las 12 horas, a las 24 horas de iniciada la VMNI y al alta de UCI.

$>$ Variables gasométricas: $\mathrm{pH}, \mathrm{PaCO} 2$, PAFI, bicarbonato y lactato, previas al inicio de la VMNI, a las 2 horas, a las 12 horas, a las 24 horas de iniciada la VMNI y al alta de UCI.

$>$ Variables bioquímicas: urea, creatinina, albúmina, sodio, potasio y bilirrubina total, previas al inicio de la VMNI; urea, creatinina y albúmina a las 12 horas, a las 24 horas de iniciada la VMNI y al alta de UCI.

$>$ Variables hematológicas: hematocrito y leucocitos, previas al inicio de la VMNI, a las 12 horas, a las 24 horas de iniciada la VMNI y al alta de UCI.

$>$ Variables ventilatorias: IPAP y EPAP previas al inicio de la VMNI, a las 2 horas, a las 12 horas, a las 24 horas de iniciada la VMNI y al alta de UCI.

$>$ Balances a las 12 horas y a las 24 horas de iniciada la VMNI.

> Con las variables al inicio de la VMNI se calculó un SAPS II (Simplified Acute Physiology Score II) modificado, en el que no se incluía el volumen urinario ya que se obtenía en un punto determinado y no con los datos de 24 horas, ni la PAFI, ya que en ese momento no se encontraba bajo VMNI.

$>$ Además se calculó un SAPS II modificado con esos mismos datos al que se añadió la puntuación correspondiente a la PAFI a las 2 horas.

Las variables fisiológicas, gasométricas, bioquímicas, hematológicas y ventilatorias únicamente se recogieron mientras se mantenía el tratamiento con VMNI. 
Los pacientes fueron divididos en cinco grupos según la etiología de la IR: reagudización de EPOC; IR hipercápnica aguda o reagudización de IR crónica hipercápnica sin EPOC; IRA hipoxémica (PAFI $<300$ y $\mathrm{PaCO}_{2}$ no elevado); EAP en paciente diagnosticado de insuficiencia cardiaca aguda o crónica; IR post-extubación (definida como la que aparece en las 48 horas siguientes a la extubación).

La radiografía de tórax al inicio de la VMNI se clasificó como: parénquima limpio; infiltrado/consolidación/derrame unilateral; infiltrado/consolidación/derrame bilateral.

Se consideró éxito de la VMNI la no necesidad de VM en las 72 horas siguientes a su retirada.

\section{Análisis estadístico:}

Para el análisis descriptivo se calcularon medias y desviaciones típicas para las variables cuantitativas y porcentajes para las variables cualitativas. En el estudio comparativo para las variables continuas se contrastaron en una primera fase del análisis la normalidad de los datos mediante el test de Kolmogorov Smirnov y la homogeneidad de varianzas mediante el test de Levene. En las variables en las que se verificaron las hipótesis de normalidad y de homogeneidad de varianzas se utilizó el test t de Student clásico, y la correspondiente aproximación de Welch en el caso de heteroscedasticidad. Cuando los grupos a comparar eran más de dos se utilizó el análisis de la varianza (ANOVA) si los datos verificaban la homoscedasticidad. El test de Bonferroni se utilizó para determinar las diferencias entre los grupos cuando el ANOVA arrojaba resultados significativos. Se utilizó el test-t para datos apareados para comparar el comportamiento medio de las variables medidas en dos tiempos diferentes. En aquellos datos en los que no se verificó la hipótesis de normalidad se utilizaron las correspondientes versiones no paramétricas de los test anteriormente nombrados. Así, para los casos de dos grupos en estudio cuyos datos son independientes y no normales, se utilizó el test de la U de Mann-Whitney y cuando los datos resultaron ser apareados el análisis se llevó a cabo por medio del test de Wilcoxon. En el supuesto de disponer en el estudio de más de dos grupos el test no paramétrico utilizado fue el test de Kruskal Wallis. El análisis de variables cualitativas se llevó a cabo con el test Chi-cuadrado para tablas de contingencia. 
Se realizó un modelo de regresión logística para estimar la probabilidad de fracaso de la VMNI. Para la realización del modelo se partió del conjunto de variables que se consideró que podían ser importantes desde el punto de vista clínico como predictoras.

Se decidió que en las variables de las que se disponía de datos al inicio de la VMNI y a las 2 horas se evaluaría la diferencia entre éstas.

Para facilitar el análisis los tipos de IR se recategorizaron en dos: por un lado los pacientes con IR hipercápnica (reagudizaciones de EPOC e IR hipercápnica sin EPOC), y por el otro los otros tres tipos (IRA hipoxémica, EAP e IR post-extubación). La variable Rx de tórax también se recodificó, agrupando los pacientes con condensación/infiltrado/derrame (unilateral o bilateral), por lo que se crearon dos grupos: Rx limpia vs resto.

Las variables analizadas en el modelo fueron finalmente:

- Las diferencias de FC, FR, TAS, PAFI, GCS, lactato y $\mathrm{T}^{\mathrm{a}}$ desde el inicio a las 2 horas.

- La bilirrubina, el SAPS II modificado, el hematocrito, los leucocitos, la creatinina y la albúmina al inicio de la VMNI.

- El tiempo desde el ingreso hospitalario y desde el ingreso en UCI hasta el inicio de la VMNI.

- El SAPS II modificado al inicio con la PAFI a las 2 horas.

- El APACHE II.

- La necesidad de soporte vasoactivo o inotrópico al inicio de la VMNI, la necesidad de sedación para la aplicación de VMNI, la existencia de inmunosupresión, el tipo de IR recodificada y la existencia o no de hallazgos radiológicos.

Para el modelo logístico se utilizó la información de aquellos pacientes que tenían información en todas las variables predictoras $(n=281)$. El archivo se dividió en dos grupos de pacientes de manera aleatoria: un grupo de 250 para la estimación de los parámetros del modelo y otro de 31 pacientes para la validación del mismo.

Dado el elevado número de predictores se realizó el procedimiento descrito por Collett ${ }^{31}$ para la selección del mejor modelo en términos de menor número de predictores y mejores 
predicciones. Este método está basado en los métodos stepwise y consiste en un algoritmo que sigue estos tres pasos:

1.- Se van introduciendo las variables predictoras una a una y se selecciona para el primer modelo la variable con mayor significación.

2.- A partir de este primer modelo con una variable se vuelve a repetir el procedimiento con el resto de ellas y se introduce la más significativa; así se repite el procedimiento hasta que no hay variables significativas.

3.- Con el modelo obtenido anteriormente se hace lo contrario con la variables del modelo, se van quitando y se ve si al quitarlas el modelo baja en ajuste o no; si no baja se quita esta variable en el modelo, y así, para el resto de variables del modelo.

En el modelo no se han considerado las interacciones entre predictoras para no obtener un modelo con excesivos parámetros. El test utilizado para la inclusión de variables fue el de la razón de verosimilitud debido a que el proceso de selección ha sido jerárquico.

A partir de las predicciones se calculó la sensibilidad y especificidad del modelo y con la muestra de validación se calcularon los valores predictivos positivos y negativos.

El punto de corte de probabilidad para asignar fracaso a la predicción fue de 0,5. A partir de los parámetros estimados en el modelo se pueden predecir la probabilidad de fracaso aplicando la siguiente expresión:

$$
\hat{\boldsymbol{p}}_{\boldsymbol{i}}=\frac{\boldsymbol{e}^{\hat{\beta}_{0}+\hat{\beta}_{1} \boldsymbol{X}_{1}+\ldots \hat{\beta}_{i} \boldsymbol{X}_{\boldsymbol{i}}+\ldots+\hat{\beta}_{\boldsymbol{p}} \boldsymbol{X}_{\boldsymbol{p}}}}{1+\boldsymbol{e}^{\hat{\beta}_{0}+\hat{\beta}_{1} \boldsymbol{X}_{1}+\ldots \hat{\beta}_{\boldsymbol{i}} \boldsymbol{X}_{\boldsymbol{i}}+\ldots+\hat{\beta}_{\boldsymbol{p}} \boldsymbol{X}_{\boldsymbol{p}}}}
$$

Los coeficientes del modelo tras la consiguiente transformación se interpretaron como oddsratios. Se calculó los intervalos de confianza al 95\% para dichos odds-ratios.

Se ha utilizado un análisis de segmentación como técnica complementaria al modelo logístico con el fin de detectar grupos de riesgo a partir de los predictores seleccionados en el modelo logístico. Para este análisis se utilizaron los 281 pacientes. 
El análisis de segmentación está basado en los métodos AID (Automatic Interaction Detection $^{32}$ ). El método utilizado consiste en un proceso iterativo de partición de la muestra total en base a las asociaciones de los predictores con la variable respuesta. La división se consideró siempre binaria. El mejor predictor en cada segmentación se elige de entre todos en función del mayor valor del estadígrafo Chi-cuadrado o menor p-valor asociado al mismo. El proceso de partición finaliza cuando no se detecta asociación entre las predictoras y la variable de interés, o bien, el tamaño de muestra es muy pequeño. El tamaño muestral máximo elegido para finalizar el proceso de segmentación fue de 30 individuos.

En los predictores cuantitativos el procedimiento busca el punto de corte del predictor que mayor asociación consigue con la variable de interés. Para evitar el incremento de error tipo I debido a la gran cantidad de comparaciones que se realizan, en este análisis se ha utilizado la penalización descrita por Sall $^{33}$ que no es tan restrictiva como la propuesta por Bonferroni y es usualmente utilizada en estos procedimientos.

Los niveles de significación utilizados para todos los análisis han sido los habituales de 0,05 y 0,01 .

El software utilizado para la realización de los análisis ha sido: IBM SPSS versión 19 y SAS JMP versión 7.

\section{Análisis mediante minería de datos:}

Independientemente del análisis estadístico convencional se realizó un estudio mediante técnicas de minería de datos, utilizando dos tipos de algoritmos. En primer lugar se aplicaron dos métodos de selección de atributos, también denominados métodos de selección de características, para determinar cuáles eran los atributos más influyentes en la clasificación de los pacientes. Posteriormente se utilizaron varios algoritmos de clasificación con objeto de construir modelos que permitieran predecir a qué clase pertenecen los pacientes no clasificados a partir de otros atributos conocidos de dichos pacientes. Una vez aplicados los algoritmos de clasificación se realizó un estudio comparativo de la precisión obtenida con el fin de determinar cuál o cuáles eran los más adecuados para el área de aplicación objeto de este trabajo. 
En todos los casos se utilizó la implementación que proporciona la herramienta Weka (http://www.cs.waikato.ac.nz/ml/weka) de dichos algoritmos.

Algoritmos de selección de atributos:

Se aplicaron dos algoritmos muy utilizados que suelen proporcionar buenos resultados, el algoritmo Correlation-based Feature Subset Selection (Correlación basada en Función de Selección de Subconjunto, CFS) y un método basado en el índice de ganancia de información que aporta cada atributo disponible.

\section{CFS:}

Este método ${ }^{34}$ evalúa la importancia de un subconjunto de atributos o características teniendo en cuenta su capacidad individual de predicción de la clase junto con el grado de redundancia entre ellos. Serán seleccionados aquellos subconjuntos de atributos que tienen una alta correlación con la clase y baja correlación entre ellos.

La aceptación o rechazo de atributos depende del grado en que contribuyen a predecir la clase en áreas del espacio de ejemplos no predichas por otras características. Para ello se utiliza la siguiente función de evaluación del subconjunto de características:

$$
M_{S}=\frac{k \overline{r_{c f}}}{\sqrt{k+k(k-1) \overline{r_{f f}}}}
$$

En ella, $\mathrm{M}_{\mathrm{s}}$ representa el "mérito" o relevancia de un subconjunto $\mathrm{S}$ que contiene $\mathrm{k}$ características, $\overline{r_{c f}}$ es la correlación media clase-característica $(\mathrm{f} \in \mathrm{S})$ y $\overline{r_{f f}}$ es la intercorrelación media característica-característica. El numerador representa el poder de predicción de un conjunto de características, mientras que el denominador representa el grado de redundancia entre dichas características.

\section{Ganancia de información:}

Este método evalúa la importancia de un atributo (característica) en función de la ganancia de información que proporciona con respecto a la clase.

El índice de ganancia (GI) de información se puede definir de la forma siguiente: 
GI (Clase, Atributo $)=I($ Clase $)-I($ Clase, Atributo $)$

Siendo I(Clase) la cantidad esperada de información (entropía) de la clase y P(Clase, Atributo) la cantidad esperada de información de la clase dado el atributo. La entropía para un conjunto de variables, $v_{i}$, se define en función de las probabilidades de dichas variables $P\left(v_{i}\right)$ :

$$
\mathrm{I}\left(P\left(v_{1}\right), \ldots, P\left(v_{\mathrm{n}}\right)\right)=\sum_{\mathrm{i}=1}^{\mathrm{n}}-P\left(v_{\mathrm{i}}\right) \log _{\mathrm{n}} P\left(v_{\mathrm{i}}\right)=\text { entropía }
$$

En el método se evalúan los valores de ganancia de cada uno de los atributos y se ordenan por dicho valor. Los de mayor ganancia serán los más importantes y por tanto los que más contribuyan en la clasificación.

Algoritmos de clasificación:

De los múltiples algoritmos de clasificación que existen en minería de datos se seleccionaron para este estudio los más representativos. Aunque se han probado muchos, en el estudio solo se documentan aquellos que han proporcionado mejores resultados.

En primer lugar se han aplicado algoritmos de clasificación individuales, dos árboles de decisión (J48 y REPTree) y una red bayesiana, y posteriormente se han construido multiclasificadores utilizando como clasificadores de base los dos algoritmos de inducción de árboles de decisión utilizados previamente de forma individual.

\section{Árboles de decisión:}

Un árbol de decisión es un conjunto de condiciones organizadas en una estructura jerárquica, de tal manera que la decisión final a tomar se puede determinar siguiendo las condiciones que se cumplen desde la raíz del árbol hasta alguna de sus hojas.

La inducción del árbol se realiza mediante un proceso en el que se van separando los ejemplos en función de la evaluación de determinadas condiciones relacionadas con los valores de los atributos. El algoritmo comienza identificando la variable más importante (aquella que se considera que influye más en la clasificación) y se le asocia el nodo raíz del 
árbol. Todos los registros del conjunto de entrenamiento se chequean frente a esa condición. Los que satisfacen la condición se colocan en la rama izquierda del árbol y los que no en la derecha (para condiciones binarias). A continuación se decide cuál es la siguiente variable en importancia y se repite el proceso.

El modelo matemático utilizado para seleccionar los atributos que influyen en la clasificación, así como los valores de los atributos que van a formar parte de las condiciones, se basa en la cantidad esperada de información (entropía) que proporciona el atributo. En la figura 9 se recoge el pseudocódigo de un algoritmo básico.

Usualmente el proceso de inducción de los árboles conlleva un proceso de poda consistente en evitar la separación repetitiva utilizando atributos que no tienen evidente relevancia, aun cuando no se haya conseguido la clasificación completa de los datos. La poda se realiza para evitar el problema de sobreadaptación (overfitting) que consiste en encontrar una regularidad irrelevante en los datos.

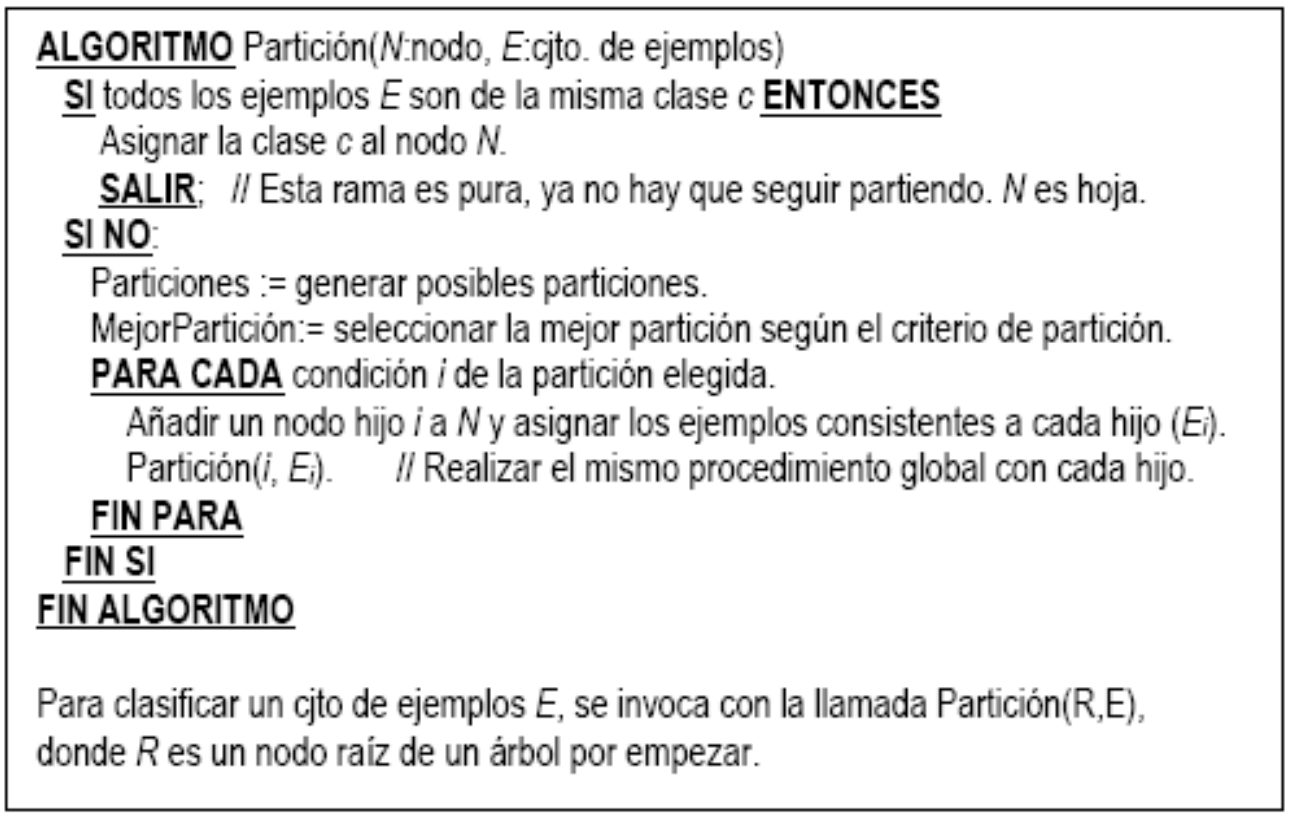

Figura 9: Algoritmo básico de aprendizaje de árboles de decisión.

En el estudio se han utilizado los algoritmos de inducción J48 y REPTree.

El algoritmo J48 es una versión avanzada de uno de los algoritmos de árboles de decisión más conocidos y utilizados, $\mathrm{C} 4.5^{35}$, que es un método basado en la ganancia de información que dispone de procedimientos de poda del árbol basados en reglas. 
REPTree es un método de aprendizaje rápido de árboles de decisión basado también en la ganancia de información que utiliza como criterio de poda la reducción del error. Este método también se utiliza para construir árboles de regresión y, en ese caso, se utiliza la varianza en lugar de la entropía para la selección de atributos y generación de las particiones.

\section{$\underline{\text { Redes bayesianas: }}$}

El aprendizaje de redes bayesianas proporciona estructuras que relacionan variables y llevan asociadas distribuciones de probabilidades condicionales relativas a dichas variables. El proceso de aprendizaje para un conjunto de datos D consiste en encontrar, entre todos los grafos posibles, el grafo $\mathrm{G}$ que mejor represente el conjunto de dependencias/independencias entre los datos. Para ello se requiere calcular las probabilidades a posteriori de todos los grafos. La complejidad de este problema es NPduro, por lo que no es factible una solución exacta y hay que recurrir a métodos de búsqueda heurística. Es necesario, por tanto, establecer una métrica de calidad que represente la adecuación de una red bayesiana a un conjunto de datos y buscar la solución que maximice esa métrica mediante un procedimiento de optimización. Los algoritmos de búsqueda más utilizados son K2, B, TAN, BAN. En este estudio se ha utilizado el algoritmo $\mathrm{K} 2^{36}$.

\section{Multiclasificadores:}

Son métodos que combinan modelos de clasificación obtenidos con diferentes métodos básicos o con diferentes conjuntos de entrenamiento con el fin de mejorar la precisión de las predicciones. Otra ventaja adicional de estas técnicas es la reducción del problema de sobreadaptación (overfitting) que consiste en encontrar una regularidad en los datos propia del conjunto de entrenamiento y que no puede hacerse extensiva a otros datos. Los multiclasificadores construyen un conjunto de hipótesis y combinan de alguna forma las predicciones del conjunto para clasificar ejemplos, seleccionando en cada caso la mejor predicción entre todas las ofrecidas por los diferentes modelos. La votación mayoritaria es el criterio de selección más simple y más utilizado. Existen muchos procedimientos para la creación de multiclasificadores: bagging, boosting, logitBoost, co-learning, stacking, cascading, etc. 
En este estudio se utilizaron los métodos de bagging y AdaBoost; este último es una variante del método de boosting.

El método de bagging (Bootstrap AGGregatING) ${ }^{37}$ consiste en crear diferentes clasificadores con el mismo algoritmo pero con diferentes conjuntos de entrenamiento. Cada uno de éstos se crea por selección aleatoria y con reemplazamiento (puede haber ejemplos repetidos) de una muestra de ejemplos del mismo tamaño que el conjunto de entrenamiento original. Una muestra bootstrap de tamaño $\mathbf{n}$ se genera al seleccionar $\mathbf{n}$ instancias del conjunto de entrenamiento de manera aleatoria de modo que se crean tantas muestras bootstrap del mismo tamaño como clasificadores existan y cada clasificador se entrena con una réplica bootstrap. De entre todas las predicciones ofrecidas por los clasificadores se selecciona la que tenga mayor número de votos.

Boosting $^{38}$ se basa en la ponderación de los ejemplos. De forma iterativa se van construyendo modelos que minimicen los errores de los construidos previamente mediante la asignación de pesos mayores a los ejemplos clasificados incorrectamente en la iteración anterior. En cada iteración, este método aprende un modelo que minimiza la suma de los pesos de los ejemplos clasificados erróneamente. Los errores de cada iteración se utilizan para actualizar los pesos de los ejemplos del conjunto de entrenamiento, de manera que se incrementa el peso de los ejemplos errados y se reduzca el peso de los ejemplos acertados. Además, cuando se utilizan para clasificar ejemplos reales, también se ponderan los modelos en función de su comportamiento en la fase de prueba.

AdaBoost es la variante de boosting más conocida. En un ciclo se aprende un modelo a través de la evidencia ponderada, se estima el error del modelo y dependiendo del valor del error se detiene el algoritmo o se continúa el proceso repitiendo el ciclo. Si se continúa iterando se actualizan los pesos de los ejemplos clasificados de forma acertada, se almacena el modelo y se efectúa la normalización del peso de todos los ejemplos. 


"Todas las verdades son fáciles de entender, una vez descubiertas"

Galileo Galilei

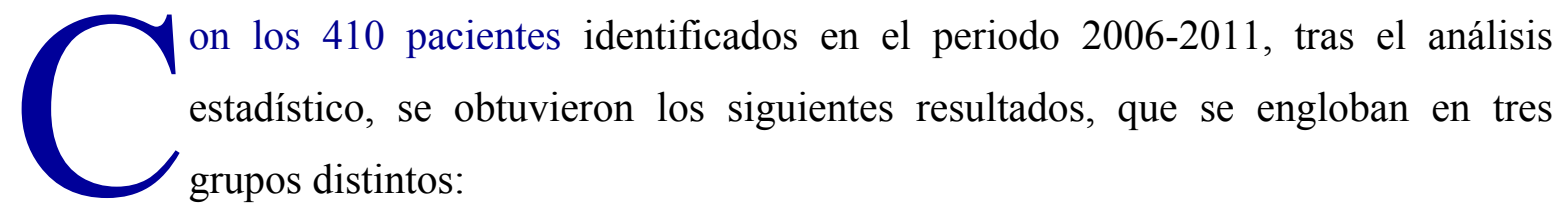

- Estudio descriptivo.

- Estudio comparativo, que principalmente intenta buscar diferencias entre los grupos según el tipo de IR, en estancia y mortalidad según el resultado de la VMNI y en las posibles variables predictoras según ese resultado.

- Modelización, en la que se trata de crear un modelo que sea capaz de predecir adecuadamente el fracaso o éxito de la VMNI mediante las diferentes variables al inicio y a las 2 horas de iniciada la VMNI.

De forma independiente se realizó un análisis mediante técnicas de minería de datos, que arrojó los resultados que se enumeran posteriormente. 




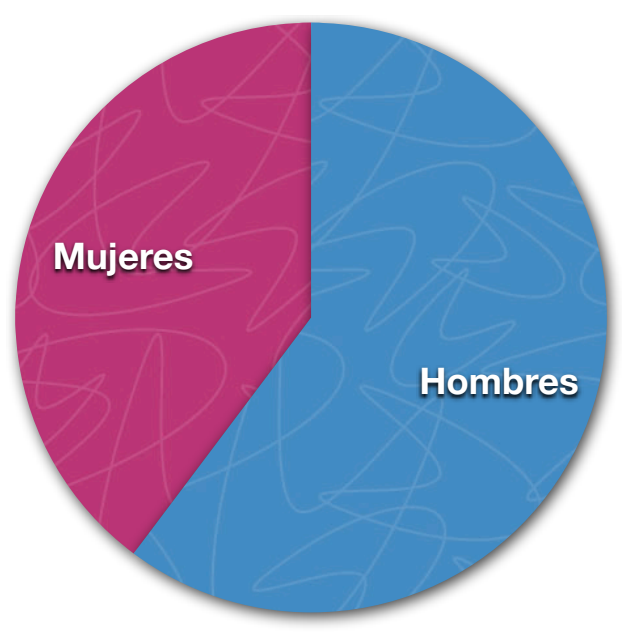

Figura 10: Distribución por sexo.
De los 410 casos, 247 eran hombres $(60,24 \%)$ y 163 mujeres (de los 389 pacientes, 152 mujeres y 237 hombres, 60,92\%). La edad media de los pacientes tratados fue de 66,69 $\pm 13,38$ años. El APACHE II medio fue de $20,83 \pm 7,44$, mientras que el SAPS II modificado al ingreso fue de $28,04 \pm 9,47$, y el SAPS II modificado con PAFI a las $2 \mathrm{~h}$ fue de $35,98 \pm 9,51$.

Tan solo en 8 ocasiones $(1,95 \%)$ se utilizó CPAP, los 402 episodios restantes fueron tratados mediante BPAP (98,05\%). En 263 ocasiones (64,14\%) se inició la VMNI en el mismo día de ingreso en UCI, disminuyendo su uso con el paso de los días (en el 90\% de los casos se inició antes del quinto día).

67 pacientes (16,34\%) recibieron VMNI antes de su ingreso en UCI; 33 CPAP (8,04\%), 31 BPAP (7,56\%) y 3 BPAP + CPAP (0,73\%). 121 pacientes $(29,51 \%)$ necesitaban soporte inotrópico o vasoactivo al inicio de VMNI.

En conjunto, la VMNI fue exitosa en 202 ocasiones (49,27\%), mientras que fracasó en 208 episodios $(50,73 \%)$. Entre las causas de fracaso de la VMNI la más frecuente fue la de trabajo respiratorio $(41,35 \%)$, seguida de la hipoxemia refractaria $(35,58 \%)$, siendo el resto de las causas mucho menos frecuentes. Hay que destacar el bajo porcentaje $(4,81 \%)$ de fracaso por intolerancia a la mascarilla. Por otro lado hay que mencionar la existencia de 6 casos $(2,88 \%)$ que fracasaron por PCR, lo que hace plantear la idoneidad de la

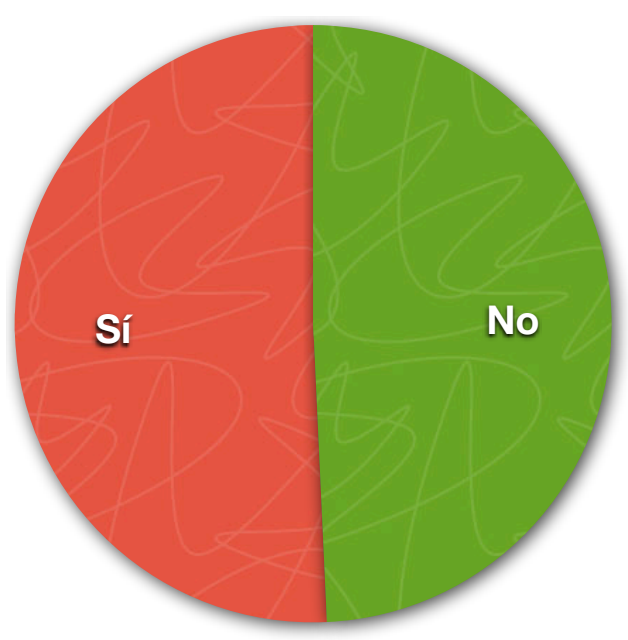

Figura 11: Porcentaje de fracaso de VMNI. indicación de la técnica. 


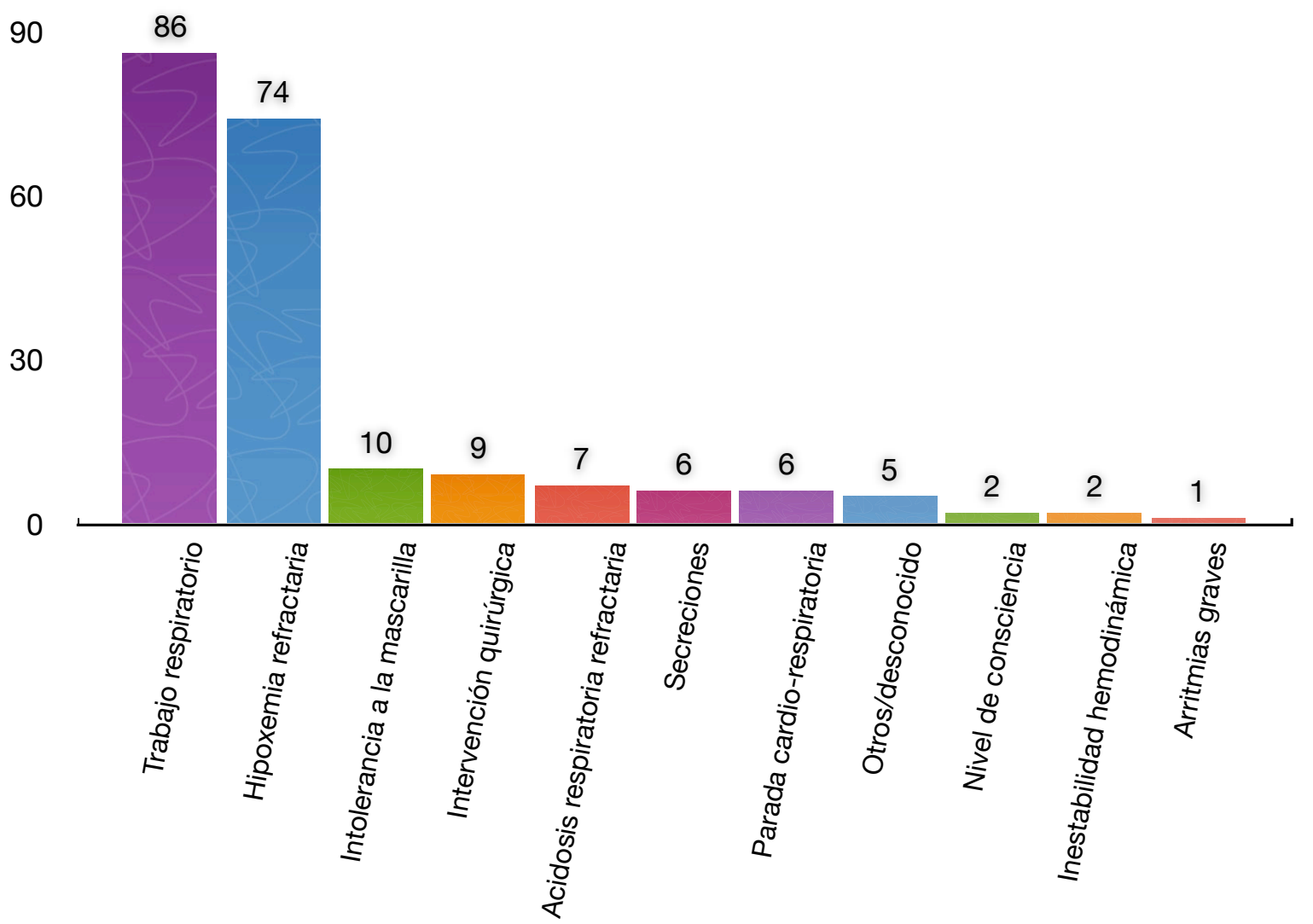

Figura 12: Causa de fracaso de la VMNI.

La incidencia de complicaciones asociadas a la técnica es poco importante, apareciendo únicamente alteraciones hemodinámicas en 18 pacientes $(4,39 \%)$ y neumonía asociada a VMNI (NAVMNI) en 1 (0,24\%). En 14 de los 18 pacientes que presentaron alteraciones hemodinámicas fracasó la VMNI. De estos 14 pacientes, en 9 ocasiones la causa del fracaso fue hemodinámica ( 2 por inestabilidad hemodinámica, 1 por arritmias graves y 6 por PCR). De estos 9 pacientes, tan solo 2 no fueron exitus (el que fracasó por arritmias y uno de los que sufrió PCR).

Hay que destacar entre los pacientes en los que fracasó la VMNI y recibieron IOT y VMI la aparición de 19 NAVM (4,63\% del total de los pacientes, un 9,13\% de los pacientes que fracasaron).

El carácter retrospectivo del estudio hizo imposible determinar de una manera adecuada la aparición de lesiones cutáneas secundarias a la aplicación de la interfase.

137 pacientes $(33,41 \%)$ fueron exitus (97 en UCI, 40 en planta). 
En cuanto al tipo de IR, el grupo más frecuente fue la IRA hipoxémica (156 pacientes, $38,05 \%)$, seguido de la IR post-extubación $(87,21,22 \%)$ y la reagudización de EPOC (78, 19,02\%). El grupo menos numeroso es el del EAP, contabilizándose únicamente 28 pacientes $(6,83 \%)$.

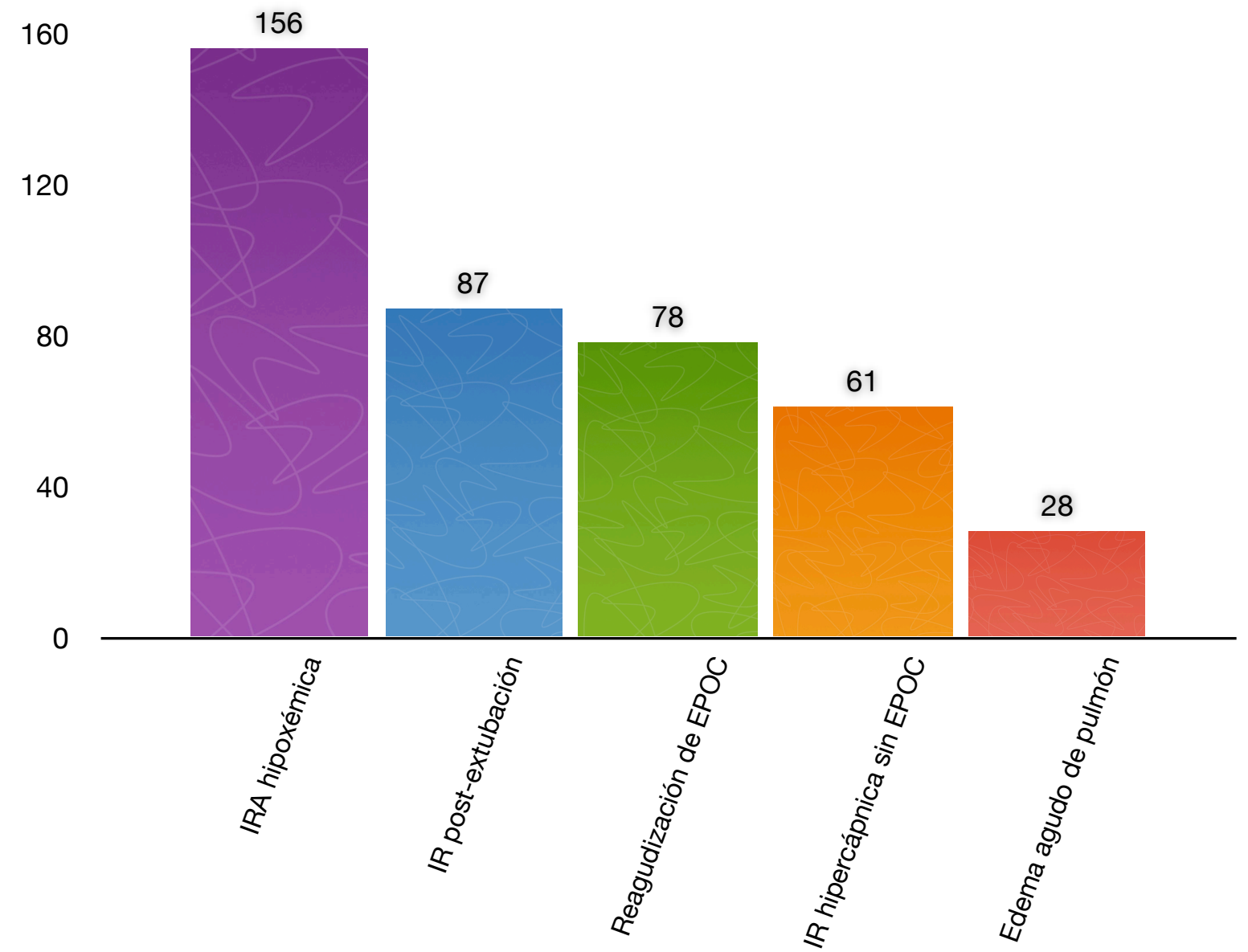

Figura 13: Número de pacientes por tipo de IR.

La tasa de éxito de la VMNI dividida por el tipo de IR varió desde el 78,57\% del EAP y el $73,08 \%$ de la reagudización de EPOC, hasta el 46\% de la IR post-extubación y el 26,28\% de la IRA hipoxémica.

De los pacientes que fracasaron con VMNI, 108 (51,92\%) fallecieron. Por tipo de IR, el porcentaje en estos pacientes varió del 83,33\% del EAP al 31,58\% en la IR hipercápnica sin EPOC (ver figura 14). 
90

60

30

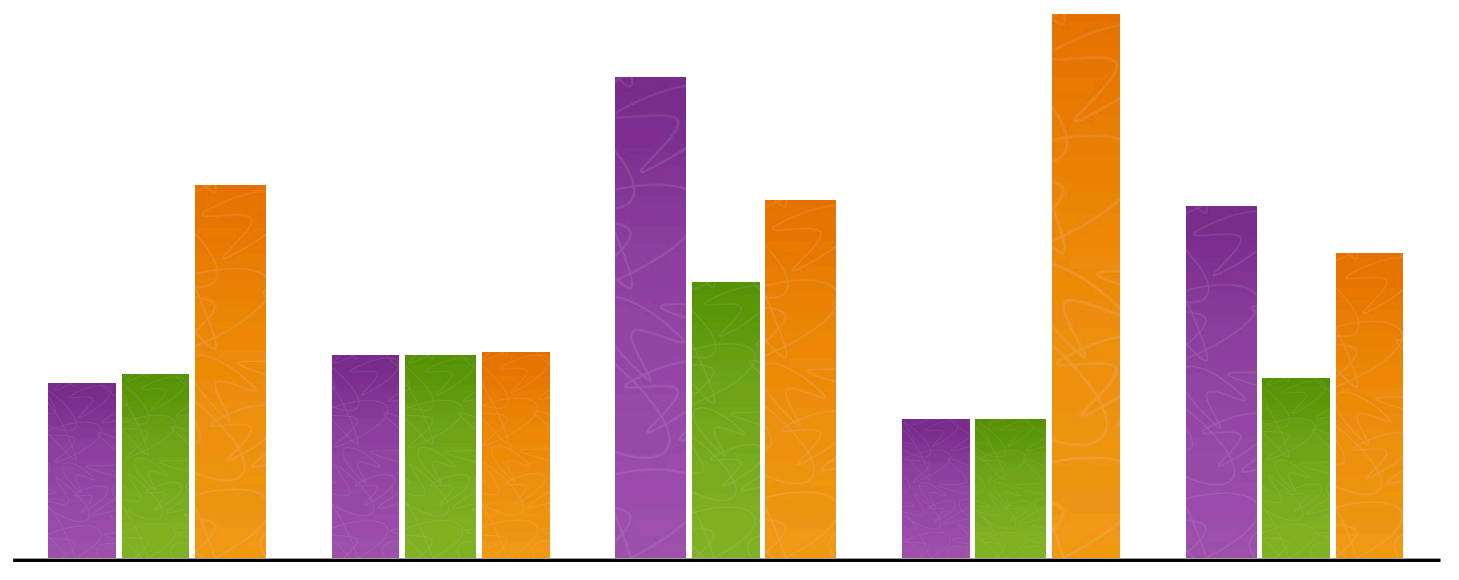

0

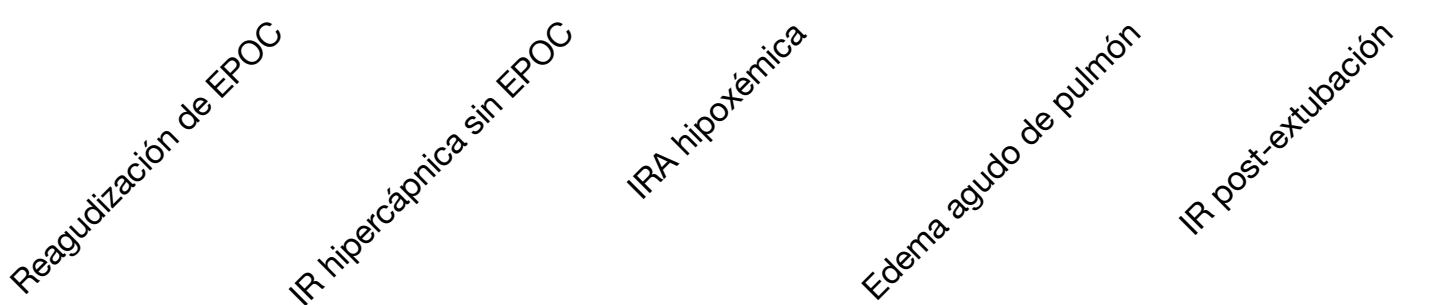

Figura 14: Porcentaje de pacientes en los que fracasa la VMNI (barras moradas), porcentaje de exitus (barras verdes) y porcentaje de exitus entre los que fracasan (barras naranjas).

Al inicio de la VMNI, la radiografía de tórax mostraba parénquima limpio en 134 pacientes $(32,69 \%)$, en $73(17,80 \%)$ se evidenció infiltrado, condensación o derrame unilateral, y en 196 (47,80\%) existía infiltrado, condensación o derrame bilateral. En 7 pacientes $(1,71 \%)$ no se realizó radiografía al inicio de la VMNI.

Con respecto a estos hallazgos radiológicos, el porcentaje de éxito con parénquima limpio fue del 64,18\%, si había hallazgos unilaterales el 43,84\% y si eran bilaterales, el 39,80\%.

40

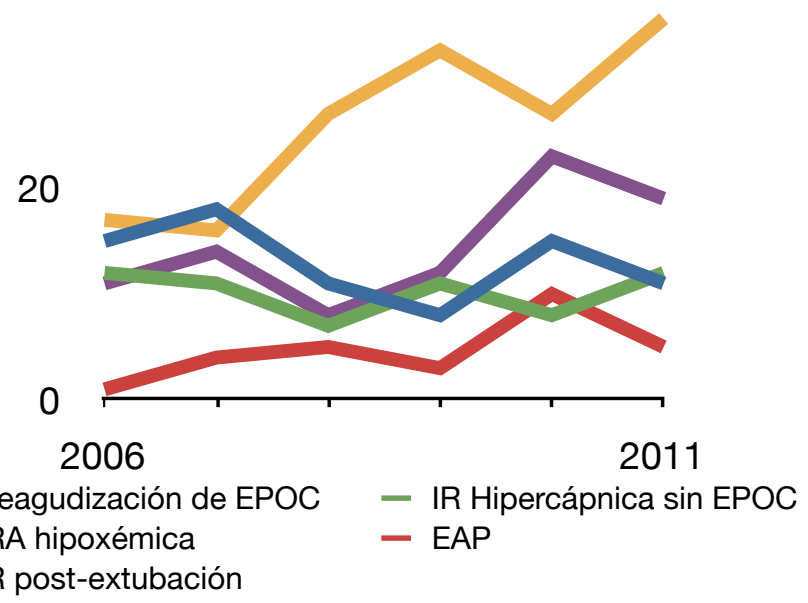

\footnotetext{
- Reagudización de EPOC - IR Hipercápnica sin EPOC

- IRA hipoxémica - EAP

- IR post-extubación
}

La VMNI se utilizó en 71 ocasiones $(17,32 \%)$ en pacientes con algún tipo de inmunosupresión, fracasando en 53 pacientes $(74,65 \%)$ y falleciendo 38 (53,52\%). De éstos, tan solo 3 pacientes tuvieron una VMNI exitosa.

Figura 15: Número de pacientes por tipo de IR y año. 
A lo largo de los años se observa un aumento en el uso de la VMNI, pasando de 56 casos en 2006 a 83 en 2011.

Por tipo de IR, el uso de VMNI en la IRA hipoxémica y en la IR post-extubación creció durante estos años, mientras que en los otros tipos se mantuvo estable.

52 pacientes $(12,68 \%)$ tenían oxigenoterapia domiciliaria, mientras que $10 \quad(2,44 \%)$ utilizaban algún tipo de VMNI domiciliaria (BPAP o CPAP).

En 60 pacientes $(14,63 \%)$ fue necesario utilizar sedación intravenosa en perfusión continua para poder aplicar la VMNI.

57 pacientes $(13,90 \%)$ recibieron traqueotomía.

El tiempo de estancia hospitalaria fue de 26,36 días $( \pm 23,11)$; el de estancia en UCI, 10,56 $( \pm 15,22)$. Entre los pacientes que no fallecieron la estancia hospitalaria fue de 27,13 días $( \pm 22,34)$, y la de UCI 9,50 $( \pm 11,65)$.

Por tipo de IR, los tiempos de estancia en UCI y hospitalaria fueron los siguientes:

- Reagudización de EPOC: 4,60 \pm 9,22 y 15,46 $\pm 12,31$ días.

- IR hipercápnica sin EPOC: 7,28 \pm 9,51 y 21,74 $\pm 14,74$ días.

- IRA hipoxémica: $13,71 \pm 19,27$ y 32,41 \pm 29 días.

- $\quad$ EAP: $3,75 \pm 2,79$ y 18,61 $\pm 14,64$ días.

- IR post-extubación: $14,72 \pm 14,15$ y 31,00 $\pm 20,96$ días. 




\section{Diferencias analíticas y fisiológicas por tipo de IR:}

Se analizaron las diferentes variables analíticas y fisiológicas en los distintos tipos de IR para evaluar las diferencias entre los grupos. Para ello se llevó a cabo un análisis de la varianza con posteriores contrastes post hoc mediante el test de Bonferroni (ya que se trata de grupos de distinto tamaño muestral).

En el análisis de las diferentes variables destacan los siguientes resultados que diferencian unos grupos de otros:

PAFI al inicio de la VMNI:

No hay diferencias significativas en las medias de esta variable para los grupos de IRA hipoxémica, con una PAFI media de 103,78, y EAP, con 131,46. Estos dos grupos difieren del resto, que a su vez son similares entre ellos: la IR hipercápnica sin EPOC presenta una PAFI media de 147,50, la IR post-extubación, de 147,42, y la reagudización de EPOC, de 154,04. Así, los grupos con EAP e IRA hipoxémica presentan significativamente mayor alteración en el intercambio de $\mathrm{O}_{2}$.

PaC02 al inicio de la VMNI:

Evaluando la $\mathrm{PaCO}_{2}$ se observan dos grupos diferentes: el formado por los individuos con IR hipercápnica sin EPOC $(79,93 \mathrm{mmHg})$ y los pacientes con reagudización de EPOC (80,10 mmHg) presenta $\mathrm{PaCO}_{2}$ medias significativamente más altas; el otro, formado por el resto de pacientes, presenta unas medias menores (IRA hipoxémica, 36,50 $\mathrm{mmHg}$; IR postextubación, 42,10 mmHg; EAP, 43,08 mmHg).

Estos resultados son los esperables ya que el grupo de IR hipercápnica sin EPOC presenta $\mathrm{PaCO}_{2}$ elevada por definición, y el de reagudización de EPOC suele presentarla muy frecuentemente. 
GCS al inicio de la VMNI.

Con respecto al GCS se pueden crear tres grupos: Los pacientes con IR hipercápnica sin EPOC (que son los que peor GCS presentan, 12,21), los pacientes con reagudización de EPOC $(13,10)$ y el resto de los pacientes (IRA hipoxémica, 14,70; EAP, 14,71; IR postextubación, 14, 76).

pH al inicio de la VMNI:

Si se comparan los $\mathrm{pH}$ medios, se observan tres grupos distintos: por un lado la IR hipercápnica sin $\operatorname{EPOC}(7,21)$ y los EPOC reagudizados $(7,24)$, por otro los $\operatorname{EAP}(7,27)$ y por último los pacientes con IRA hipoxémica $(7,35)$ y con IR post-extubación $(7,37)$.

FR al inicio de la VMNI:

En esta variable los pacientes se reparten en dos grupos, por un lado la IR hipercápnica sin EPOC (25,51 resp/min) y la reagudización de EPOC (27,76 resp/min), y por el otro el resto de los pacientes (EAP, 30,61 resp/min; IR post-extubación, 31,44 resp/min; IRA hipoxémica, 31,61 resp/min).

SAPS II modificado al inicio de la VMNI:

En esta variable se aprecian dos grupos, la IR post-extubación $(23,33)$ y la reagudización de EPOC $(27,65)$, con un SAPS II modificado más bajo, y el resto de ellos, con un SAPS II modificado mayor (EAP, 28,95; IRA hipoxémica, 29,34; IR hipercápnica sin EPOC, 30,69).

\section{APACHE II:}

En el APACHE II se encontraron diferencias significativas entre las medias de los grupos de pacientes con reagudización de EPOC (el de menor gravedad, con una media de 19,01) y de IRA hipoxémica (el de mayor gravedad, con una media de 22,08). No se aprecian diferencias estadísticamente significativas en el resto de los grupos entre sí, ni de estos grupos con la reagudización de EPOC ni con la IRA hipoxémica. 


\section{Horas de VMNI según el resultado de la VMNI:}

La media de horas de VMNI fue de 19,72 para los que no fracasaron y de 16,40 para los que sí, mientras que las medianas fueron de 10 horas para los que no fracasaron y 7 en los que sí.

Estas diferencias son altamente significativas $(\mathrm{p}<0,01)$, pudiendo afirmar que el número promedio de horas de VMNI en personas sin fracaso es significativamente mayor que en los pacientes que presentaron fracaso de la técnica.

\section{Días de estancia hospitalaria y estancia en UCI según el resultado de la VMNI:}

Al evaluar los tiempos de estancia, se observa que en los pacientes en los que no fracasó la VMNI, la estancia hospitalaria fue de $20,80( \pm 17,02)$ y la estancia en UCI de 4,67 $( \pm 5,02)$. En los que sí fracasó, $31,75( \pm 26,74)$ y 16,27 $( \pm 19,16)$, siendo ambas diferencias estadísticamente significativas $(\mathrm{p}<0,01)$.

Diferencias fisiológicas y analíticas al inicio y a las 2 horas según el resultado de la VMNI:

Analizando las variables fisiológicas y analíticas al inicio de la VMNI y a las 2 horas según el éxito o fracaso de la VMNI, se observan los siguientes resultados (figuras 16, 17 y 18).

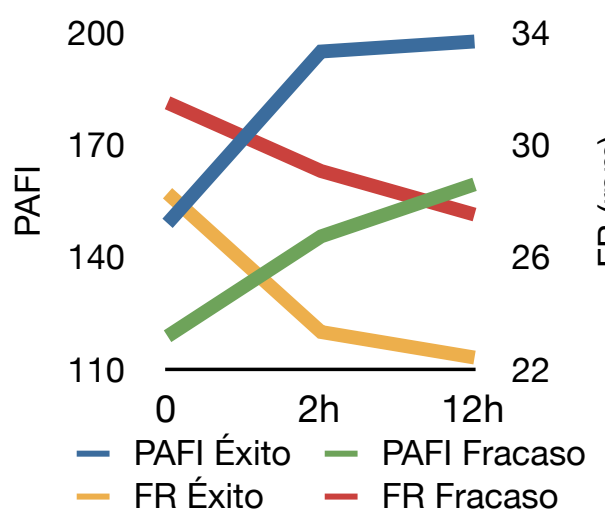

Figura 16: PAFI y FR al inicio, 2 y $12 \mathrm{~h}$
De todas estas variables, se aprecian diferencias estadísticamente significativas en el APACHE II, $\mathrm{pH}, \mathrm{PaCO}_{2}, \mathrm{PAFI}$, bicarbonato, TAS, FR, GCS, albúmina, lactato y bilirrubina al inicio, y en la FR, FC, TAS, PAFI, bicarbonato, lactato, $\mathrm{PaCO}_{2} \mathrm{y}$ SAPS II con la PAFI a las 2 horas de iniciada la VMNI. Además fue estadísticamente significativo el tiempo desde el ingreso hospitalario hasta el inicio de la VMNI, y el cambio de PAFI y de FR desde el inicio a las $2 \mathrm{~h}$ de VMNI $(\mathrm{p}<0,05)$. 


\begin{tabular}{|c|c|c|c|c|c|}
\hline Variables al inicio & $\mathrm{N}$ & Media & $\mathrm{N}$ & Media & $\begin{array}{l}\text { Análisis univariante } \\
\text { ( } p \text { valor) }\end{array}$ \\
\hline APACHE II & 202 & $19,30 \pm 6,69$ & 208 & $22,31 \pm 7,85$ & $<0,001$ \\
\hline $\mathrm{pH}$ & 190 & $7,29 \pm 0,13$ & 201 & $7,34 \pm 0,12$ & $<0,001$ \\
\hline $\mathrm{PaCO} 2(\mathrm{mmHg})$ & 189 & $61,87 \pm 28,73$ & 201 & $45,55 \pm 21,04$ & $<0,001$ \\
\hline PAFI & 183 & $148,62 \pm 62,07$ & 195 & $118,47 \pm 56,43$ & $<0,001$ \\
\hline Bicarbonato (mEq/l) & 187 & $28,43 \pm 9,99$ & 200 & $23,59 \pm 7,76$ & $<0,001$ \\
\hline TAS $(\mathrm{mmHg})$ & 202 & $138,29 \pm 30,89$ & 208 & $128,97 \pm 30,29$ & $<0,005$ \\
\hline $\mathrm{TAD}(\mathrm{mmHg})$ & 202 & $69,88 \pm 17,46$ & 208 & $66,78 \pm 17,56$ & NS \\
\hline FC (Ipm) & 202 & $104,53 \pm 22,39$ & 208 & $106,44 \pm 22,30$ & NS \\
\hline FR (resp/min) & 202 & $28,24 \pm 7,90$ & 208 & $31,44 \pm 8,36$ & $<0,001$ \\
\hline GCS & 202 & $13,78 \pm 2,07$ & 208 & $14,29 \pm 1,74$ & $<0,005$ \\
\hline Hematocrito (\%) & 199 & $36,02 \pm 8,45$ & 207 & $32,13 \pm 7,12$ & $<0,001$ \\
\hline Leucocitos $\left(x 1000 / \mathrm{mm}^{3}\right)$ & 199 & $13,33 \pm 6,63$ & 207 & $12,75 \pm 8,59$ & NS \\
\hline Urea (mg/dl) & 196 & $71,45 \pm 42,56$ & 207 & $69,51 \pm 42,69$ & NS \\
\hline Creatinina & 199 & $1,47 \pm 1,41$ & 207 & $1,45 \pm 1,24$ & NS \\
\hline Albúmina (g/dl) & 119 & $3,08 \pm 0,76$ & 133 & $2,47 \pm 0,71$ & $<0,001$ \\
\hline Lactato $(\mathrm{mmol} / \mathrm{l})$ & 176 & $1,92 \pm 2,18$ & 193 & $2,22 \pm 1,86$ & $<0,005$ \\
\hline Temperatura $\left({ }^{\circ} \mathrm{C}\right)$ & 202 & $36,81 \pm 0,83$ & 208 & $36,88 \pm 0,79$ & NS \\
\hline SAPS II & 170 & $27,26 \pm 9,07$ & 182 & $28,76 \pm 9,81$ & NS \\
\hline Potasio (mmol/l) & 198 & $4,20 \pm 0,80$ & 207 & $4,10 \pm 0,70$ & NS \\
\hline Sodio (mmol/l) & 198 & $139 \pm 6$ & 207 & $139 \pm 6$ & NS \\
\hline Bilirrubina (mg/dl) & 189 & $0,69 \pm 0,60$ & 198 & $1,48 \pm 2,35$ & $<0,001$ \\
\hline
\end{tabular}

Figura 17: Características fisiológicas y de laboratorio basales (NS, no significativo).

\begin{tabular}{|c|c|c|c|c|c|}
\hline Variables a las 2 horas & $\mathrm{N}$ & Éxito & $\mathrm{N}$ & Fracaso & $\begin{array}{l}\text { Análisis univariante } \\
\text { ( } p \text { valor })\end{array}$ \\
\hline $\mathrm{pH}$ & 187 & $7,35 \pm 0,10$ & 149 & $7,3562 \pm 0,11$ & NS \\
\hline $\mathrm{PaCO} 2(\mathrm{mmHg})$ & 187 & $51,93 \pm 20,40$ & 149 & $44,10 \pm 17,76$ & $<0,001$ \\
\hline PAFI & 185 & $194,49 \pm 76,29$ & 145 & $145,13 \pm 65,62$ & $<0,001$ \\
\hline Bicarbonato & 185 & $28,70 \pm 9,82$ & 148 & $24,24 \pm 7,80$ & $<0,001$ \\
\hline TAS $(\mathrm{mmHg})$ & 198 & $129,75 \pm 19,05$ & 169 & $125,65 \pm 24,71$ & $<0,05$ \\
\hline TAD $(\mathrm{mmHg})$ & 198 & $61,72 \pm 11,12$ & 169 & $61,78 \pm 14,07$ & NS \\
\hline FC (Ipm) & 198 & $92,55 \pm 17,58$ & 169 & $101,38 \pm 19,89$ & $<0,001$ \\
\hline FR (resp/min) & 198 & $23,28 \pm 5,11$ & 169 & $29,01 \pm 7,98$ & $<0,001$ \\
\hline GCS & 198 & $14,66 \pm 0,83$ & 169 & $14,52 \pm 1,23$ & NS \\
\hline IPAP $\left(\mathrm{cmH}_{2} \mathrm{O}\right)$ & 197 & $16,29 \pm 4,21$ & 164 & $15,54 \pm 3,41$ & NS \\
\hline $\operatorname{EPAP}\left(\mathrm{cmH}_{2} \mathrm{O}\right)$ & 198 & $6,61 \pm 1,77$ & 169 & $6,91 \pm 1,73$ & NS \\
\hline Lactato (mmol/l) & 176 & $1,575 \pm 1,81$ & 142 & $1,91 \pm 1,61$ & $<0,005$ \\
\hline Temperatura $\left({ }^{\circ} \mathrm{C}\right)$ & 197 & $36,79 \pm 0,72$ & 169 & $36,87 \pm 0,74$ & NS \\
\hline SAPS II & 159 & $34,70 \pm 8,83$ & 124 & $37,61 \pm 10,13$ & $<0,05$ \\
\hline
\end{tabular}

Figura 18: Características fisiológicas y de laboratorio tras 2 horas de VMNI (NS, no significativo). 


\section{Variables categóricas según el resultado de la VMNI:}

En relación a estas variables, se aprecian diferencias estadísticamente significativas en la VMNI preUCI $(p<0,01)$, soporte vasoactivo $(p<0,05)$, oxigenoterapia domiciliaria $(p<0,05)$, sedación para la VMNI $(\mathrm{p}<0,001)$ e inmunosupresión $(\mathrm{p}<0,001)$.

200

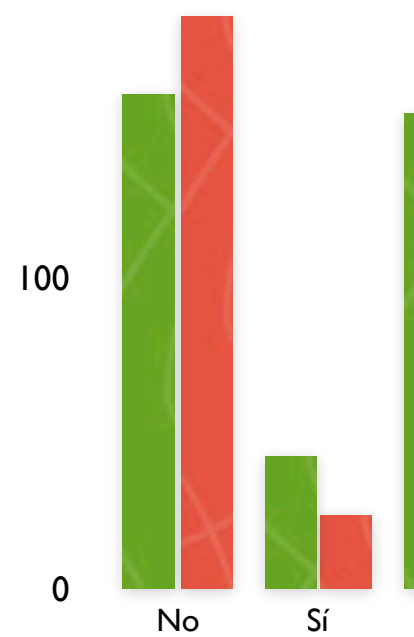

VMNI preUCI

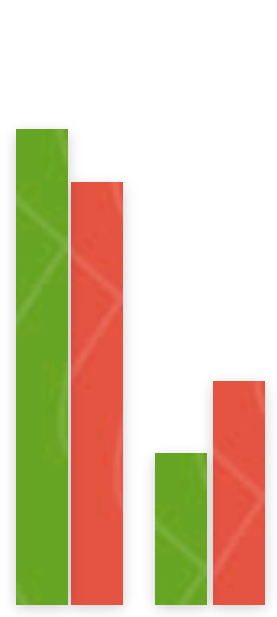

No SVA

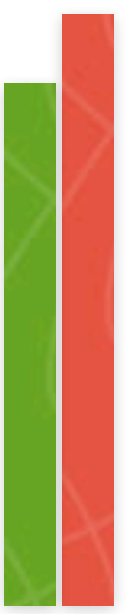

No

$\mathrm{O}_{2}$ domiciliario

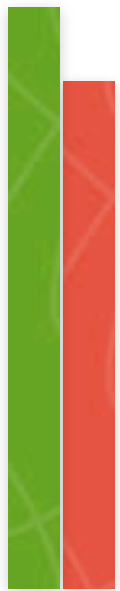

No

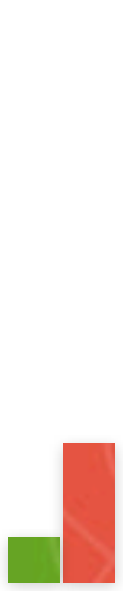

Sí

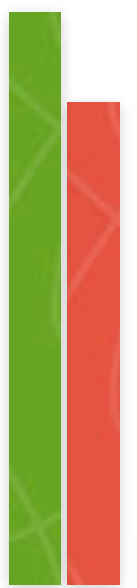

No

Inmunosupresión

Figura 19: Número de pacientes que tuvieron éxito (verde) o fracasaron (rojo) con la VMNI según la presencia de variables categóricas.

Se puede observar que la presencia de VMNI preUCI o de $\mathrm{O}_{2}$ domiciliario tienen un efecto "protector"; los pacientes que presentaban una de esas variables fracasaban menos que los que no la presentaban. Por el contrario, la presencia del resto de variables (soporte vasoactivo, sedación o inmunosupresión) era marcador de fracaso.

\section{Días de estancia en UCI y hospitalaria según el tipo de IR y el resultado de la VMNI:}

Comparando la estancia en UCI y la estancia hospitalaria en los pacientes en los que la VMNI fue exitosa frente a los pacientes en los que fracasó, se observan los siguientes resultados:

- Reagudización de EPOC: 2,65 vs 9,9 y 14,46 vs 18,19 días, siendo la diferencia en estancia en UCI estadísticamente significativa $(p<0,005)$.

- IR hipercápnica sin EPOC: 4,07 vs 14,37 y 19,86 vs 25,89 días; la estancia en UCI presenta diferencias estadísticamente significativas $(\mathrm{p}<0,005)$. 
- IRA hipoxémica: 5,98 vs 16,47 y 29,02 vs 33,62 días; se encuentran también diferencias estadísticamente significativas en la estancia en UCI $(p<0,001)$.

- EAP: 3,36 vs 5,17 y 18,14 vs 20,33 días; ambas no significativas.

- IR post-extubación: 7,57 vs 20,81 y 23,87 vs 37,06 días; en este caso las diferencias en las dos variables presenta significación estadística $(p<0,005$ y $p<0,001$ respectivamente).

\section{Mortalidad según el resultado de la VMNI:}

Evaluando la mortalidad con respecto al fracaso de la VMNI, se observa una mortalidad mucho mayor (51,92 vs 14,36\%) en el grupo que fracasa, siendo esta diferencia estadísticamente significativa $(\mathrm{p}<0,001)$.

\section{Mortalidad según el resultado de la VMNI ajustada por gravedad:}

Evaluando cómo se distribuyó la mortalidad según fracaso o éxito de la VMNI, comparando pacientes con APACHE II bajo (marcando el límite en 20) y alto, se observa que en ambos grupos la mortalidad en los que fracasa es mayor que en los que tiene éxito $(42,86$ vs 13,39\% en el grupo con APACHE II bajo; 58,97 vs 16,00\% en el de APACHE II alto), siendo las diferencias entre ambos estadísticamente significativas $(\mathrm{p}<0,001)$.

\section{Mortalidad según el resultado de la VMNI y las horas de VMNI:}

Para intentar evaluar si la necesidad de VMNI prolongada tenía alguna influencia sobre la mortalidad, se agruparon los pacientes en intervalos de 5 horas de VMNI, dejando en el último grupo los de 75 o más horas de VMNI.

Al comparar los grupos, se observó que en los pacientes en los que no fracasó, no había una relación clara entre la mortalidad y las horas de ventilación (figura 20). En cambio, en el grupo que sí fracasó (figura 21), la tendencia es a una mayor mortalidad con el paso de las horas, lo que sugiere un potencial efecto negativo de prolongar la VMNI en pacientes que van a fracasar. 


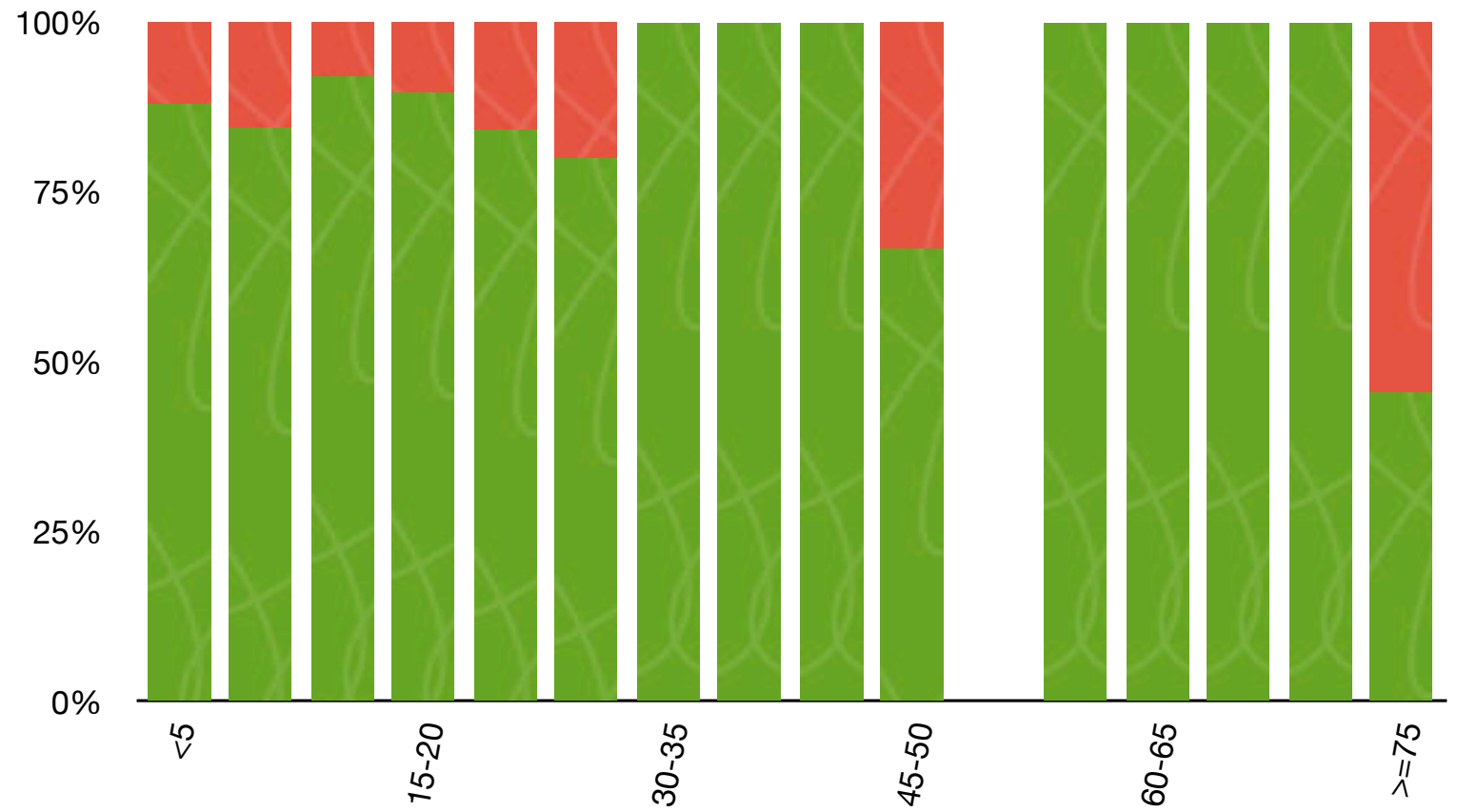

Figura 20: Exitus (verde= no; rojo= sí) por horas de VMNI en los pacientes en los que tuvo éxito.

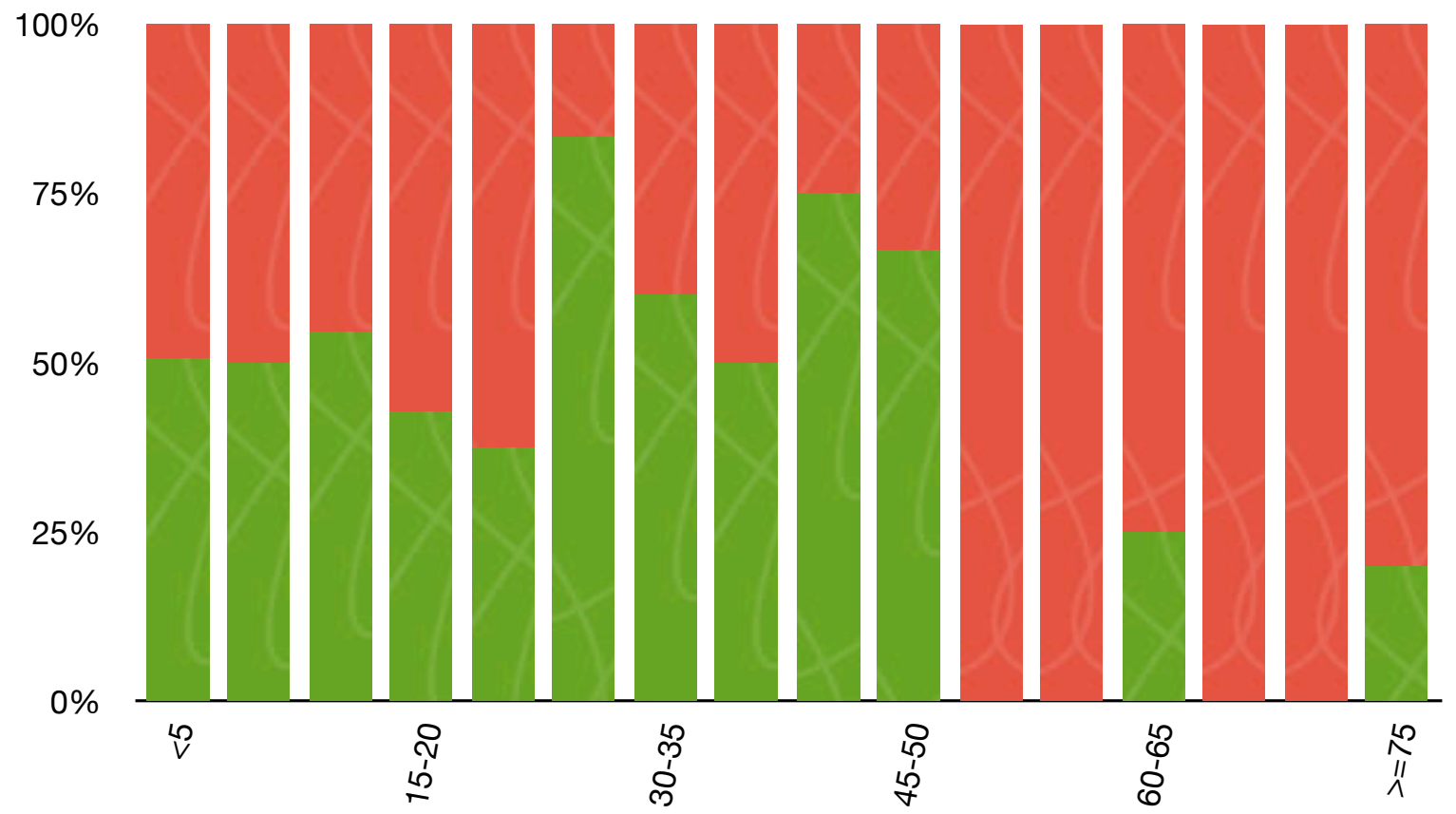

Figura 21: Exitus (verde= no; rojo= sî) por horas de VMNI en los pacientes en los que fracasó.

\section{Mortalidad según el tipo de IR y el resultado de la VMNI:}

Al comparar los pacientes que fallecieron habiendo tenido una VMNI exitosa frente a los que fracasaron, separándolos por tipo de IR se obtuvieron los siguientes datos: 
- Reagudización de EPOC: 17,54 vs 57,14\%.

- IR hipercápnica sin EPOC: 30,95 vs 31,58\%.

- IRA hipoxémica: 7,32 vs 54,78\%.

- $\quad$ EAP: 4,55 vs $83,33 \%$.

- IR post-extubación: 5,00 vs 46,81\%.

La diferencia de mortalidad en la reagudización de EPOC es estadísticamente significativa, con $\mathrm{p}<0,001$; en la IR hipercápnica sin EPOC es no significativa; en el resto se encuentran diferencias altamente significativas $(\mathrm{p}<0,005)$, aunque el reducido número de pacientes en alguna casilla hace que el test sea menos fiable en estos grupos.

\section{Fracaso por PCR:}

Otro de los datos llamativos del estudio es la existencia de 6 pacientes que sufrieron PCR mientras recibían VMNI (5 de ellos fueron exitus). Aunque el porcentaje es pequeño $(1,46 \%)$, lo que hace que la valoración estadística sea limitada, comparando las variables al ingreso de estos pacientes con el resto de los del estudio se observa que presentaban una gravedad mayor, evidenciada por las diferencias tanto en APACHE II (20,68 vs 30,50, con una mortalidad predicha del 38,9 vs 73,3\%) como por SAPS II modificado al inicio de la VMNI (27,90 vs 40,25). Además, el lactato sérico al inicio de la VMNI fue significativamente mayor en el grupo que fracasó (2,04 vs 4,7 mmol/l).

\section{Incidencia de NAVM:}

Como se ha comentado previamente, tan solo se registró un episodio de NAVM entre los pacientes en los que la VMNI fue exitosa, mientras que aparecieron 19 episodios en los que fracasó, siendo la diferencia estadísticamente significativa $(\mathrm{p}<0,001)$.

\section{Diferencias analíticas y fisiológicas al inicio y a las 2 horas en IRA hipoxémica según el resultado de la VMNI:}

Analizando únicamente el grupo de IRA hipoxémica (comparando los pacientes en los que fracasó la VMNI con los que no lo hizo) se observaron diferencias estadísticamente significativas en el APACHE II $(p<0,001)$, en la PAFI $(p<0,005)$, y la albúmina al ingreso 
( $p<0,05)$, en la FC ( $p<0,05)$, la FR $(p<0,001)$ y la PAFI a las 2 horas de VMNI $(p<0,001), y$ en el cambio de FR $(p<0,001)$ y de PAFI $(p<0,05)$ desde el inicio a las 2 horas.

Diferencias en las variables categóricas en la IRA hipoxémica según el resultado de la VMNI:

Se encontraron diferencias estadísticamente significativas en la existencia de inmunosupresión, en la necesidad de sedación para VMNI y en la Rx de tórax, todas con un $\mathrm{p}<0,05$, siendo el resto de las categorías no significativas estadísticamente. 


Como se explicó en el capítulo de material y métodos, se realizó un modelo de regresión logística para identificar las mejores variables predictoras de fracaso o éxito de manera independiente. Para facilitar el análisis los tipos de IR se recategorizaron en dos: por un lado los pacientes con IR hipercápnica (reagudizaciones de EPOC e IR hipercápnica sin EPOC), y por el otro los otros tres tipos (IRA hipoxémica, EAP e IR post-extubación). La variable $\mathrm{Rx}$ de tórax también se recodificó, agrupando los pacientes con condensación, infiltrado o derrame (unilateral o bilateral), por lo que se crearon dos grupos: Rx limpia vs resto.

Tras realizar la selección del modelo, las variables que mejores resultados mostraron como marcadores de fracaso de VMNI fueron el APACHE II, el tipo de IR, el uso de sedación para la aplicación de VMNI, los hallazgos en Rx tórax, la bilirrubina al inicio de la VMNI y las diferencias de PAFI, FC y FR entre el ingreso y las 2 horas.

El valor del test de razón de verosimilitud para este modelo es de 110,43, con un pvalor $<0,0001$, lo que nos indica que el modelo es significativo.

Observando la tabla se aprecia que salvo la diferencia de FC y la Rx tórax, que se encuentran cercanas a la significación, el resto de las variables son estadísticamente significativas.

\begin{tabular}{lccc}
\hline \multicolumn{1}{c}{ Variables } & B & Sig. & Exp(B) \\
\hline APACHE II & 0,082 & 0,001 & 1,086 \\
Tipo de IR recodificada & 0,977 & 0,017 & 2,657 \\
Necesidad de sedación & 1,965 & 0,001 & 7,134 \\
Bilirrubina al inicio & 0,772 & 0,007 & 2,164 \\
Cambio de GCS en 2h & 0,414 & 0,016 & 1,513 \\
Cambio de PAFI en 2h & 0,006 & 0,028 & 1,006 \\
Cambio de FC en 2h & $-0,019$ & 0,077 & 0,981 \\
Cambio de FR en 2h & $-0,063$ & 0,025 & 0,939 \\
Rx al inicio recodificada & 0,721 & 0,072 & 2,057 \\
\hline
\end{tabular}

Las odds-ratio (denominadas $\operatorname{Exp}(\mathrm{B})$ en la tabla) superiores a 1 indican riesgo de fracaso, las inferiores son factores de protección. Se puede observar que los pacientes que recibieron sedación tenían una probabilidad de fracasar 7 veces superior a los que no la recibieron. Según el Figura 22: Modelo de regresión logística. tipo de IR, los pacientes recategorizados como no hipercápnicos (IRA hipoxémica, IR post-extubación y EAP) tenían 2,6 veces más probabilidades de fracasar que los hipercápnicos (reagudización de EPOC e IR hipercápnica $\sin$ EPOC). 
En lo que respecta a las diferencias, la interpretación se complica; mientras que en las diferencias de GCS y de PAFI la mejoría se refleja con números negativos, en las de FC y FR dicha mejoría se evidencia en números positivos.

Así, un aumento de un punto del GCS (del valor inicial al valor a las 2 horas) se traduce en un valor negativo en el modelo, lo que supone una evolución favorable; por lo tanto, cuanto mayor sea el valor negativo mejor será la evolución. El odds-ratio indica que el incremento de una unidad (por ejemplo de -3 a -2 ) supone una probabilidad 1,5 veces mayor de fracasar.

En la FR, por el contrario, un aumento de un punto indica una probabilidad 0,93 veces mayor de fracasar, es decir, es menos probable que se produzca el fracaso. Obteniendo el inverso del odds-ratio se puede facilitar la interpretación, indicándonos una probabilidad 1,07 veces mayor de tener éxito. Si consideramos un incremento de 10 unidades, el oddsratio es de 0,53 , y su inverso de 1,87 , reflejando una probabilidad 1,87 veces mayor de tener éxito.

Este modelo clasificó bien un 77\% de los pacientes (con una sensibilidad de 0,70 y una especificidad de 0,84).

Para validar los resultados se eligieron 31 pacientes al azar, que se extrajeron del número total de pacientes previamente a la realización del modelo, observando posteriormente cómo los clasificaba y su resultado final.

En estos pacientes el modelo clasificó correctamente un 74\% de los pacientes, con un valor predictivo positivo (VPP) de 0,66 (es decir, de los pacientes que el modelo predice que van a fracasar, el 66\% lo hacen realmente) y un valor predictivo negativo (VPN) de 0,77 (un $77 \%$ de los pacientes en los que el modelo predice éxito lo presentan verdaderamente).

El análisis de segmentación realizado complementariamente al modelo logístico permitió crear el siguiente árbol de decisiones: 


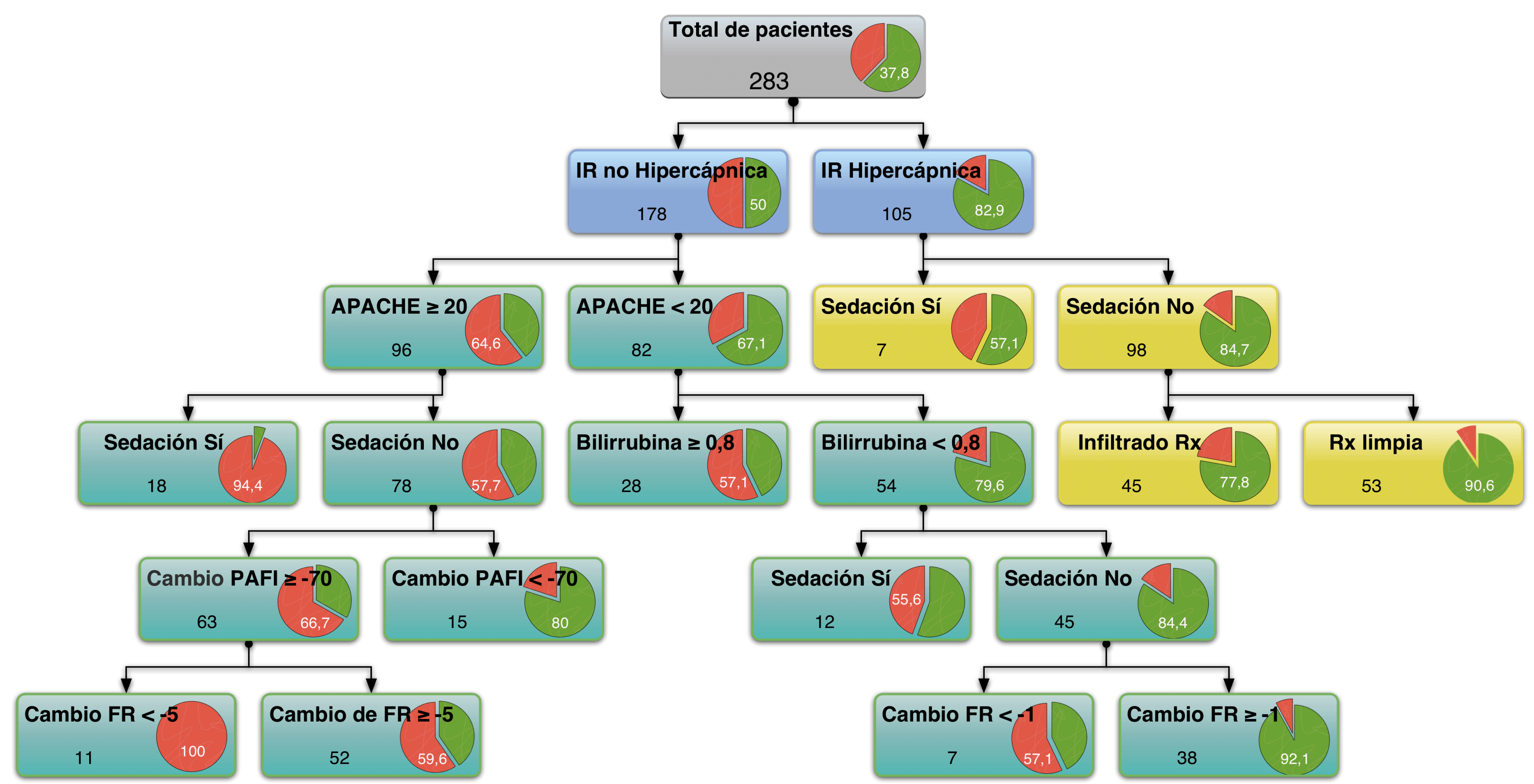

Figura 23: Árbol de decisión. El número indica el total de pacientes de cada rama. En el gráfico se muestra el porcentaje de fracasos (rojo) y éxitos de la VMNI. 


Las técnicas mencionadas en la sección correspondiente a Minería de datos del capítulo de Material y Métodos se aplicaron para seleccionar los atributos más influyentes en la clasificación de los pacientes según éxito o fracaso de la VMNI y para construir modelos de clasificación que permitirán predecir el éxito o fracaso en futuros pacientes.

Mediante el algoritmo de ganancia de información se obtienen los atributos ordenados de mayor a menor influencia en la clasificación. A continuación se muestran dichos atributos junto con el valor de ganancia que proporcionan:

- Balance a las 24 horas: 0.166223 .

- $\quad$ Tipo de IR: 0.128263

- $\quad$ FR a las 2 horas: 0.105935.

- Balance a las 12 horas: 0.084582

- Horas de VMNI: 0.075279.

- $\mathrm{PaCO}_{2}: 0.069931$.

- Hematocrito: 0.052912 .

- PAFI a las 2 horas: 0.049067.

- Bilirrubina al inicio: 0.048926.

- PAFI al inicio: 0.048919.

- Albúmina al inicio: 0.040725 .

- Leucocitos al inicio: 0.039125

- Bicarbonato al inicio: 0.038874.

- Inmunosupresión: 0.035938.

- Radiografía de tórax: 0.034527.

- APACHE II: 0.03182.

- Necesidad de sedación para la VMNI: 0.030361.

- Tiempo desde el ingreso hospitalario hasta el inicio de la VMNI: 0.030361.

- $\quad$ FC a las 2 horas: 0.027969.

- Bicarbonato a las 2 horas: 0.027872 .

- FR al inicio: 0.027752 .

- pH al inicio: 0.02528 .

- $\mathrm{PaCO}_{2}$ a las 2 horas: 0.0238 .

- Cambio de FR desde el ingreso a las 2 horas: 0.023245 . 
- GCS al inicio de la VMNI: 0.019628.

- $\quad$ FR a las 12 horas de la VMNI: 0.01466.

- Bicarbonato a las 12 horas de la VMNI: 0.0128.

- Uso de VMNI preUCI: 0.012665.

- Uso de BPAP preUCI: 0.012168.

- $\quad \mathrm{PaCO}_{2}$ a las 12 horas: 0.011958 .

- Oxigenoterapia domiciliaria: 0.011029.

- Uso de soporte vasoactivo al inicio de la VMNI: 0.009345.

- $\quad$ GCS a las 12 horas de la VMNI: 0.004908.

- $\quad \mathrm{PaCO}_{2}$ a las 24 horas de la VMNI: 0.004739.

- FR a las 24 horas de la VMNI: 0.004132.

- Bicarbonato a las 24 horas de la VMNI: 0.003963.

- PAFI a las 24 horas de la VMNI: 0.003709.

- Decisión de LMSV: 0.003568.

- $\quad$ Tipo de VMNI: 0.003545.

- VMNI domiciliaria: 0.000836.

- Sexo: 0.00052 .

- Uso de CPAP preUCI: 0.000342.

Mediante el algoritmo CFS se seleccionaron las siguientes variables en orden de importancia: horas de VMNI, APACHE II, $\mathrm{PaCO}_{2}$, PAFI, bicarbonato, hematocrito y leucocitos al inicio de la VMNI, PAFI y FR a las 2 horas de la VMNI, balance a las 12 y 24 horas de la VMNI, tipo de IR, necesidad de sedación para la VMNI, tiempo desde el ingreso hospitalario hasta el inicio de la VMNI y cambio de FR desde el inicio a las 2 horas.

Los algoritmos para la creación de modelos predictores se realizaron inicialmente sobre el fichero completo, del que se habían eliminado atributos que reflejan resultados, como variables al alta, exitus, estancias, traqueotomías o IOT.

Posteriormente se aplicaron los mismos algoritmos sobre el fichero del que se habían dejado únicamente los atributos seleccionados mediante los métodos mencionados anteriormente. 
El resumen de resultados es el siguiente:

\begin{tabular}{ll}
\hline \multicolumn{1}{c}{ Algoritmo } & Precisión \\
\hline Árbol de decisión J48 & $68.7805 \%$ \\
Árbol de decisión REPTree & $69.0244 \%$ \\
Red de Bayes & $71.9512 \%$ \\
Bagging con J48 & $73.6585 \%$ \\
Bagging con REPTree & $74.6341 \%$ \\
AdaBoost con J48 & $73.4146 \%$ \\
AdaBoost con REPTree & $71.4634 \%$ \\
\hline
\end{tabular}

Figura 24: Resumen de resultados sobre el fichero completo.

\begin{tabular}{ll}
\hline \multicolumn{1}{c}{ Algoritmo } & Precisión \\
\hline Árbol de decisión J48 & $69.5122 \%$ \\
Árbol de decisión REPTree & $70.7317 \%$ \\
Red de Bayes & $71.4634 \%$ \\
Bagging con J48 & $71.9512 \%$ \\
Bagging con REPTree & $74.8780 \%$ \\
AdaBoost con J48 & $71.7073 \%$ \\
AdaBoost con REPTree & $74.6341 \%$ \\
\hline
\end{tabular}

Figura 25: Resumen de resultados sobre los atributos seleccionados mediante ganancia de información.

\begin{tabular}{ll}
\hline \multicolumn{1}{c}{ Algoritmo } & Precisión \\
\hline Árbol de decisión J48 & $71.4634 \%$ \\
Árbol de decisión REPTree & $72.4390 \%$ \\
Red de Bayes & $75.6098 \%$ \\
Bagging con J48 & $76.8293 \%$ \\
Bagging con REPTree & $73.1707 \%$ \\
AdaBoost con J48 & $74.3902 \%$ \\
AdaBoost con REPTree & $73.6585 \%$ \\
\hline
\end{tabular}

Figura 26: Resumen de resultados sobre los atributos seleccionados mediante CFS.

Como se puede observar, la precisión de los distintos algoritmos se sitúa entre el $68 \%$ y el $77 \%$ aproximadamente.

El que mejor resultado mostró fue el que se obtuvo con el método de Bagging con J48 sobre el conjunto de atributos seleccionados mediante CFS, con una precisión de 76,8293\%. El sumario de resultados por clase para este caso es el siguiente:

\begin{tabular}{ccccccc}
\hline Clase & Tasa TP & Tasa FP & Precisión & Recall & Medida-F & Área ROC \\
\hline No & 0,743 & 0,207 & 0,777 & 0,743 & 0,759 & 0,828 \\
Sí & 0,793 & 0,257 & 0,76 & 0,793 & 0,776 & 0,828 \\
\hline
\end{tabular}

Figura 27: Resultados con Bagging con J48 sobre atributos seleccionados mediante CFS.

En la tabla anterior se puede observar que tanto la precisión como la tasa de verdaderos positivos (TP) y la de falsos positivos (FP) es muy similar para ambas clases, por lo que el 
clasificador tendrá similar probabilidad de acierto en la predicción de éxito y de fracaso de VMNI. Este hecho lo confirman los valores de recall, medida-F (combinación de precisión y recall) y el área bajo la curva ROC (Receiver Operating Characteristic, Característica Operativa del Receptor). El recall se calcula mediante los valores de TP, FP y falsos negativos (FN): Recall $=\mathrm{TP} /(\mathrm{TP}+\mathrm{FN})$.

En la figura siguiente se muestran de forma gráfica los resultados recogidos en las tablas anteriores. En ella se puede observar que en la mayoría de los casos la aplicación previa del método de selección de atributos CFS consigue mejorar de forma significativa la precisión de los clasificadores.

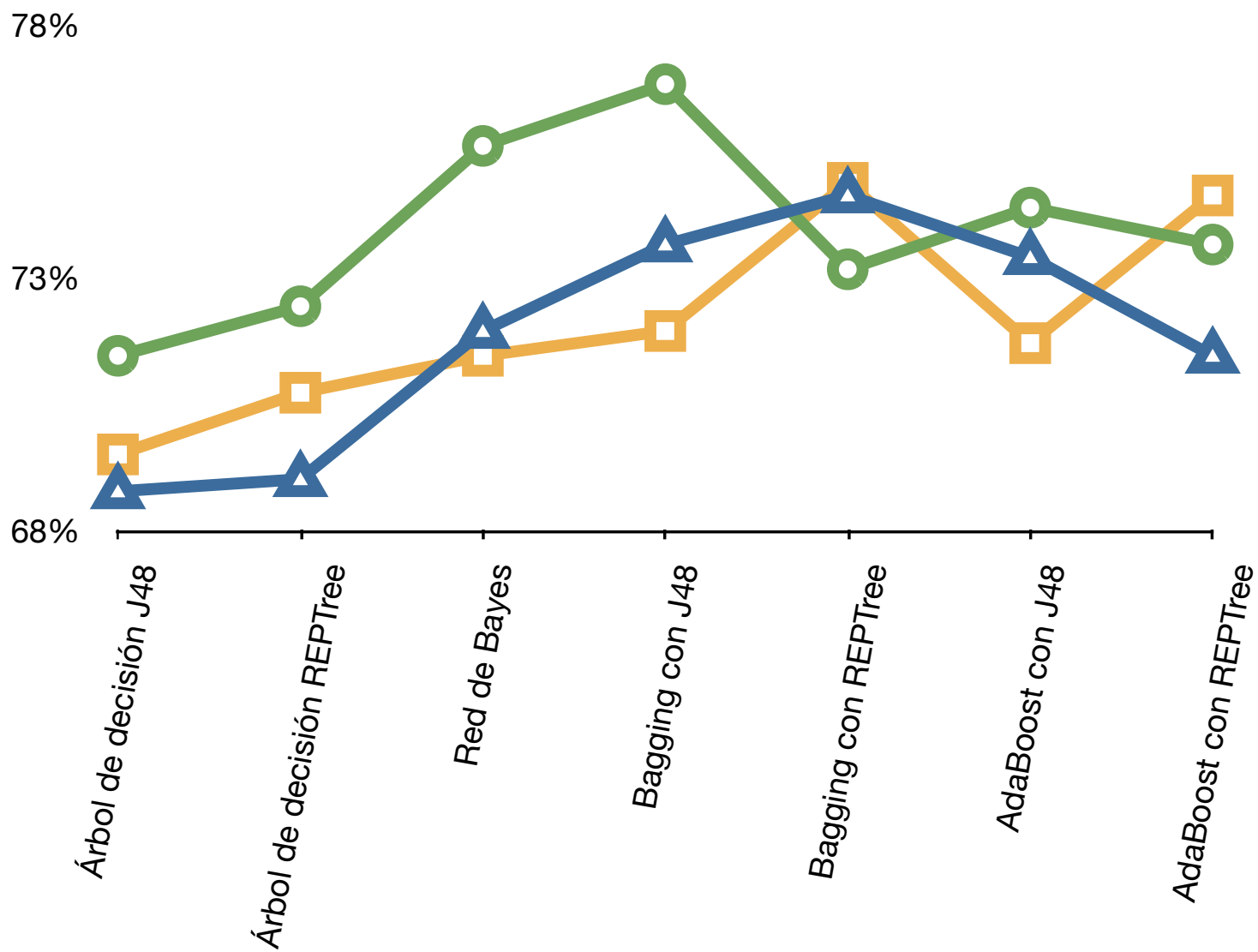

\section{Todos los atributos o CFS Ganancia de información}

Figura 28: Precisión según tipo de algoritmo y los atributos seleccionados. 

"Es mejor debatir una cuestión sin resolverla, que resolver una cuestión sin debatirla" Joseph Joubert

a distribución de pacientes en nuestro estudio por tipo de IR difiere ligeramente de
la nacional ${ }^{39}$. Se evidencia un menor porcentaje de EAP y EPOC, con una cifra
mucho mayor de IRA hipoxémicas. Estas variaciones con respecto a la distribución nacional probablemente se deban en parte a las características de las diferentes UCIs, y que el mayor porcentaje de EAP de la nacional sea debido a que en muchas de estas unidades se atiende a pacientes cardiológicos, mientras que en nuestro hospital estos enfermos ingresan en la Unidad Coronaria. En una encuesta europea ${ }^{40}$ se observa la IR hipercápnica (incluyendo pacientes sin y con EPOC) como el escenario más habitual de VMNI, seguido del EAP, la IRA hipoxémica y por último en weaning y en IR postextubación. Este estudio incluye no solo a intensivistas, refleja también las respuestas de neumólogos y otros especialistas, lo que puede interferir en esta distribución. En el trabajo de Esteban et $\mathrm{al}^{41}$ se observa que el grupo en el que se utiliza más es en la IRA hipoxémica.

Por años el aumento en el número de pacientes tratados con VMNI concuerda con la literatura $^{41}$, que muestra esa tendencia a lo largo de los años, con una reducción en el número de pacientes EPOC y un aumento de los que presentan IRA hipoxémica. Al igual que en dicho estudio no se observan cambios significativos ni en el fracaso de la VMNI ni en la mortalidad. 


\section{Éxito de la VMNI:}

El porcentaje de éxito de la VMNI varía en los ensayos randomizados despendiendo sobre todo del tipo de pacientes tratados. En un estudio con pacientes de diferentes tipos ${ }^{42}$ la tasa de fracaso fue del $58 \%$. En estudios prospectivos no controlados, ésta varía entre el 23 y el $38,6 \%{ }^{43-47}$.

En el trabajo de Honrubia et $\mathrm{al}^{42}$ se observa una tendencia no significativa a una disminución en la mortalidad en UCI y la hospitalaria.

Una de las dificultades a la hora de comparar resultados es la diferencia en la definición de fracaso de VMNI, ya que mientras que en algunos estudios se entiende como la necesidad de IOT en las 48-72 horas posteriores a la retirada de la VMNI, en otros ese periodo se amplía hasta el alta. Por otro lado, los criterios de necesidad de IOT varían de unos a otros, así que pacientes que en unos trabajos entrarían en el grupo de fracaso de VMNI, en otros serían clasificados como éxito. En nuestro estudio, como se mencionó en el capítulo de material y métodos, no había un criterio específico de cese de VMNI para IOT y conexión a VM, sino que era el médico responsable del paciente el que lo decidía según la situación clínica y gasométrica.

Además, otro de los problemas para comparar diferencias de resultados entre estudios puede ser la distinta proporción de pacientes según el tipo de IR. Por eso, puede ser más eficaz confrontar con trabajos sobre un tipo específico de pacientes.

EPOC: Desde los primeros estudios en estos pacientes ${ }^{48}$ la evidencia es abrumadora a favor de su utilización, permitiendo evitar la IOT en un porcentaje importante de los mismos. En el mencionado estudio de Brochard et $\mathrm{al}^{48}$ solo 1 de 13 pacientes $(7,69 \%)$ precisó IOT. De nuevo Brochard et $\mathrm{al}^{49}$ en un análisis randomizado muestran su eficacia, con un fracaso del $26 \%$. En otros estudios, el fracaso varió entre el 15 y el $23 \%{ }^{50,51}$. En el trabajo de Squadrone et $\mathrm{al}^{52}$, en el que trataban pacientes con criterios de IOT, el fracaso fue mucho mayor $(62,5 \%)$. En el estudio de Díaz et $\mathrm{al}^{53}$, que incluía pacientes en coma, la tasa de éxito era del $70,1 \%$ en pacientes con GCS $>8$ y del $80 \%$ en el grupo con GCS $\leq 8$. 
Por tanto, la tasa de fracaso en nuestro estudio se situó en torno a las cifras de los grandes trabajos publicados.

Por otra parte, su eficacia también se demuestra a la hora de disminuir la mortalidad, las complicaciones y la estancia hospitalaria desde los primeros estudios ${ }^{49,54}$, beneficios que se han confirmado posteriormente tanto en ensayos randomizados ${ }^{51,55}$ como en metanálisis ${ }^{56}$.

La evidencia disponible sugiere que su utilidad principal es en los pacientes con una reagudización moderada (con $\mathrm{pH}$ entre 7,25-7,35). Análisis en pacientes menos graves ${ }^{57,58}$ muestran resultados contradictorios; mientras que el de Keenan et $\mathrm{al}^{57}$ no muestra grandes beneficios (salvo mayor disminución de la disnea), con una mala tolerancia a la VMNI, el de Pastaka et $\mathrm{al}^{58}$ sí que consigue una disminución de la estancia hospitalaria y una recuperación más rápida del $\mathrm{pH}$ y la $\mathrm{PaCO}_{2}$, por lo que la utilización de la VMNI en pacientes sin acidosis respiratoria (o con acidosis leve) continúa siendo controvertida. En el extremo opuesto, el de los pacientes más graves, la probabilidad de fracaso y necesidad de IOT es mucho mayor, llegando hasta el $62 \%^{52}$. Sin embargo, los pacientes en los que no fracasa presentaron una menor mortalidad y estancias hospitalaria y en UCI, sin encontrarse peores resultados en los pacientes en los que fracasó frente al grupo control (con VMI); además, en los pacientes en los que fracasó la VMNI el retraso en la IOT no supuso peor pronóstico. En otros estudios ${ }^{53,59}$ se demuestra que incluso los pacientes en coma hipercápnico pueden ser tratados de una forma eficaz, por lo que merece la pena un intento de VMNI aunque sean pacientes de mayor gravedad.

En nuestro estudio los resultados son concordantes con la evidencia disponible, manifestando una menor mortalidad en los pacientes en los que la VMNI fue exitosa, que precisaron además un menor tiempo de estancia en UCI, mientras que la diferencia en estancia hospitalaria no fue significativa. Así pues, el alto porcentaje de éxito y la menor mortalidad y estancia en UCI en el grupo de éxito de VMNI confirman la utilidad de la técnica en los pacientes con reagudización de EPOC.

EAP: Con la reagudización de EPOC es la patología en la que mayor evidencia hay. Bersten et $\mathrm{al}^{60}$, en un ensayo randomizado que compara tratamiento con CPAP vs oxigenoterapia convencional, encuentran que los pacientes tratados con CPAP no necesitaron IOT en ningún caso (mientras que el $35 \%$ de los tratados con $\mathrm{O}_{2}$ suplementario la precisaron). 
Desde entonces el uso de CPAP en la IR secundaria a EAP es parte del tratamiento habitual. Varios estudios ${ }^{61-65}$ han evaluado la eficacia de la BPAP en estos pacientes, encontrando una tasa de intubación entre el 7 y el 20\%. Hay que destacar que el de Mehta et al $^{61}$ encontró una tasa de infarto agudo de miocardio mayor en el grupo de la BPAP (BPAP 71\% vs CPAP 31\%), resultado que no se ha reproducido en estudios posteriores. En los metanálisis realizados ${ }^{66-69}$, no se aprecian grandes diferencias en resultados ni en complicaciones entre CPAP y BPAP, sugiriendo la utilización de BPAP en los pacientes con EAP e hipercapnia.

Varios trabajos ${ }^{60,62,64}$, muestran una mejoría más rápida de parámetros como la PAFI, la FR, la $\mathrm{FC}$ o la $\mathrm{PaCO}_{2}$, aunque no consiguen demostrar diferencias en estancia o mortalidad. Sin embargo, los diferentes metanálisis publicados ${ }^{67,69,70}$ sí que evidencian disminución en la mortalidad, en la estancia hospitalaria o en la estancia en UCI. En un metanálisis del 2010, Weng et $\mathrm{al}^{69}$ encuentran que el tratamiento con CPAP reduce la necesidad de IOT y la mortalidad (sobre todo en los estudios en los que la proporción con IAM o isquemia coronaria era mayor), mientras que en los que se tratan con BPAP se reduce la necesidad de IOT. Los resultados del último metanálisis ${ }^{71}$ son similares, confirmando que ambas técnicas son eficaces aunque el efecto reductor de la mortalidad es mayor en la CPAP.

En nuestro estudio, el porcentaje de fracaso, situado en el 21,4\%, es similar a la evidencia disponible. Se observa también una menor mortalidad en los pacientes con VMNI exitosa frente a los que fracasan. La estancia en UCI y la estancia hospitalaria muestran una tendencia a ser menores en los que no fracasan, pero con resultados no significativos.

Sin embargo, el escaso número de pacientes con EAP en nuestro trabajo hacen que los datos deban ser valorados con precaución.

IRA hipoxémica: El uso de la VMNI en la IRA hipoxémica está mucho menos respaldado por la literatura. Una de las mayores limitaciones a la hora de marcar indicaciones es la gran variabilidad en cuanto a la etiología de la hipoxemia, ya que engloba múltiples patologías, lo que hace que la eficacia de la VMNI varíe muchísimo de unos estudios a otros. En un primer análisis que compara VMNI vs VMI en pacientes con IRA hipoxémica ${ }^{72}$, la tasa de IOT es del $31 \%$, demostrando una eficacia similar en la mejoría del intercambio de gases y con menor aparición de complicaciones serias y menor estancia en UCI en el grupo de 
VMNI. En otro estudio randomizado que compara VMNI vs oxigenoterapia convencional ${ }^{73}$, la necesidad de IOT en el brazo de la VMNI fue del 25\%; en un análisis randomizado en pacientes con trauma torácico, la tasa de IOT en el grupo de VMNI fue del 12\%. En estudios no randomizados ${ }^{27,45,74-78}$ el porcentaje de fracasos varió entre el 23 y el 56\%.

Este amplio abanico de resultados refleja la dificultad de comparar trabajos. Pese a todo, la gran tasa de fracaso de nuestro estudio $(73,7 \%)$ supone un dato a evaluar. Revisando los indicadores de gravedad de estos estudios (SAPS II y APACHE II), y las diferentes variables (principalmente PAFI, FR y FC) al inicio de la VMNI, se evidencian grandes diferencias entre unos y otros:

- El SAPS II variaba entre el 29 y el 46\% (salvo el trabajo de Antonelli et al ${ }^{72}$, en el que se utilizaba el SAPS I, que era de 13). En esta variable, nuestro estudio se sitúa en el rango bajo (29), aunque en este caso la comparación es difícil, ya que salvo en el estudio de Schettino et $\mathrm{al}^{79}$ y en el nuestro, en el resto el SAPS II calculado es el original, lo que incluye la diuresis en 24 horas. Al ser el SAPS II modificado de nuestro estudio el calculado con las variables en el momento de inicio de la VMNI, y no con las peores de las primeras 24 horas de ingreso (además de no incluir diuresis), la puntuación total es menor. Además, en el análisis de Schettino et al ${ }^{79}$ no se especifica si se puntuó la PAFI (que en nuestro estudio no se incluyó ya que se interpretó que no se administraba VM, al utilizarse los datos previos a la conexión a VMNI).

- Tan solo un estudio ${ }^{77}$ cuantificó el APACHE II, con una media de 14,9, mientras que en nuestros datos fue de 22.

- La PAFI inicial iba de 102 a 212, situándose la de nuestro trabajo en 108, la segunda más baja.

- FR: Con un rango entre 25 y $47 \mathrm{resp} / \mathrm{min}$, en nuestros datos la frecuencia media fue de $31 \mathrm{resp} / \mathrm{min}$.

- Edad: La edad media se situaba entre los 43 y los 73 años, estando en nuestro análisis en 64 años.

En definitiva, aunque las diferencias en la forma de calcular el SAPS II impiden una comparación adecuada, y tan solo un estudio utilizaba el APACHE II, las variables del 
nuestro se encontraban en el rango de las observadas en los previos. Como ya se ha mencionado, la tendencia de nuestros datos es a situarse en la zona alta en cuanto a gravedad, pero no parece suficiente para explicar un fracaso tan elevado. Nuestro estudio refleja por tanto la necesidad de revisar adecuadamente los criterios de elección de la VMNI en pacientes con IRA hipoxémica en nuestra unidad para intentar disminuir este elevado número de fracasos, reafirmando las conclusiones de estudios anteriores ${ }^{79}$.

En lo que respecta a los beneficios de la VMNI en estos pacientes en cuanto a reducción de la mortalidad o de las estancias, el estudio randomizado de Antonelli et $\mathrm{al}^{72}$ frente a VMI mostró una disminución del número de complicaciones serias, de la necesidad de VM y de la estancia en UCI. Otros trabajos como el de Ferrer et $\mathrm{al}^{73}$ muestran resultados similares. Un estudio que compara CPAP con oxigenoterapia convencional ${ }^{80}$ no disminuía la necesidad de IOT ni las estancias o la mortalidad. En IRA hipoxémica secundaria a trauma torácico $^{81}$ se observó una menor necesidad de IOT.

El metanálisis de Keenan et $\mathrm{al}^{82}$ confirma esa menor necesidad de IOT en los pacientes con IRA hipoxémica, además de una menor estancia y mortalidad en UCI. Sin embargo, los estudios analizados muestran grandes diferencias en resultados, por lo que se concluye que la VMNI no puede ser recomendada de forma generalizada para las IRA hipoxémicas.

Los análisis observacionales ${ }^{74}$ muestran que los pacientes que responden a la VMNI tienen menor mortalidad, estancia en UCI y número de complicaciones.

Nuestros datos en este subgrupo muestran una mayor mortalidad en los pacientes en los que fracasa la VMNI, con una estancia en UCI y hospitalaria más prolongadas, siendo las diferencias en las dos primeras estadísticamente significativas.

Se confirma por tanto la necesidad de nuevos estudios en este tipo de pacientes que sean capaces de identificar de una forma precoz a los pacientes respondedores a VMNI para evitar su uso en los que tengan menos posibilidades de evitar la IOT, y así no retrasarla, lo que podría tener un efecto deletéreo.

De manera particular, como se mencionó previamente, los resultados en este grupo de pacientes nos indican la conveniencia de una reflexión profunda en nuestro servicio sobre la 
utilización de VMNI en la IRA hipoxémica dada la gran tasa de fracaso encontrada y su elevada mortalidad asociada.

IR hipercápnica sin EPOC: Es la categoría que dispone de menor evidencia, con pocos trabajos y además de patologías muy diversas. En un estudio prospectivo no controlado de pacientes hipercápnicos ${ }^{53}$, el subgrupo de pacientes no EPOC tuvo un porcentaje de éxito del $89 \%$, mientras que Schettino et $\mathrm{al}^{79}$ refieren un éxito del $38 \%$ y Phua et $\mathrm{al}^{83}$ del $53 \%$.

En nuestros datos, el fracaso fue del 31,1\%, encontrándose dentro del rango de los estudios previos. En el estudio de Phua et $\mathrm{al}^{83}$ se observa mayor mortalidad en el grupo de pacientes sin EPOC que en los EPOC, siendo la estancia en UCI y hospitalaria menores (4 y 11 días) que en el nuestro ( 7 y 21 respectivamente).

Además, en ese trabajo se observa una mayor mortalidad, estancia hospitalaria y estancia en UCI en los pacientes con VMNI no exitosa.

Al contrario que en la evidencia previa ${ }^{83}$, en nuestro estudio no se observa una mayor mortalidad ni un mayor fracaso de la VMNI en los pacientes no EPOC con respecto a los EPOC, incluso aunque los pacientes no EPOC de nuestro análisis tenían un menor GCS y un mayor SAPS II modificado al ingreso que los EPOC.

Podemos concluir por tanto que la VMNI puede ser utilizada en pacientes con IR hipercápnica sin EPOC con grandes posibilidades de éxito.

IR post-extubación: La mayor evidencia disponible sobre la eficacia de la VMNI durante el weaning se encuentra en la prevención de la IR post-extubación en pacientes de riesgo, sobre todo en pacientes hipercápnicos ${ }^{84,85}$. Sin embargo, en los pacientes que ya han desarrollado la IR, su utilidad es más discutida. La gran diversidad de causas de la IR postextubación y la amplia variedad de patologías por las que el paciente necesitó la IOT son factores que complican la evaluación de la eficacia de la VMNI en estos pacientes. Dos estudios randomizados ${ }^{86,87}$ no encontraron diferencias en la necesidad de reintubación, 72 y $48 \%$ (vs oxigenoterapia convencional, 69 y 48\% respectivamente), y uno de ellos ${ }^{87}$ además mostró una mayor mortalidad en el grupo que recibió VMNI, lo que se atribuyó al retraso 
en la IOT. En un trabajo que compara IOT vs CPAP nasal vs BPAP en el postoperatorio de Cirugía Cardiaca $^{88}$, se evitó la IOT en un 74,2 y un $77,8 \%$ respectivamente.

Un estudio no randomizado en pacientes con IR en el postoperatorio de esofagectomía ${ }^{89}$, mostraba una tasa de reintubación del 25\%. Un análisis retrospectivo en pacientes con IR en el postoperatorio de Cirugía Cardiaca presentaba una tasa éxito del 94\%, probablemente debido a que la IR fue causada en la mayoría de los pacientes por EAP o por atelectasias, donde su eficacia es mucho mayor. Además, refieren que la VMNI fue iniciada muy precozmente tras la aparición de la IR, que era moderada.

En el metanálisis publicado en $2012^{90}$, se observó reducción en la estancia en UCI en weaning y en post-cirugía, en la tasa de reintubación en post-cirugía, y en la incidencia de neumonía en weaning y en post-cirugía. Además se evidenció aumento de la supervivencia hospitalaria en weaning y en post-cirugía.

Nuestros datos mostraron un fracaso del 54\%, con una mortalidad del $27,6 \%(46,8 \%$ de los pacientes en los que fracasó y $5 \%$ de los pacientes en los que se tuvo éxito). Es llamativo el hecho de que todos los pacientes fueron tratados por IR establecida; en ningún caso se utilizó como prevención de la IR en pacientes de riesgo tras la extubación, por lo que es posible que podríamos haber conseguido mejores resultados si se hubiesen identificado pacientes de riesgo y se hubiese utilizado la VMNI en ellos de forma profiláctica, donde la evidencia disponible es mayor. Además, sería necesario plantearse por qué no se utiliza la VMNI como maniobra de weaning, otro de los ámbitos soportados por evidencia clara, lo que podría suponer un punto de mejora claro en el tratamiento de nuestros pacientes.

Pacientes inmunodeprimidos: El grupo de pacientes con algún tipo de inmunosupresión es uno de los más estudiados como potenciales beneficiarios del uso de VMNI. En ensayos randomizados $^{91,92}$ el porcentaje de fracaso de la VMNI fue del 20 y el 46\%. En cuanto a la mortalidad, en estos dos estudios se situó en un 35 y un 50\%.

El porcentaje de éxito de la VMNI en nuestro estudio fue tan solo del 25,4\%, con una mortalidad del 53,5\% (16,7\% en los que la VMNI fue exitosa, frente a $66 \%$ en los que fracasó). Comparando con análisis observacionales ${ }^{93-95}$ en los que la tasa de éxito fue del 54 , el 46 y el $31 \%$, y la mortalidad del 49 , el 61 y el 65,4\%, nuestros resultados son algo 
peores en cuanto a éxito de la técnica (con un porcentaje de fracaso similar al de los pacientes del estudio de Depuydt et $\mathrm{al}^{95}$ ventilados con VMNI), siendo similares en lo que respecta a la mortalidad. Una de las posibilidades de este elevado fracaso podría ser la utilización de CPAP en un amplio número de pacientes que desarrollan IR en la planta de Hematología; así, los que responden a esas medidas no son ingresados en nuestra unidad, por lo que esto podría suponer un sesgo ya que estaríamos ingresando pacientes más graves, con menos posibilidades de tener buena evolución con VMNI, y no incluiríamos a un porcentaje de pacientes respondedores.

Pese al bajo porcentaje de respuesta a la VMNI, la gran diferencia de mortalidad entre los que fracasaron y los que no, asociada al mal pronóstico que supone la necesidad de VMI en pacientes inmunodeprimidos sugiere que puede merecer la pena una prueba de VMNI (siempre que la situación del paciente no recomiende una IOT inmediata). En el estudio de Gristina et $\mathrm{al}^{93}$ la mortalidad fue similar en los pacientes que recibieron VMI desde el inicio y los que recibieron VMNI y fracasaron, lo que apoya esta postura sin pensar que se somete a los pacientes a un mayor riesgo, siempre que se monitorice al paciente de una forma adecuada y no se retrase la IOT si es necesaria. Existen variables pronósticas de fracaso de $\mathrm{VMNI}^{93,94}$, como un SAPS II elevado, una FR elevada con VMNI, la necesidad de vasopresores o de técnicas de reemplazo renal, el inicio tardío de la VMNI desde el ingreso en UCI o la presencia de ALI o SDRA, que nos pueden ayudar a evitar esta demora.

\section{Complicaciones relacionadas con la VMNI:}

Como se reflejó en el capítulo de resultados, la incidencia de complicaciones fue poco importante, con una sola NAVMNI, y 18 alteraciones hemodinámicas. Sí es más preocupante el gran número de fracasos en los pacientes con dichas alteraciones (14 de 18), incluidos $6(1,5 \%)$ en los que la causa de fracaso fue PCR. La incidencia de PCR varía mucho de unos estudios a otros, desde unos en los que no existen ${ }^{49}$, a otros ${ }^{42}$ en los que el porcentaje llegó hasta el 7\%. El estudio observacional de Schettino et al ${ }^{79}$ refiere un $9 \%$ de fracasos por PCR, aunque en este apartado engloba las paradas reales y las paradas inminentes, sin especificar porcentajes para cada uno de los apartados. Las diferencias en APACHE II y SAPS II modificado al inicio de la VMNI entre los pacientes que sufrieron PCR y el resto en nuestros datos reflejan una mayor gravedad, lo que hace plantearse la 
cuestión de si la VMNI estaba indicada o estaban "demasiado graves" para tolerarla. Revisando paciente por paciente se observa que todos presentaban pluripatología, incluyendo un paciente con adenocarcinoma de próstata y metástasis óseas, dos con neoplasias hematológicas, uno con EPOC (que fue el que sobrevivió) y otro con miocardiopatía dilatada grave). Estos datos aclaran el manejo conservador de estos pacientes pese a su gravedad.

Hay que destacar también el estudio de Mehta et $\mathrm{al}^{61}$, que reflejaba un aumento de la incidencia de IAM en los pacientes con BPAP vs los que recibían CPAP (para el tratamiento de EAP). En nuestros datos no se registró ningún IAM. Todos los pacientes que presentaron PCR sufrieron actividad eléctrica sin pulso $o$ asistolia, sin datos electrocardiográficos que sugirieran un evento isquémico en ninguno de ellos.

En cuanto a las NAVMNI, los porcentajes varían de unos estudios a otros, destacando un $8 \%$ y un $10 \%{ }^{91,92}$ en pacientes inmunodeprimidos. En otros trabajos, la incidencia de neumonía nosocomial oscilaba entre el 10 el $23 \%{ }^{42,73,96}$. Guérin et al ${ }^{97}$ en un estudio prospectivo observacional diseñado para evaluar el efecto de la VMNI sobre la incidencia de NAVM (se dividieron los pacientes en cuatro grupos según la VM que recibieron: VMNI y después VMI, VMI y después VMNI, solo VMI y solo VMNI), demostraron una disminución muy significativa en el grupo de pacientes que no recibieron VMI. En nuestros datos, la incidencia de NAVMNI fue del 0,2\%, mientras que la de NAVM invasiva fue de $4,6 \%$, unos datos concordantes con esa reducción de la NAVM.

La gran mayoría de los estudios reflejan como complicaciones frecuentes las lesiones cutáneas $^{42,54}$. El carácter retrospectivo de nuestro trabajo y la dificultad para identificar mediante la revisión de historias clínicas la aparición de estas lesiones hizo que no se haya recogido el porcentaje de esta complicación. Sin embargo, sí se puede indicar que aun no disponiendo de datos exactos, la impresión es que la aparición de lesiones cutáneas es relativamente frecuente, y probablemente la complicación más habitual si hubiese podido medirse. Hay que destacar el hecho de que en nuestro hospital solo se dispone de forma habitual de mascarillas nasales o faciales. Existen varios estudios ${ }^{98-101}$ que muestran que el uso de helmets o mascarillas totales disminuyen la aparición de estas lesiones; sería interesante disponer de varios tipos de interfases para poder alternar su utilización y así 
conseguir reducir dichas lesiones, sobre todo en los pacientes en los que es necesario un uso prolongado de la VMNI, hecho que aumenta la probabilidad de que aparezcan.

\section{Diferencias intergrupales de las variables analíticas y fisiológicas:}

En los datos extraídos para evaluar las diferencias intergrupales se evidencian varios hallazgos relevantes:

En cuanto a la PAFI, los pacientes con una mayor gravedad son los que presentan IRA hipoxémica y EAP, destacando la PAFI de los primeros $(103,78)$, lo que nos indica una importante diferencia en cuanto a este parámetro.

Observando la $\mathrm{PaCO}_{2}$, el pH y el GCS, íntimamente ligados, se observa, como era de esperar, que los pacientes con un mayor $\mathrm{PaCO}_{2}$ y un menor $\mathrm{pH}$ y GCS son los pacientes con reagudización de EPOC y con IR hipercápnica sin EPOC (incluso en el caso del GCS, el nivel de consciencia es menor en los pacientes con IR hipercápnica sin EPOC que en las reagudizaciones de EPOC). Los pacientes con EAP se sitúan en un grupo medio de pH $(7,27)$, pero con un $\mathrm{PaCO}_{2}$ normal $(43 \mathrm{mmHg})$, siendo en este caso acidosis metabólica.

\section{Variables pronósticas según la modelización:}

Una de los mayores intereses en la investigación en VMNI es la identificación de los pacientes susceptibles de ser tratados con esta técnica; además de intentar clarificar las patologías que van a responder mejor, un objetivo fundamental es identificar precozmente qué pacientes en cada categoría tienen más posibilidades de fracasar o de tener éxito.

Se han realizado varios estudios (tanto prospectivos como retrospectivos) con dicho objetivo de identificación de variables pronósticas de éxito o fracaso de VMNI. Analizando las diferencias entre los grupos según respuesta se extraen antecedentes personales, parámetros fisiológicos o variables analíticas que pueden predecir la respuesta.

En los diferentes trabajos con población general (no centrados en un solo tipo de IR), los parámetros identificados como predictores de fracaso fueron la presencia de neumonía ${ }^{42}$, un APACHE II elevado $^{42}$, una FR $>35^{42}$, un SAPS II elevado ${ }^{47,79,102,103}$, la mala tolerancia a la 
$\mathrm{VMNI}^{102}$, una IPAP elevada ${ }^{47}$, un $\mathrm{pH}^{\text {bajo }}{ }^{47}$, el GCS antes de la VMNI ${ }^{79}$, el PAFI antes de la $\mathrm{VMNI}^{79}$ y la albúmina antes de la $\mathrm{VMNI}^{79,103}$.

En pacientes con reagudizaciones de EPOC es donde mayor número de estudios hay en este sentido. Como predictores de fracaso se encontraron la concentración de $\mathrm{H}^{+}$y la $\mathrm{PaCO}_{2}$ al inicio $^{104}$, el fallo multiorgánico máximo medido con el Sequential Organ Failure Assesment index Score $(\mathrm{SOFA})^{53}$, un APACHE II elevado ${ }^{83,105,106}$, un GCS disminuido basal ${ }^{105}$, un $\mathrm{pH}$ basal bajo ${ }^{105,107}$, un $\mathrm{pH}$ a las dos horas bajo ${ }^{105}$, una FR basal elevada ${ }^{105}$ y edad avanzada ${ }^{106}$; como predictores de éxito, la mejoría de la acidosis y la disminución en la $\mathrm{FR}^{104}$, y el GCS a la hora de iniciada la VMNI en pacientes en coma hipercápnico ${ }^{53}$.

En pacientes con IRA hipoxémica, los parámetros que se mostraron como predictores de éxito fueron la edad ${ }^{72}$, la mejoría del gradiente respiratorio con $\mathrm{VMNI}^{72}$, el $\mathrm{SAPS}^{72}$, reducción de la FR y de las necesidades de $\mathrm{O}_{2}$ a las 24 horas $^{75}$ y la PAFI basal ${ }^{77}$.

En pacientes con SDRA, se identificaron el SAPS II ${ }^{76}$, el APACHE II ${ }^{108}$, la PAFI a la hora ${ }^{76}$ o la FR a la hora ${ }^{108}$.

En cuanto a los predictores en neumonía, se evidenciaron el cambio de la PAFI y del Oxigenation Index (presión media vía aérea $x \mathrm{FiO}_{2}$ x 100/ $\mathrm{PaO}_{2}$ ) antes-después de la $\mathrm{VMNI}^{78}$, el SOFA máximo ${ }^{27}$, la presencia de empeoramiento radiológico ${ }^{27}$, la FC tras una hora de $\mathrm{VMNI}^{27}$, la PAFI tras una hora de $\mathrm{VMNI}^{27}$ y el bicarbonato tras una hora de $\mathrm{VMNI}^{27}$.

En los pacientes con IR hipercápnica sin EPOC, los predictores de fracaso identificados fueron un APACHE II elevado ${ }^{83}$, una FC elevada ${ }^{83}$ y una $\mathrm{PaCO}_{2}$ elevada tras una hora de $\mathrm{VMNI}^{83}$ y la presencia de neumonía ${ }^{83}$.

En el postoperatorio de Cirugía Torácica, se encontraron como marcadores de fracaso la presencia de comorbilidades cardíacas $^{109}$, la falta de respuesta inicial a la VMNI ${ }^{109}$, el aumento de la FR el primer día ${ }^{110}$, el aumento del SOFA el primer día ${ }^{110}$, el número de broncoscopias realizadas ${ }^{110}$, el número de horas con VMNI en las 48 horas iniciales $^{110}$ y el deterioro radiológico ${ }^{110}$. 
En pacientes hematológicos, las variables predictoras de fracaso fueron un SAPS II elevado ${ }^{93}$, el diagnóstico de ALI o $\mathrm{SDRA}^{93,94}$, la $\mathrm{FR}$ con $\mathrm{VMNI}^{94}$, el retraso desde el ingreso al inicio de la $\mathrm{VMNI}^{94}$, la necesidad de vasopresores $^{94}$ y la necesidad de hemodiálisis ${ }^{94}$.

En pacientes pediátricos se identificaron como predictores de fracaso el diagnóstico de SDRA $^{111}$ y un Pediatric Organ Dysfunction Score (Score de Disfunción Orgánica Pediátrica, PELOD) elevado ${ }^{111}$.

De forma general se puede afirmar que los diferentes estudios identificaron que los pacientes más graves tenían más posibilidades de fracasar con VMNI; así, los indicadores de gravedad (SAPS II o APACHE II), la peor situación basal (en cuanto a PAFI, FR, afectación radiológica o nivel de consciencia) o la escasa respuesta inicial a la VMNI (no mejoría de la FR, la PAFI o el nivel de consciencia) son variables que aparecen en varios estudios como predictoras.

En nuestro estudio el análisis univariante encontró diferencias estadísticamente significativas en el APACHE II, $\mathrm{pH}, \mathrm{PaCO}_{2}$, PAFI, bicarbonato, TAS, FR, GCS, albúmina, lactato y bilirrubina al inicio, en la FR, FC, PAFI, bicarbonato, lactato, $\mathrm{PaCO}_{2}$ y SAPS II con la PAFI a las 2 horas de iniciada la VMNI, en el tiempo desde el ingreso hospitalario hasta el inicio de la VMNI, y en el cambio de PAFI y de FR desde el inicio a las $2 \mathrm{~h}$ de VMNI.

Además, las variables categóricas identificadas como predictoras fueron el uso de VMNI preUCI, el uso de soporte vasoactivo al inicio de la VMNI, la oxigenoterapia domiciliaria, la necesidad de sedación para la VMNI y la presencia de inmunosupresión.

Es destacable que las diferencias en fracaso entre los pacientes que tenían $\mathrm{O}_{2}$ domiciliario o VMNI preUCI fueran estadísticamente significativas, indicando un posible efecto beneficioso de la presencia de estas variables; probablemente estos hallazgos reflejen un sesgo, ya que el 63,5 y el 58,2\% de los pacientes que las presentaban eran reagudizaciones de EPOC, con una probabilidad de fracaso de VMNI menor que otro tipo de pacientes. 
Lo mismo sucede con el $\mathrm{pH}$, la $\mathrm{PaCO}_{2}$ y el GCS al ingreso, observándose que los pacientes en los que la VMNI fue exitosa tenían “peores” parámetros (un pH y un GCS más bajo, con una $\mathrm{PaCO}_{2}$ más alta). La influencia de los pacientes hipercápnicos (en los que la eficacia de la VMNI es mayor) en estos datos vuelve a ser la explicación más probable para justificar estos resultados.

Finalmente, el modelo de regresión logística identificó como variables predictoras de fracaso el APACHE II, el tipo de IR (siendo el grupo de IR no hipercápnicas marcador de fracaso), el uso de sedación para la aplicación de VMNI, la bilirrubina al inicio de la VMNI y las diferencias de PAFI, GCS y FR entre el ingreso y las 2 horas.

Estos hallazgos son concordantes con estudios anteriores, evidenciando que una peor situación general o una mala respuesta a inicial a la VMNI son marcadores de mal pronóstico.

Posiblemente el hallazgo de la bilirrubina al inicio como predictor de fracaso refleje a pacientes con mayor afectación orgánica no respiratoria; otros estudios ${ }^{27,53}$ muestran que los pacientes con más fallo de órganos (cuantificado mediante la escala de SOFA en esos estudios) tienen peor pronóstico.

En cuanto a la necesidad de sedación por intolerancia a la VMNI, hay estudios ${ }^{112}$ que muestran su utilidad, mejorando su tolerancia (con una necesidad de IOT del 39\%). Sin embargo, en nuestro estudio su uso sigue siendo un marcador de mala respuesta (con un fracaso del $75 \%$ de los pacientes que la necesitaron).

\section{Minería de datos:}

Analizando los datos obtenidos tras la aplicación de los diferentes algoritmos de minería de datos para identificar predictores de fracaso de VMNI destacan varios hallazgos:

- La selección de atributos mediante CFS o mediante ganancia de información obtiene como atributos predictores varios de los evidenciados mediante la estadística clásica, como el APACHE II, el tipo de IR, la PAFI al inicio y a las 2 horas o la FR a las 2 horas. 
- Al haberse realizado el análisis con todos los datos recogidos, incluidos datos tardíos (a las 12 horas y a las 24 horas de iniciada la VMNI) los resultados arrojan nuevos datos a tener en cuenta. Por ejemplo, los balances a las 12 horas y a las 24 horas de iniciada la VMNI tienen un peso importante en el ranking de atributos obtenido mediante el método de ganancia de información, ocupando el cuarto y el primer lugar. Esto viene a reflejar la importancia de evitar balances muy positivos en estos pacientes; aunque no están realizados en pacientes con VMNI sino en el tratamiento del daño pulmonar agudo, la utilización de una estrategia restrictiva en el manejo de volumen puede disminuir la duración de la VM y de la estancia en $\mathrm{UCI}^{113}$. Por otro lado, esta necesidad de balances positivos también puede reflejar la mayor gravedad de esos pacientes, que precisan mayor aporte de volumen para mantener la estabilidad hemodinámica, además de tener una función renal más deteriorada, con lo que conseguir diuresis adecuadas para forzar balances equilibrados o negativos se hace más complicado.

\section{Limitaciones del estudio:}

La mayor de las limitaciones del estudio es la de ser un estudio observacional retrospectivo. El hecho de no ser un estudio randomizado controlado dificulta la interpretación y la hace más susceptible a sesgos.

Además, no existía un protocolo específico de inclusión, exclusión y manejo (la decisión de IOT, por ejemplo, era tomada por el médico según su criterio), por lo que el grupo de pacientes tratados es muy heterogéneo (tanto en gravedad como en tipo de patología), y el resultado de la VMNI puede estar sesgado al no tener un umbral de IOT establecido).

Hay que destacar, sin embargo, que esta limitación es a la vez una de las partes "fuertes" del estudio, ya que refleja el uso de la VMNI en la práctica clínica diaria, fuera de los ensayos clínicos.

Otra de las limitaciones es el carácter unicéntrico del estudio, lo que requiere que su extrapolación a otros hospitales sea realizada con cautela. 



espués de realizar un estudio retrospectivo, descriptivo y longitudinal de la utilización de ventilación mecánica no invasiva en una unidad de cuidados intensivos, en el que se analiza la eficacia de dicha técnica y se buscan factores predictores de éxito o fracaso, hemos llegado a las siguientes conclusiones:

1. La ventilación mecánica no invasiva es una técnica útil para el tratamiento de pacientes con insuficiencia respiratoria grave, que permite evitar la intubación orotraqueal en aproximadamente la mitad de los pacientes tratados. La aparición de complicaciones relevantes es poco frecuente.

2. Su eficacia en las insuficiencias respiratorias hipercápnicas (tanto en pacientes con enfermedad pulmonar obstructiva crónica como sin ella) y en el edema agudo de pulmón es alta, con un porcentaje de éxito muy elevado.

3. Su utilidad en la insuficiencia respiratoria post-extubación y en la insuficiencia respiratoria hipoxémica es mucho menos clara, presentando una alta tasa de fracaso.

4. Los pacientes tratados con éxito con ventilación mecánica no invasiva precisan menor estancia en UCI y hospitalaria, presentando una mortalidad menor que los pacientes en los que fracasa. 
5. La ventilación mecánica no invasiva puede tener su utilidad en el subgrupo de pacientes inmunodeprimidos, pudiendo evitar la intubación orotraqueal en un tipo de pacientes en los que esto implica muy mal pronóstico.

6. Las técnicas de minería de datos pueden ser un nuevo método para el manejo de grandes cantidades de datos en la investigación clínica, permitiendo procesar un número elevado de variables eficazmente, lo que las convierte en una herramienta complementaria a la estadística convencional.

7. A la luz de los resultados del presente estudio de Tesis Doctoral, se demuestra la existencia de predictores de fracaso en el uso de la ventilación mecánica no invasiva. Son indicadores del mismo el APACHE II, el tipo de insuficiencia respiratoria, la necesidad de sedación para la aplicación de la ventilación mecánica no invasiva, los hallazgos en la radiografía de tórax, la bilirrubina al inicio y las diferencias de cociente $\mathrm{PaO}_{2} / \mathrm{FiO}_{2}$, frecuencia cardiaca y frecuencia respiratoria entre el inicio de la ventilación mecánica no invasiva y las 2 horas de tratamiento.

8. Demostrada la existencia de predictores de fracaso, éstos se convierten en una excelente ayuda para el manejo de pacientes críticos con insuficiencia respiratoria susceptibles de ser tratados mediante ventilación mecánica no invasiva, y deberán ser tenidos en cuenta para decidir la idoneidad del tratamiento (tanto para su inicio como para su retirada y posterior intubación orotraqueal y conexión a ventilación mecánica invasiva si la probabilidad de éxito es escasa). 


\section{BIBLIOGRAFÍA}



1. Rozman C, Carellach F. Farreras-Rozman: Medicina interna. 16 ed. España: Elsevier; 2008.

2. West JB. Fisiopatología pulmonar. 6 ed. Buenos Aires: Medica Panamericana; 2004.

3. Brown LK. Hypoventilation syndromes. Clin Chest Med 2010, Jun;31(2):249-70.

4. Fauci AS, Braunwald E, Isselbacher KJ, Wilson JD, Martin JB, Kasper DL, et al. Harrison. Principios de Medicina Interna. 14 ed. Madrid: McGraw-Hill; 1998.

5. Irwin RS, Rippe JM. Irwin \& Rippe's Medicina Intensiva. 5 ed. Madrid: Marbán Libros; 2006 .

6. Curley G, Laffey JG, Kavanagh BP. Bench-To-Bedside review: Carbon dioxide. Crit Care 2010;14(2):220.

7. Decramer M, Janssens W, Miravitlles M. Chronic obstructive pulmonary disease. Lancet 2012, Apr 7;379(9823):1341-51.

8. McMurray JJ, Pfeffer MA. Heart failure. Lancet 2005;365(9474):1877-89.

9. Tobin MJ, editor. Principles \& Practice of Mechanical Ventilation. 2nd ed. McGraw-Hill; 2006.

10. Reisner-Sénélar L. The birth of intensive care medicine: Björn ibsen's records. Intensive Care Med 2011, Jul;37(7):1084-6.

11. Esquinas A, editor. Tratado de ventilación mecánica no invasiva. Práctica clínica y metodología. 1 ed. Madrid: Grupo Aula Médica, S.L.; 2006.

12. Sullivan CE, Issa FG, Berthon-Jones M, Eves L. Reversal of obstructive sleep apnoea by continuous positive airway pressure applied through the nares. Lancet 1981, Apr $18 ; 1(8225): 862-5$.

13. Tobin MJ. Mechanical ventilation. N Engl J Med 1994, Apr 14;330(15):1056-61. 
14. Parrillo JE, Dellinger RP. Tratado de Medicina Intensiva. 2 ed. Madrid: Harcourt Brace; 2003.

15. Joseph NM, Sistla S, Dutta TK, Badhe AS, Parija SC. Ventilator-Associated pneumonia: A review. Eur J Intern Med 2010, Oct;21(5):360-8.

16. Del Sorbo L, Goffi A, Ranieri VM. Mechanical ventilation during acute lung injury: Current recommendations and new concepts. Presse Med 2011, Dec;40(12 Pt 2):e569-83.

17. Gordo F, Delgado C, Calvo E. Mechanical ventilation induced lung injury. Med Intensiva 2007;31(1):18-26.

18. Tremblay LN, Slutsky AS. Ventilator-Induced injury: From barotrauma to biotrauma. Proc Assoc Am Physicians 1998;110(6):482-8.

19. Gallardo JM, Gómez T, Sancho JN, González M. Ventilación no invasiva. Arch Bronconeumol 2010;46(Supl 6):14-21.

20. Peter JV, Moran JL, Phillips-Hughes J, Warn D. Noninvasive ventilation in acute respiratory failure-a meta-analysis update. Crit Care Med 2002, Mar;30(3):555-62.

21. Bauman KA, Hyzy RC. Noninvasive positive pressure ventilation in acute respiratory failure in adults. In: UpToDate. Waltham, MA: UpToDate; 2012.

22. Hess DR. The evidence for noninvasive positive-pressure ventilation in the care of patients in acute respiratory failure: A systematic review of the literature. Respir Care 2004, Jul;49(7):810-29.

23. Gregoretti C, Confalonieri M, Navalesi P, Squadrone V, Frigerio P, Beltrame F, et al. Evaluation of patient skin breakdown and comfort with a new face mask for non-invasive ventilation: A multi-center study. Intensive Care Med 2002, Mar;28(3):278-84.

24. Barrot, E, Sánchez, E. Ventilación mecánica no invasiva. En: Manual Separ de Procedimientos. Barcelona: Editorial Respira; 2008. 
25. Ueno Y, Nakanishi N, Oto J, Imanaka H, Nishimura M. A bench study of the effects of leak on ventilator performance during noninvasive ventilation. Respir Care 2011, Nov;56(11):1758-64.

26. Cabrini L, Landoni G, Zangrillo A. Noninvasive ventilation failure: The answer is blowing in the leaks. Respir Care 2011, Nov;56(11):1857-8.

27. Carrillo A, Gonzalez-Diaz G, Ferrer M, Martinez-Quintana ME, Lopez-Martinez A, Llamas $\mathrm{N}$, et al. Non-Invasive ventilation in community-acquired pneumonia and severe acute respiratory failure. Intensive Care Med 2012, Mar;38(3):458-66.

28. Nava S, Hill NS. Non-Invasive ventilation in acute respiratory failure. The Lancet 2009;374(9685):250-9.

29. Lightowler JV, Wedzicha JA, Elliott MW, Ram FS. Non-Invasive positive pressure ventilation to treat respiratory failure resulting from exacerbations of chronic obstructive pulmonary disease: Cochrane systematic review and meta-analysis. BMJ 2003, Jan 25;326(7382):185.

30. Mehta S, Hill NS. Noninvasive ventilation. Am J Respir Crit Care Med 2001, Feb;163(2):540-77.

31. Collett D. Modelling binary data. 1 ed. London; New York: Chapman \& Hall; 1991.

32. Morgan JN, Sonquist JA. Problems in the analysis of survey data and a proposal. Journal of the American Statistical Association 1963;58:415-34.

33. Sall J. Monte Carlo calibration of distributions of partition statistics. Technical report; 2002. Disponible en: jmp.com/software/whitepapers/pdfsmontecarlocal.pdf.

34. Hall MA. Correlation-based Feature Selection for Machine Learning [Tesis doctoral]. Hamilton, Nueva Zelanda: University of Waikato; 1999

35. Quinlan JR. C4.5: Programs for machine learning. San Mateo, California: Morgan Kaufmann Publishers; 1993. 
36. Cooper GF, Herskovits E. A bayesian method for the induction of probabilistic networks from data. Machine Learning 1992;9:309-47.

37. Breiman L. Bagging predictors. Machine Learning 1996;24(2):123-40.

38. Freund Y, Schapire RE. Experiments with a new boosting algorithm; Proceedings 13th international conference on machine learning. 1996.

39. Fernández-Vivas M, González-Díaz G, Caturla-Such J, Delgado-Vílchez FJ, SerranoSimón JM, Carrillo-Alcaraz A, et al. Use of non-invasive ventilation in acute respiratory failure. Multicenter study in intensive care units. Med Intensiva 2009, May;33(4):153-60.

40. Crimi C, Noto A, Princi P, Esquinas A, Nava S. A european survey of noninvasive ventilation practices. Eur Respir J 2010, Aug;36(2):362-9.

41. Esteban A, Ferguson ND, Meade MO, Frutos-Vivar F, Apezteguia C, Brochard L, et al. Evolution of mechanical ventilation in response to clinical research. Am J Respir Crit Care Med 2008, Jan 15;177(2):170-7.

42. Honrubia T, García López FJ, Franco N, Mas M, Guevara M, Daguerre M, et al. Noninvasive vs conventional mechanical ventilation in acute respiratory failure: A multicenter, randomized controlled trial. Chest 2005, Dec;128(6):3916-24.

43. Meduri GU, Turner RE, Abou-Shala N, Wunderink R, Tolley E. Noninvasive positive pressure ventilation via face mask. First-Line intervention in patients with acute hypercapnic and hypoxemic respiratory failure. Chest 1996, Jan;109(1):179-93.

44. Poponick JM, Renston JP, Bennett RP, Emerman CL. Use of a ventilatory support system (BiPAP) for acute respiratory failure in the emergency department. Chest 1999, Jul;116(1):166-71.

45. Singh VK, Khanna P, Rao BK, Sharma SC, Gupta R. Outcome predictors for noninvasive positive pressure ventilation in acute respiratory failure. J Assoc Physicians India 2006, May;54:361-5. 
46. Agarwal R, Gupta R, Aggarwal AN, Gupta D. Noninvasive positive pressure ventilation in acute respiratory failure due to COPD vs other causes: Effectiveness and predictors of failure in a respiratory ICU in north India. Int J Chron Obstruct Pulmon Dis 2008;3(4):73743.

47. Yamauchi LY, Travaglia TC, Bernardes SR, Figueiroa MC, Tanaka C, Fu C. Noninvasive positive-pressure ventilation in clinical practice at a large university-affiliated brazilian hospital. Clinics (Sao Paulo) 2012, Jul;67(7):767-72.

48. Brochard L, Isabey D, Piquet J, Amaro P, Mancebo J, Messadi AA, et al. Reversal of acute exacerbations of chronic obstructive lung disease by inspiratory assistance with a face mask. N Engl J Med 1990, Nov 29;323(22):1523-30.

49. Brochard L, Mancebo J, Wysocki M, Lofaso F, Conti G, Rauss A, et al. Noninvasive ventilation for acute exacerbations of chronic obstructive pulmonary disease. N Engl J Med 1995, Sep 28;333(13):817-22.

50. Antón A, Güell R, Gómez J, Serrano J, Castellano A, Carrasco JL, Sanchis J. Predicting the result of noninvasive ventilation in severe acute exacerbations of patients with chronic airflow limitation. Chest 2000, Mar;117(3):828-33.

51. Plant PK, Owen JL, Elliott MW. Early use of non-invasive ventilation for acute exacerbations of chronic obstructive pulmonary disease on general respiratory wards: A multicentre randomised controlled trial. Lancet 2000, Jun 3;355(9219):1931-5.

52. Squadrone E, Frigerio P, Fogliati C, Gregoretti C, Conti G, Antonelli M, et al. Noninvasive vs invasive ventilation in COPD patients with severe acute respiratory failure deemed to require ventilatory assistance. Intensive Care Med 2004, Jul;30(7):1303-10.

53. Díaz GG, Alcaraz AC, Talavera JC, Pérez PJ, Rodriguez AE, Cordoba FG, Hill NS. Noninvasive positive-pressure ventilation to treat hypercapnic coma secondary to respiratory failure. Chest 2005, Mar;127(3):952-60. 
54. Celikel T, Sungur M, Ceyhan B, Karakurt S. Comparison of noninvasive positive pressure ventilation with standard medical therapy in hypercapnic acute respiratory failure. Chest 1998, Dec;114(6):1636-42.

55. Clini E, Sturani C, Rossi A, Viaggi S, Corrado A, Donner CF, et al. The italian multicentre study on noninvasive ventilation in chronic obstructive pulmonary disease patients. Eur Respir J 2002, Sep;20(3):529-38.

56. Ram FS, Picot J, Lightowler J, Wedzicha JA. Non-Invasive positive pressure ventilation for treatment of respiratory failure due to exacerbations of chronic obstructive pulmonary disease. Cochrane Database Syst Rev 2004(3):CD004104.

57. Keenan SP, Powers CE, McCormack DG. Noninvasive positive-pressure ventilation in patients with milder chronic obstructive pulmonary disease exacerbations: A randomized controlled trial. Respir Care 2005, May;50(5):610-6.

58. Pastaka C, Kostikas K, Karetsi E, Tsolaki V, Antoniadou I, Gourgoulianis KI. NonInvasive ventilation in chronic hypercapnic COPD patients with exacerbation and a $\mathrm{pH}$ of 7.35 or higher. Eur J Intern Med 2007, Nov;18(7):524-30.

59. Scala R, Naldi M, Archinucci I, Coniglio G, Nava S. Noninvasive positive pressure ventilation in patients with acute exacerbations of COPD and varying levels of consciousness. Chest 2005, Sep;128(3):1657-66.

60. Bersten AD, Holt AW, Vedig AE, Skowronski GA, Baggoley CJ. Treatment of severe cardiogenic pulmonary edema with continuous positive airway pressure delivered by face mask. N Engl J Med 1991, Dec 26;325(26):1825-30.

61. Mehta S, Jay GD, Woolard RH, Hipona RA, Connolly EM, Cimini DM, et al. Randomized, prospective trial of bilevel versus continuous positive airway pressure in acute pulmonary edema. Crit Care Med 1997, Apr;25(4):620-8.

62. Nava S, Carbone G, DiBattista N, Bellone A, Baiardi P, Cosentini R, et al. Noninvasive ventilation in cardiogenic pulmonary edema: A multicenter randomized trial. Am J Respir Crit Care Med 2003, Dec 15;168(12):1432-7. 
63. Park M, Sangean MC, Volpe Mde S, Feltrim MI, Nozawa E, Leite PF, et al. Randomized, prospective trial of oxygen, continuous positive airway pressure, and bilevel positive airway pressure by face mask in acute cardiogenic pulmonary edema. Crit Care Med 2004, Dec;32(12):2407-15.

64. Gray A, Goodacre S, Newby DE, Masson M, Sampson F, Nicholl J, 3CPO Trialists. Noninvasive ventilation in acute cardiogenic pulmonary edema. N Engl J Med 2008, Jul $10 ; 359(2): 142-51$

65. Nouira S, Boukef R, Bouida W, Kerkeni W, Beltaief K, Boubaker H, et al. NonInvasive pressure support ventilation and CPAP in cardiogenic pulmonary edema: A multicenter randomized study in the emergency department. Intensive Care Med 2011, Feb;37(2):249-56.

66. Ho KM, Wong K. A comparison of continuous and bi-level positive airway pressure non-invasive ventilation in patients with acute cardiogenic pulmonary oedema: A metaanalysis. Crit Care 2006;10(2):R49.

67. Vital FM, Saconato H, Ladeira MT, Sen A, Hawkes CA, Soares B, et al. Non-Invasive positive pressure ventilation (CPAP or bilevel NPPV) for cardiogenic pulmonary edema. Cochrane Database Syst Rev 2008(3):CD005351.

68. Agarwal R, Aggarwal AN, Gupta D. Is noninvasive pressure support ventilation as effective and safe as continuous positive airway pressure in cardiogenic pulmonary oedema? Singapore Med J 2009, Jun;50(6):595-603.

69. Weng CL, Zhao YT, Liu QH, Fu CJ, Sun F, Ma YL, et al. Meta-Analysis: Noninvasive ventilation in acute cardiogenic pulmonary edema. Ann Intern Med 2010, May 4;152(9):590-600.

70. Masip J, Roque M, Sánchez B, Fernández R, Subirana M, Expósito JA. Noninvasive ventilation in acute cardiogenic pulmonary edema: Systematic review and meta-analysis. JAMA 2005, Dec 28;294(24):3124-30. 
71. Mariani J, Macchia A, Belziti C, Deabreu M, Gagliardi J, Doval H, et al. Noninvasive ventilation in acute cardiogenic pulmonary edema: A meta-analysis of randomized controlled trials. J Card Fail 2011, Oct;17(10):850-9.

72. Antonelli M, Conti G, Rocco M, Bufi M, De Blasi RA, Vivino G, et al. A comparison of noninvasive positive-pressure ventilation and conventional mechanical ventilation in patients with acute respiratory failure. N Engl J Med 1998, Aug 13;339(7):429-35.

73. Ferrer M, Esquinas A, Leon M, Gonzalez G, Alarcon A, Torres A. Noninvasive ventilation in severe hypoxemic respiratory failure: A randomized clinical trial. Am J Respir Crit Care Med 2003, Dec 15;168(12):1438-44.

74. Antonelli M, Conti G, Moro ML, Esquinas A, Gonzalez-Diaz G, Confalonieri M, et al. Predictors of failure of noninvasive positive pressure ventilation in patients with acute hypoxemic respiratory failure: A multi-center study. Intensive Care Med 2001, Nov;27(11):1718-28.

75. Cheung TM, Yam LY, So LK, Lau AC, Poon E, Kong BM, Yung RW. Effectiveness of noninvasive positive pressure ventilation in the treatment of acute respiratory failure in severe acute respiratory syndrome. Chest 2004, Sep;126(3):845-50.

76. Antonelli M, Conti G, Esquinas A, Montini L, Maggiore SM, Bello G, et al. A multiplecenter survey on the use in clinical practice of noninvasive ventilation as a first-line intervention for acute respiratory distress syndrome. Crit Care Med 2007, Jan;35(1):18-25.

77. Agarwal R, Handa A, Aggarwal AN, Gupta D, Behera D. Outcomes of noninvasive ventilation in acute hypoxemic respiratory failure in a respiratory intensive care unit in north India. Respir Care 2009, Dec;54(12):1679-87.

78. Carron M, Freo U, Zorzi M, Ori C. Predictors of failure of noninvasive ventilation in patients with severe community-acquired pneumonia. J Crit Care 2010, Sep;25(3):540.e914. 
79. Schettino G, Altobelli N, Kacmarek RM. Noninvasive positive-pressure ventilation in acute respiratory failure outside clinical trials: Experience at the Massachusetts General Hospital. Crit Care Med 2008, Feb;36(2):441-7.

80. Delclaux C, L'Her E, Alberti C, Mancebo J, Abroug F, Conti G, et al. Treatment of acute hypoxemic nonhypercapnic respiratory insufficiency with continuous positive airway pressure delivered by a face mask: A randomized controlled trial. JAMA 2000, Nov 8;284(18):2352-60.

81. Hernandez G, Fernandez R, Lopez-Reina P, Cuena R, Pedrosa A, Ortiz R, Hiradier P. Noninvasive ventilation reduces intubation in chest trauma-related hypoxemia: A randomized clinical trial. Chest 2010, Jan;137(1):74-80.

82. Keenan SP, Sinuff T, Cook DJ, Hill NS. Does noninvasive positive pressure ventilation improve outcome in acute hypoxemic respiratory failure? A systematic review. Crit Care Med 2004, Dec;32(12):2516-23.

83. Phua J, Kong K, Lee KH, Shen L, Lim TK. Noninvasive ventilation in hypercapnic acute respiratory failure due to chronic obstructive pulmonary disease vs. Other conditions: Effectiveness and predictors of failure. Intensive Care Med 2005, Apr;31(4):533-9.

84. Ferrer M, Valencia M, Nicolas JM, Bernadich O, Badia JR, Torres A. Early noninvasive ventilation averts extubation failure in patients at risk: A randomized trial. Am J Respir Crit Care Med 2006, Jan 15;173(2):164-70.

85. Girault C, Bubenheim M, Abroug F, Diehl JL, Elatrous S, Beuret P, et al. Noninvasive ventilation and weaning in patients with chronic hypercapnic respiratory failure: A randomized multicenter trial. Am J Respir Crit Care Med 2011, Sep 15;184(6):672-9.

86. Keenan SP, Powers C, McCormack DG, Block G. Noninvasive positive-pressure ventilation for postextubation respiratory distress: A randomized controlled trial. JAMA 2002, Jun 26;287(24):3238-44. 
87. Esteban A, Frutos-Vivar F, Ferguson ND, Arabi Y, Apezteguía C, González M, et al. Noninvasive positive-pressure ventilation for respiratory failure after extubation. $\mathrm{N}$ Engl $\mathrm{J}$ Med 2004, Jun 10;350(24):2452-60.

88. Boeken U, Schurr P, Kurt M, Feindt P, Lichtenberg A. Early reintubation after cardiac operations: Impact of nasal continuous positive airway pressure (nCPAP) and noninvasive positive pressure ventilation (NPPV). Thorac Cardiovasc Surg 2010, Oct;58(7):398-402.

89. Michelet P, D'Journo XB, Seinaye F, Forel JM, Papazian L, Thomas P. Non-Invasive ventilation for treatment of postoperative respiratory failure after oesophagectomy. $\mathrm{Br} \mathrm{J}$ Surg 2009, Jan;96(1):54-60.

90. Glossop AJ, Shepherd N, Bryden DC, Mills GH. Non-Invasive ventilation for weaning, avoiding reintubation after extubation and in the postoperative period: A meta-analysis. $\mathrm{Br} \mathrm{J}$ Anaesth 2012, Sep;109(3):305-14.

91. Antonelli M, Conti G, Bufi M, Costa MG, Lappa A, Rocco M, et al. Noninvasive ventilation for treatment of acute respiratory failure in patients undergoing solid organ transplantation: A randomized trial. JAMA 2000, Jan 12;283(2):235-41.

92. Hilbert G, Gruson D, Vargas F, Valentino R, Gbikpi-Benissan G, Dupon M, et al. Noninvasive ventilation in immunosuppressed patients with pulmonary infiltrates, fever, and acute respiratory failure. N Engl J Med 2001, Feb 15;344(7):481-7.

93. Gristina GR, Antonelli M, Conti G, Ciarlone A, Rogante S, Rossi C, et al. Noninvasive versus invasive ventilation for acute respiratory failure in patients with hematologic malignancies: A 5-year multicenter observational survey. Crit Care Med 2011, Oct;39(10):2232-9.

94. Adda M, Coquet I, Darmon M, Thiery G, Schlemmer B, Azoulay E. Predictors of noninvasive ventilation failure in patients with hematologic malignancy and acute respiratory failure. Crit Care Med 2008, Oct;36(10):2766-72. 
95. Depuydt PO, Benoit DD, Vandewoude KH, Decruyenaere JM, Colardyn FA. Outcome in noninvasively and invasively ventilated hematologic patients with acute respiratory failure. Chest 2004, Oct;126(4):1299-306.

96. Ferrer M, Esquinas A, Arancibia F, Bauer TT, Gonzalez G, Carrillo A, et al. Noninvasive ventilation during persistent weaning failure: A randomized controlled trial. Am J Respir Crit Care Med 2003, Jul 1;168(1):70-6.

97. Guérin C, Girard R, Chemorin C, De Varax R, Fournier G. Facial mask noninvasive mechanical ventilation reduces the incidence of nosocomial pneumonia. A prospective epidemiological survey from a single ICU. Intensive Care Med 1997, Oct;23(10):1024-32.

98. Rocco M, Dell'Utri D, Morelli A, Spadetta G, Conti G, Antonelli M, Pietropaoli P. Noninvasive ventilation by helmet or face mask in immunocompromised patients: A casecontrol study. Chest 2004, Nov;126(5):1508-15.

99. Principi T, Pantanetti S, Catani F, Elisei D, Gabbanelli V, Pelaia P, Leoni P. Noninvasive continuous positive airway pressure delivered by helmet in hematological malignancy patients with hypoxemic acute respiratory failure. Intensive Care Med 2004, Jan;30(1):147-50.

100. Ozsancak A, Sidhom SS, Liesching TN, Howard W, Hill NS. Evaluation of the total face mask for noninvasive ventilation to treat acute respiratory failure. Chest 2011, May;139(5):1034-41.

101. Criner GJ, Travaline JM, Brennan KJ, Kreimer DT. Efficacy of a new full face mask for noninvasive positive pressure ventilation. Chest 1994, Oct;106(4):1109-15.

102. Carlucci A, Richard JC, Wysocki M, Lepage E, Brochard L, SRLF Collaborative Group on Mechanical Ventilation. Noninvasive versus conventional mechanical ventilation. An epidemiologic survey. Am J Respir Crit Care Med 2001, Mar;163(4):874-80.

103. Schettino G, Altobelli N, Kacmarek RM. Noninvasive positive pressure ventilation reverses acute respiratory failure in select "do-not-intubate" patients. Crit Care Med 2005, Sep;33(9):1976-82. 
104. Plant PK, Owen JL, Elliott MW. Non-Invasive ventilation in acute exacerbations of chronic obstructive pulmonary disease: Long term survival and predictors of in-hospital outcome. Thorax 2001, Sep;56(9):708-12.

105. Confalonieri M, Garuti G, Cattaruzza MS, Osborn JF, Antonelli M, Conti G, et al. A chart of failure risk for noninvasive ventilation in patients with COPD exacerbation. Eur Respir J 2005, Feb;25(2):348-55.

106. Berkius J, Sundh J, Nilholm L, Fredrikson M, Walther SM. Long-Term survival according to ventilation mode in acute respiratory failure secondary to chronic obstructive pulmonary disease: A multicenter, inception cohort study. J Crit Care 2010, Sep;25(3):539.e13-8.

107. Ambrosino N, Foglio K, Rubini F, Clini E, Nava S, Vitacca M. Non-Invasive mechanical ventilation in acute respiratory failure due to chronic obstructive pulmonary disease: Correlates for success. Thorax 1995, Jul;50(7):755-7.

108. Yoshida Y, Takeda S, Akada S, Hongo T, Tanaka K, Sakamoto A. Factors predicting successful noninvasive ventilation in acute lung injury. J Anesth 2008;22(3):201-6.

109. Lefebvre A, Lorut C, Alifano M, Dermine H, Roche N, Gauzit R, et al. Noninvasive ventilation for acute respiratory failure after lung resection: An observational study. Intensive Care Med 2009, Apr;35(4):663-70.

110. Riviere S, Monconduit J, Zarka V, Massabie P, Boulet S, Dartevelle P, Stéphan F. Failure of noninvasive ventilation after lung surgery: A comprehensive analysis of incidence and possible risk factors. Eur J Cardiothorac Surg 2011, May;39(5):769-76.

111. Essouri S, Chevret L, Durand P, Haas V, Fauroux B, Devictor D. Noninvasive positive pressure ventilation: Five years of experience in a pediatric intensive care unit. Pediatr Crit Care Med 2006, Jul;7(4):329-34.

112. Rocco M, Conti G, Alessandri E, Morelli A, Spadetta G, Laderchi A, et al. Rescue treatment for noninvasive ventilation failure due to interface intolerance with remifentanil analgosedation: A pilot study. Intensive Care Med 2010, Dec;36(12):2060-5. 
113. National Heart, Lung, and Blood Institute Acute Respiratory Distress Syndrome (ARDS) Clinical Trials Network, Wiedemann HP, Wheeler AP, Bernard GR, Thompson BT, Hayden D, et al. Comparison of two fluid-management strategies in acute lung injury. N Engl J Med 2006, Jun 15;354(24):2564-75. 